\title{
TASK 8 - REDUCING POWER PRODUCTION COSTS BY UTILIZING PETROLEUM COKE
}

Final Report

for the period August 24, 1998, through June 30, 1999

Prepared for:

Mr. Phillip Goldberg

Federal Energy Technology Center

U.S. Department of Energy

PO Box 10940, MS 922-324C

Pittsburgh, PA 15236-0940

DOE Cooperative Agreement No. DE-FC26-98FT40321-04

Performance Monitor: Phillip Goldberg

Prepared by:

Kevin C. Galbreath

Donald L. Toman Christopher J. Zygarlicke

Energy \& Environmental Research Center University of North Dakota PO Box 9018

Grand Forks, ND 58202-9018

99-EERC-09-05

September 1999 


\section{Task 62 - Reducing Power Production Costs by Utilizing Petroleum Coke}

TR-

Final Report, August 1999

EPRI Project Manager

A. Mehta 


\section{Citations}

This report was prepared by

Energy \& Environmental Research Center

University of North Dakota

PO Box 9018

Grand Forks, ND 58202-9018

Principal Investigator

Kevin C. Galbreath

This report describes research sponsored by EPRI and the U.S. Department of Energy.

Task 62 - Reducing Power Production Costs by Utilizing Petroleum Coke: EPRI, Palo Alto, CA and U.S. Department of Energy, Pittsburgh, PA: 1999.

TR- 


\section{DISCLAIMER}

This report was prepared as an account of work sponsored by an agency of the United States Government. Neither the United States Government, nor any agency thereof, nor any of their employees makes any warranty, express or implied, or assumes any legal liability or responsibility for the accuracy, completeness, or usefulness of any information, apparatus, product, or process disclosed or represents that its use would not infringe privately owned rights. Reference herein to any specific commercial product, process, or service by trade name, trademark, manufacturer, or otherwise does not necessarily constitute or imply its endorsement, recommendation, or favoring by the United States Government or any agency thereof. The views and opinions of authors expressed herein do not necessarily state or reflect those of the United States Government or any agency thereof.

This report is available to the public from the National Technical Information Service, U.S. Department of Commerce, 5285 Port Royal Road, Springfield, VA 22161; phone orders accepted at (703) 487-4650.

\section{EERC DISCLAIMER}

LEGAL NOTICE This research report was prepared by the Energy \& Environmental Research Center (EERC), an agency of the University of North Dakota, as an account of work sponsored by the U.S. Department of Energy (DOE). Because of the research nature of the work performed, neither the EERC nor any of its employees makes any warranty, express or implied, or assumes any legal liability or responsibility for the accuracy, completeness, or usefulness of any information, apparatus, product, or process disclosed, or represents that its use would not infringe privately owned rights. Reference herein to any specific commercial product, process, or service by trade name, trademark, manufacturer, or otherwise does not necessarily constitute or imply its endorsement or recommendation by the EERC.

\section{ACKNOWLEDGMENT}

This report was prepared with the support of EPRI Agreement WO4798-01 and DOE Federal Energy Technology Center Cooperative Agreement No. DE-FC26-98FT40321-08 However, any opinions, findings, conclusions, or recommendations expressed herein are those of the authors(s) and do not necessarily reflect the views of EPRI or DOE. 


\section{EXECUTIVE SUMMARY}

The effects of blending petroleum shot cokes with Powder River Basin (PRB) subbituminous coals on grindability, combustion reactivity, fouling/slagging, and electrostatic precipitator (ESP) fly ash collection efficiency were investigated over a 2 -year period. Testing was conducted using three different laboratory-scale downfired combustion systems. Fly ash and deposit samples were analyzed using a variety of techniques, including inductively coupled plasma-atomic emission spectroscopy, x-ray diffraction, $x$-ray absorption fine-structure spectroscopy, wavelengthdispersive x-ray fluorescence spectrometry, scanning electron microscopy, electron probe microanalysis, and digital image analysis.

A PRB subbituminous coal with a Hardgrove grindability index (HGI) of about 56 at 26 wt\% moisture and a petroleum shot coke with an average HGI of 38 were used for testing the effects of parent fuel hardness on PRB coal-petroleum coke blend grindability. Samples of the PRB coal, petroleum shot coke, and coal-coke blends of 95:5 and 85:15 (on a weight basis) were pulverized under identical conditions. Ni and V analyses of three size fractions $(<45 \mu \mathrm{m}, \geq 45 \mu \mathrm{m}$ but $<75 \mu \mathrm{m}$, and $\geq 75 \mu \mathrm{m}$ ) for each pulverized fuel indicate that the finest particle-size fraction of the petroleum coke is significantly enriched in $\mathrm{V}$ and $\mathrm{Ni}$, whereas $\mathrm{V}$ and $\mathrm{Ni}$ are uniformly distributed among the three particle-size fractions of the pulverized PRB coal. The finest particle-size fractions of the coal-coke blends are not enriched in $\mathrm{V}$ and Ni relative to their coarser size fractions, suggesting that the softer $\mathrm{Ni}$ - and $\mathrm{V}$-depleted coal particles are preferentially fractioned into the finest size fractions during pulverization.

Combustion kinetic testing in a drop-tube furnace of a PRB coal, petroleum coke, and an $80 \mathrm{wt} \%$ PRB coal-20 wt\% petroleum coke blend indicates that the parent fuels essentially burn independently of each other. It was demonstrated that the combustion kinetics of a given coalpetroleum coke blend in the drop-tube furnace can be predicted from those of the parent fuels because of the two-stage combustion process.

Measurements of deposits (i.e., initial slagging temperatures, crushing strengths, and ash fouling deposition rates) produced from burning PRB coal-petroleum coke blends (coke blends of $0 \%$, $10 \%$, and $20 \%$ on a weight basis) in a drop-tube furnace under slagging and high-temperature fouling conditions indicate that petroleum coke blending with PRB coal impedes the rate of fouling deposit growth but promotes slagging and slag deposit strength. Although petroleum coke blending slows the rate of ash fouling deposition, it promotes ash sulfation and the formation of an anhydrite-rich base layer on tube surfaces.

Testing of a PRB coal and two (95:5 and 85:15) coal-coke blends in a 42-MJ/hr (40,000 Btu/hr) downfired combustion system indicates that the primary effect of petroleum coke blending on flue gas composition is a significant increase in sulfur concentration. Sulfur speciation analyses using U.S. Environmental Protection Agency Method 8 and a controlled condensation method at temperatures of $275^{\circ}$ and $580^{\circ} \mathrm{C}$ indicate that although $\mathrm{SO}_{2}(\mathrm{~g})$ concentrations increase significantly with increasing coke blending, $\mathrm{SO}_{3}(\mathrm{~g})$ remains undetectable $(<0.5 \mathrm{ppmv})$. Mass balance calculations and chemical analyses of fly ashes indicate that petroleum coke blending promotes the conversion of fuel sulfur to inorganic $\mathrm{SO}_{4}$ compounds in the fly ash as well as the desired effect of improving ash resistivity characteristics. An x-ray absorption fine-structure 
spectroscopy analysis of an 85:15 (coal:coke) blend fly ash suggests that $\mathrm{V}^{+5}$ catalysis of $\mathrm{SO}_{2}(\mathrm{~g})$ oxidation accounts for the increase in fly ash sulfation. 


\section{TABLE OF CONTENTS}

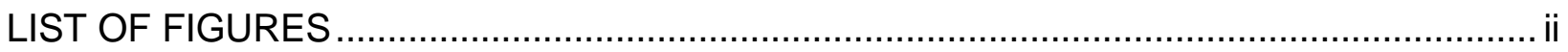

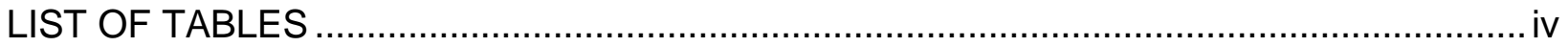

Chapter 1 Introduction ........................................................................................... 1-1

Chapter 2 Effect of PRB Coal-Petroleum Coke Blending on Grindability ......................... 2-1

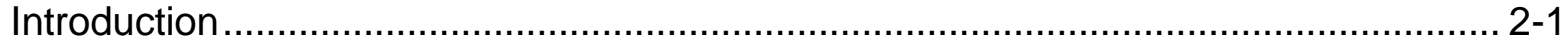

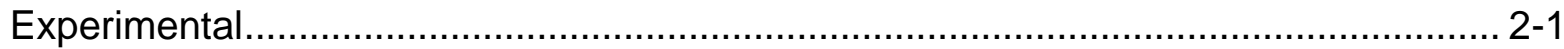

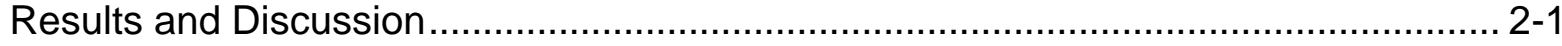

Chapter 3 Combustion Kinetics of PRB Coal-Petroleum Coke Blends .......................... 3-1

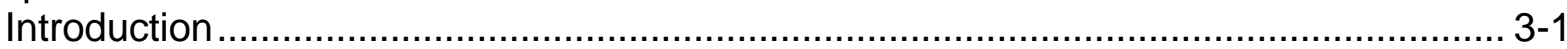

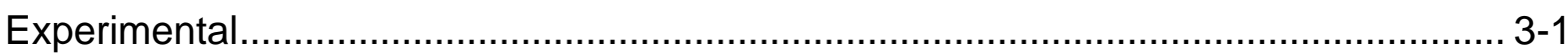

Results and Discussion ................................................................................. 3-2

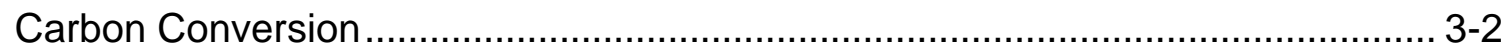

Kinetic Calculations and Modeling …….......................................................... 3-7

Chapter 4 Effect of PRB Coal-Petroleum Coke Blending on Fouling and Slagging

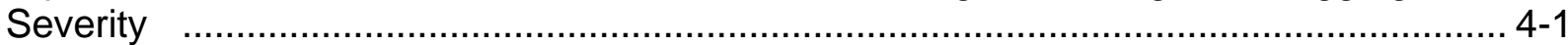

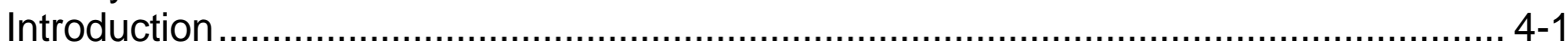

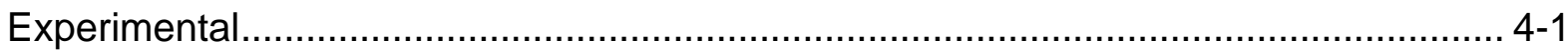

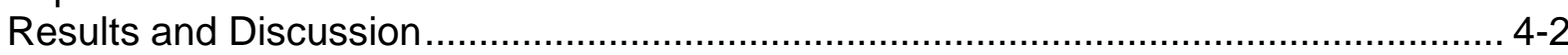

Chapter 5 Effect of PRB Coal-Petroleum Coke Blending on ESP Fly Ash Collection

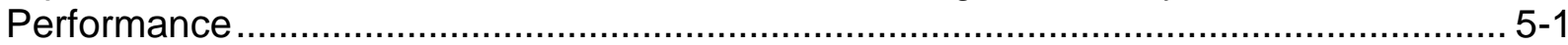

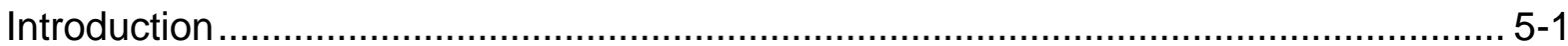

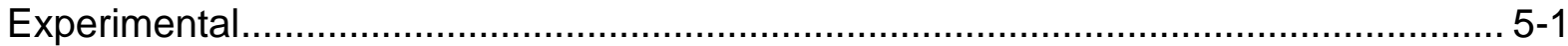

Results and Discussion .................................................................................. 5-2

Chapter 6 Vanadium Speciation in PRB Coal-Petroleum Coke Fly Ash ......................... 6-1

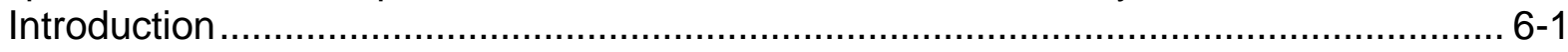

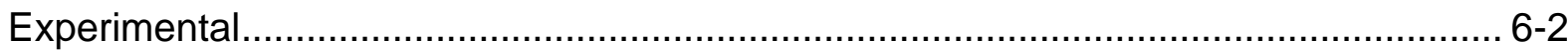

Results and Discussion.................................................................................... 6-3

Chapter 7 Conclusions .........................................................................................

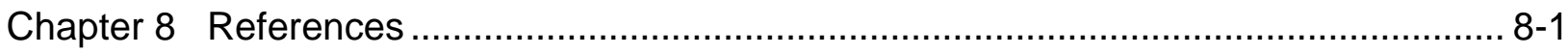

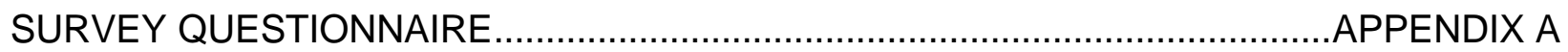

DESCRIPTION OF THE ATMOSPHERIC DROP-TUBE FURNACE..................APPENDIX B

DESCRIPTION OF THE OPTICAL ACCESS DROP-TUBE FURNACE ............ APPENDIX C

DESCRIPTION OF THE CONVERSION AND ENVIRONMENTAL PROCESS

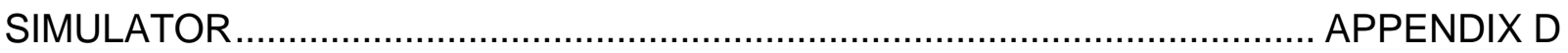




\section{LIST OF FIGURES}

2-1 $\mathrm{Ni}$ and $\mathrm{V}$ concentrations of the coal, coal-coke blends, and coke......................2-2

2-2 Size distributions of the fuels as a function of blend ratio ..................................2-2

2-3 $\mathrm{V}$ and $\mathrm{Ni}$ contents for three size fractions of the fuels as a function of blend ratio.

3-1 Carbon conversion as a function of residence time and temperature for the $80: 20$ PRB coal-petroleum coke blend

3-2 Carbon conversion as a function of residence time and temperature for the PRB coal.

3-3 Carbon conversion as a function of residence time and temperature for the petroleum cake

3-4 (a) Comparison of calculated and empirical carbon conversion results at $800^{\circ} \mathrm{C}$;

(b) comparison of calculated and empirical carbon conversion results at $900^{\circ} \mathrm{C}$;

(c) comparison of calculated and empirical carbon conversion results at $1000^{\circ} \mathrm{C}$

3-5 Backscattered electron image of coal ash and unburned petroleum coke particles produced from an $80: 20 \mathrm{caol}-$ coke blend at $1000^{\circ} \mathrm{C}$ for $0.4 \mathrm{~s}$

3-6 Backscattered electron image of coal ash and unburned petroleum coke particles produced from an $80: 20 \mathrm{coal}-$ coke blend at $900^{\circ} \mathrm{C}$ for $0.6 \mathrm{~s}$

3-7 Backscattered electron image of coal ash and unburned petroleum coke particles produced from an $80: 20 \mathrm{coal}-$ coke blend at $800^{\circ} \mathrm{C}$ for $0.8 \mathrm{~s}$

3-8 Best-fit curves for the 80:20 PRB coal-petroleum coke blend carbon conversion results

3-9 (a) Arrhenius plots of global PRB coal reaction rates at various residence times versus the inverse of temperature; (b) Arrhernius plots of global petroleum coake reaction rates at various residence times versus the inverse of temperature; (c) Arrhenius plots of global 80:20 PRB coal-petroleum coke reaction rates at various residence times versus the inverse of temperature

4-1 Bar plot of average crushing strengths for deposits produced in the ODTF by burning three PRB coal-petroleum shot coke blends (100:0, 90:10, and 80:20) under slagging condititions 


\section{LIST OF FIGURES (continued)}

4-2 Bar plot of average crushing strengths for deposits produced in the ODTF by burning three PRB coal-petroleum shot coke blends (100:0, 90:10, and 80:20) under high-temperature fouling conditions.

4-3 Growth factors versus time for deposits produced in the ODTF by burning PRB coal-petroleum shot coke blends under high-temperature fouling conditions. ....4-5

4-4 Backscattered electron image of a fouling deposit produced from a 90\% PRB coal $-10 \%$ petroleum coke blend

4-5 Backscattered electron image of mineral crystals in a fouling deposit produced from a $90 \%$ PRB coal- $10 \%$ petroleum coke blend

4-6 Photograph of a slag deposit produced from the $80 \%$ PRB coal-20\% petroleum coke blend

5-1 Schematic of the 40,000-Btu/hr combustor showing $\mathrm{SO}_{3}(\mathrm{~g})$ sampling locations and temperatures

5-2 V K-edge XANES spectrum of the PRB coal-petroleum coke ash blend $.5-4$

5-3 V K-edge XANES spectra of five $\mathrm{V}$ reference compounds $.5-4$

6-1 Eh-pH diagram of aqueous vanadium

6-2 Distribution of vanadium species as a function of $\mathrm{pH}$ and concentration 


\section{LIST OF TABLES}

3-1 Proximate and Ultimate Analysis Results for the PRB Coal and Petroleum Coke Fuels

3-2a Carbon Conversion Results for the PRB Coal .............................................. $3-3$

3-2b Carbon Conversion Results for the Petroleum Coke ......................................... $3-4$

3-2c Carbon Conversion Results forthe 80:20 PRB Coal-Petroleum Coke Blend ........3-5

3-3a Calculated Kinetic Parameters for the PRB Coal ..............................................3-13

3-3b Calculated Kinetic Parameters for the Petroleum Coke....................................3-14

3-3c Calculated Kinetic Parameters for the 80:20 PRB Coal-Petroleum Coke Blend

3-4 Values from Regression Analysis ..........................................................

3-5 Comparison of Empirical and Predicted Carbon Conversions for the 80:20 Blend

4-1 Proximate and Ultimate Analysis Results of the PRB Coal and Petroleum Coke Fuels

4-2 PRB Coal Mineralogical Composition .........................................................

4-3 Chemical Compositions of PRB Coal-Petroleum Shot Coke Blends ...................4-3

4-4 Deposit Initial Slagging Temperatures......................................................... 4-3

4-5 Deposit Mineral Species ..........................................................................

4-6 Crystalline Components of Slag Deposits ................................................... $4-6$

4-7 Crystalline Components of High-Temperature Fouling Deposits ..........................4-6

4-8 Enrichment-Depletion Factors for Selected Slag and High-Temperature Fouling Deposits Produced in the ODTF.....

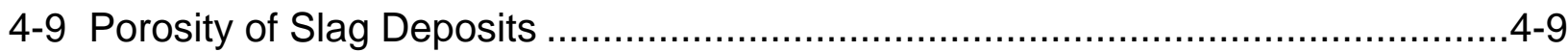




\section{LIST OF TABLES (continued)}

4-10 Average Porosity of High-Temperature Fouling Deposits................................4-9

5-1 Proximate and Ultimate Analysis Results of the PRB Coal and Petroleum Coke

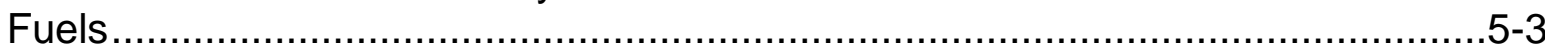

5-2 Flue Gas Compositions, Mean Values of Five Analyses with 95\% Confidence Limits

5-3 Chemical Compositions of the Baghouse Ashes .............................................. 5-3

6-1 Composition of Ash Samples Generated in EERC Conversion and Environmental Process Simulator Facility .......................................................................6-3

6-2 Composition of Full-Scale Ash Samples.........................................................6-3

6-3 Reagents for the Spectrophotometric Determination of $\mathrm{V}(\mathrm{IV})$ and $\mathrm{V}(\mathrm{V})$..............6-5

6-4 Color Development Using Colormetric Indicators ..........................................6-5 


\section{Chapter 1 Introduction}

Petroleum coke, a byproduct of the petroleum-refining process, is an attractive primary or supplemental fuel for power production primarily because of a progressive and predictable increase in the production volumes of petroleum coke $(1,2)$. Petroleum coke is most commonly blended with coal in proportions suitable to meet sulfur emission compliance. Petroleum coke is generally less reactive than coal; therefore, the cofiring of petroleum coke with coal typically improves ignition, flame stability, and carbon loss relative to the combustion of petroleum coke alone. Although petroleum coke is a desirable fuel for producing relatively inexpensive electrical power, concerns about the effects of petroleum coke blending on combustion and pollution control processes exist in the coal-fired utility industry (3).

The Energy \& Environmental Research Center (EERC) completed a 2-year technical assessment of petroleum coke as a supplemental fuel. A survey questionnaire was sent to seven electric utility companies that are currently cofiring coal and petroleum coke in an effort to solicit specific suggestions on research needs and fuel selections. An example of the letter and survey questionnaire is presented in Appendix A. Interest was expressed by most utilities in evaluating the effects of petroleum coke blending on grindability, combustion reactivity, fouling, slagging, and fly ash emissions control. Unexpectedly, concern over corrosion was not expressed by the utilities contacted. Although all seven utilities responded to the question, only two utilities, Northern States Power Company (NSP) and Ameren, sent fuels to the EERC for evaluation. Both utilities sent subbituminous coals from the Power River Basin and petroleum shot coke samples. Petroleum shot coke is produced unintentionally during operational upsets in the petroleum refining process. This report evaluates the effects of petroleum shot coke blending on grindability, fuel reactivity, fouling/slagging, and electrostatic precipitator (ESP) fly ash collection efficiency. 


\section{Chapter 2 Effect of PRB Coal-Petroleum Coke Blending on Grindability}

\section{Introduction}

A Power River Basin (PRB) subbituminous coal and a petroleum shot coke were received from NSP for testing the effects of parent fuel properties on coal-coke blend grindability. Petroleum cokes are generally harder than coals, as indicated by Hardgrove grindability index (HGI) values. The PRB coal has a typical HGI of 56 at $26 \mathrm{wt} \%$ moisture, whereas the petroleum shot coke has an average HGI, based on six measurements in 1998, of 38 (4). Therefore, the softer coal component may concentrate in the finer size fractions during the pulverizing of coal-coke blends. The possibility of a coal-coke size fractionation effect was investigated because it may also adversely affect combustion performance.

\section{Experimental}

The PRB coal, petroleum shot coke, and coal-coke blends of 95:5 and 85:15 (on a weight basis) were selected to investigate the possibility of a coal-coke size fractionation effect. These fuels were pulverized using a Micron Powder Systems Bantam Mill, a small hammer mill. The mill was operated under settings indentical to those typically used to produce a standard coal combustion grind (i.e., 70\%-80\% - 200 mesh). After the fuels were pulverized, sieve analyses were conducted to determine the size distributions of the pulverized fuels. The Ni and $\mathrm{V}$ contents of the pulverized products in each of three size fractions $(\geq 200$ mesh, $<200$ mesh but $\geq 325$ mesh, and $<325$ mesh) were determined using microwave digestion (American Society for Testing and Materials [ASTM] D 3683) and inductively coupled plasma-atomic emission spectroscopy (ICP-AES) (Environmental Protection Agency [EPA] Method 6010) to assess the preferential partitioning of coal and petroleum coke. $\mathrm{Ni}$ and $\mathrm{V}$ are significantly enriched in petroleum cokes relative to coals and are, therefore, good tracers for the coke component.

\section{Results and Discussion}

Samples of the PRB coal, petroleum coke, and coal-coke blends of 95:5 and 85:15 (on a weight basis) were pulverized under identical conditions. As indicated in Figure 2-1, Ni and V are significantly enriched in the petroleum coke relative to the coal and are, therefore, good tracers for examining the possibility of a size fractionation effect as a result of the pulverizing process. Seive analyses were conducted on the four fuels to determine their particle-size distributions. The pulverizer reduced the two parent fuels to approximately the same size, as indicated in Figure 2-2. However, the pulverized 95:5 blend was significantly finer, whereas the 85:15 blend was significantly coarser relative to the parent fuels. Summations of the Ni and V contents for three size fractions $(<45 \mu \mathrm{m}, \geq 45 \mu \mathrm{m}$ but $<75 \mu \mathrm{m}$, and $\geq 75 \mu \mathrm{m})$ of the fuels are compared in Figure 2-3. The finest particle-size fraction of the petroleum coke is significantly enriched in $\mathrm{V}$ and $\mathrm{Ni}$ relative to its coarser size fractions. In contrast, $\mathrm{V}$ and $\mathrm{Ni}$ are uniformly distributed among the three particle-size fractions of the pulverized PRB coal. The finest particle-size fractions of the coal-coke blends are not significantly enriched in $\mathrm{V}$ and $\mathrm{Ni}$ relative to their coarser size 


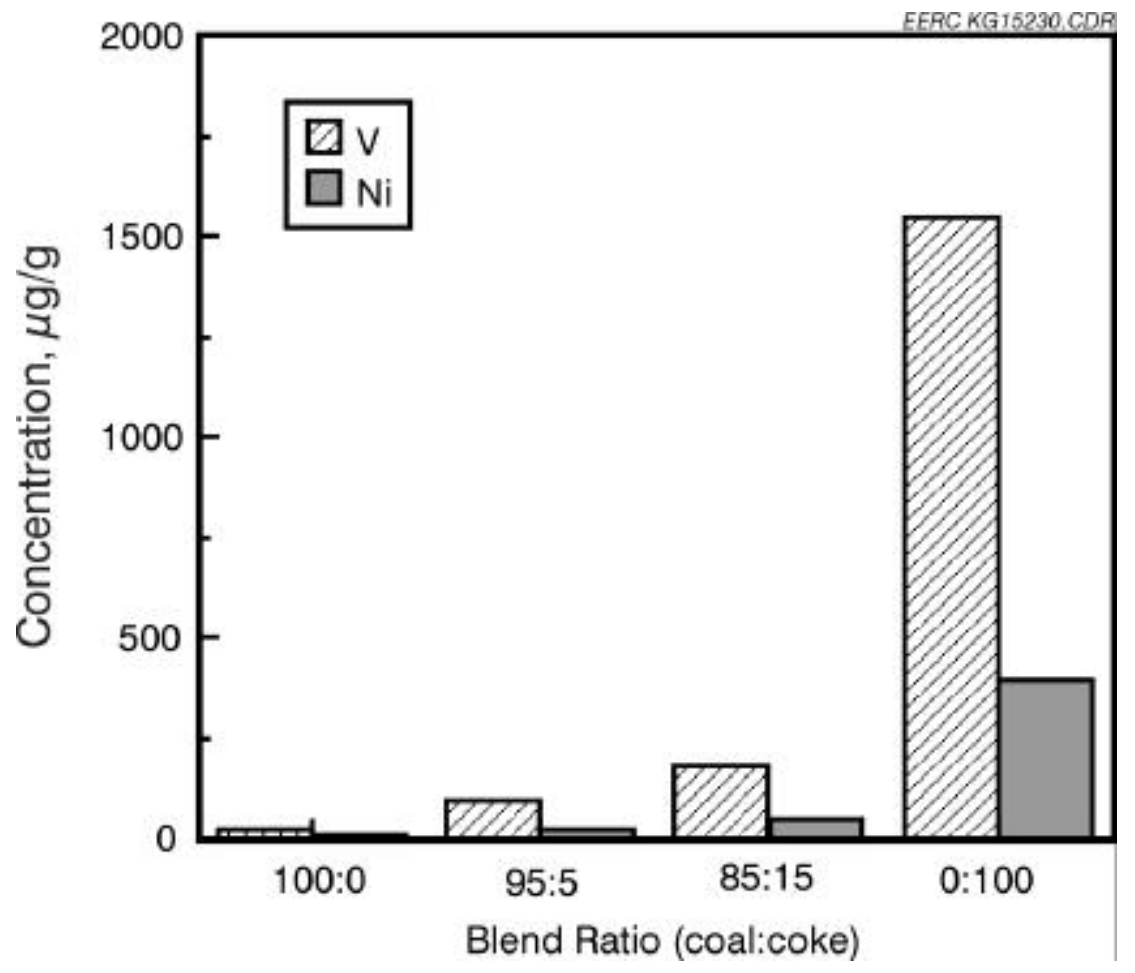

Figure 2-1 Ni and V concentrations of the coal, coal-coke blends, and coke.

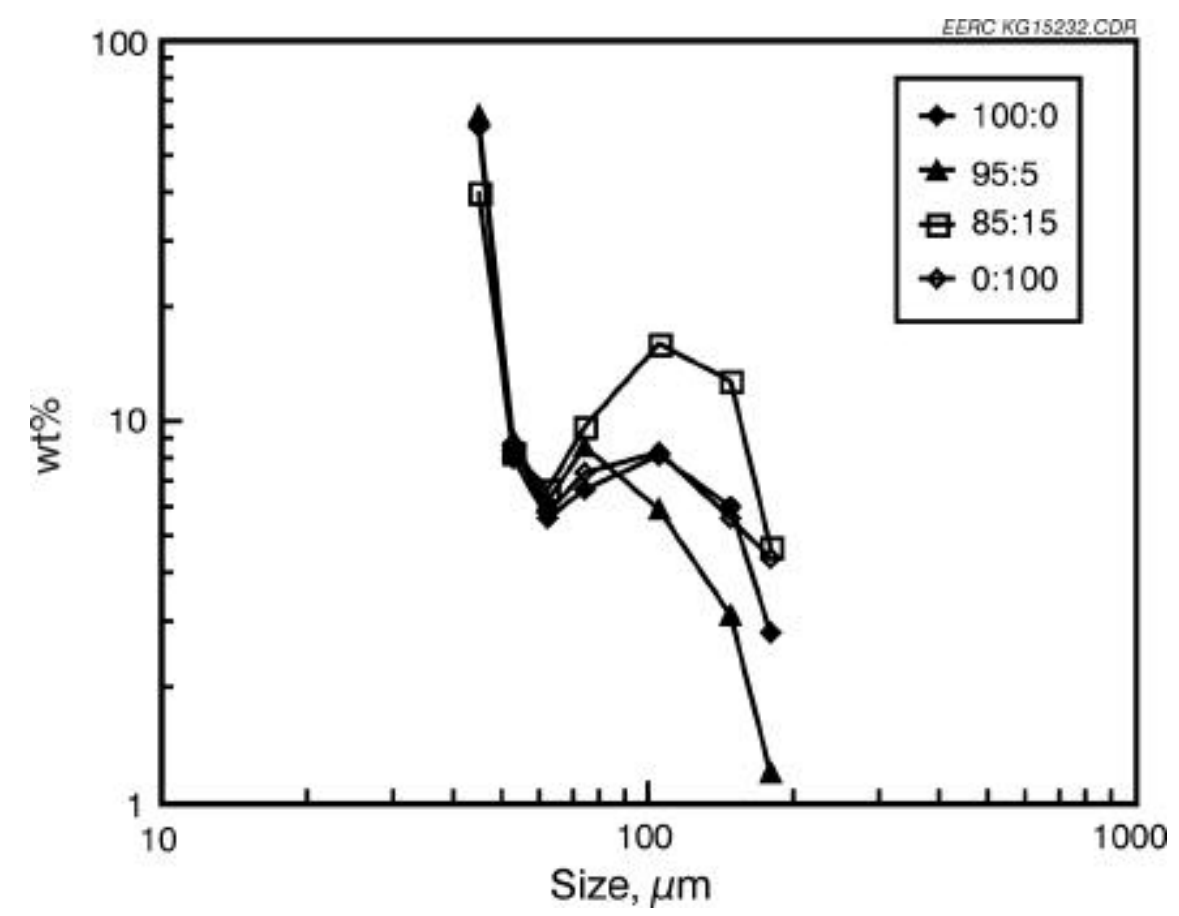

Figure 2-2 Size distributions of the fuels as a function of blend ratio (coal:coke on a weight basis). 


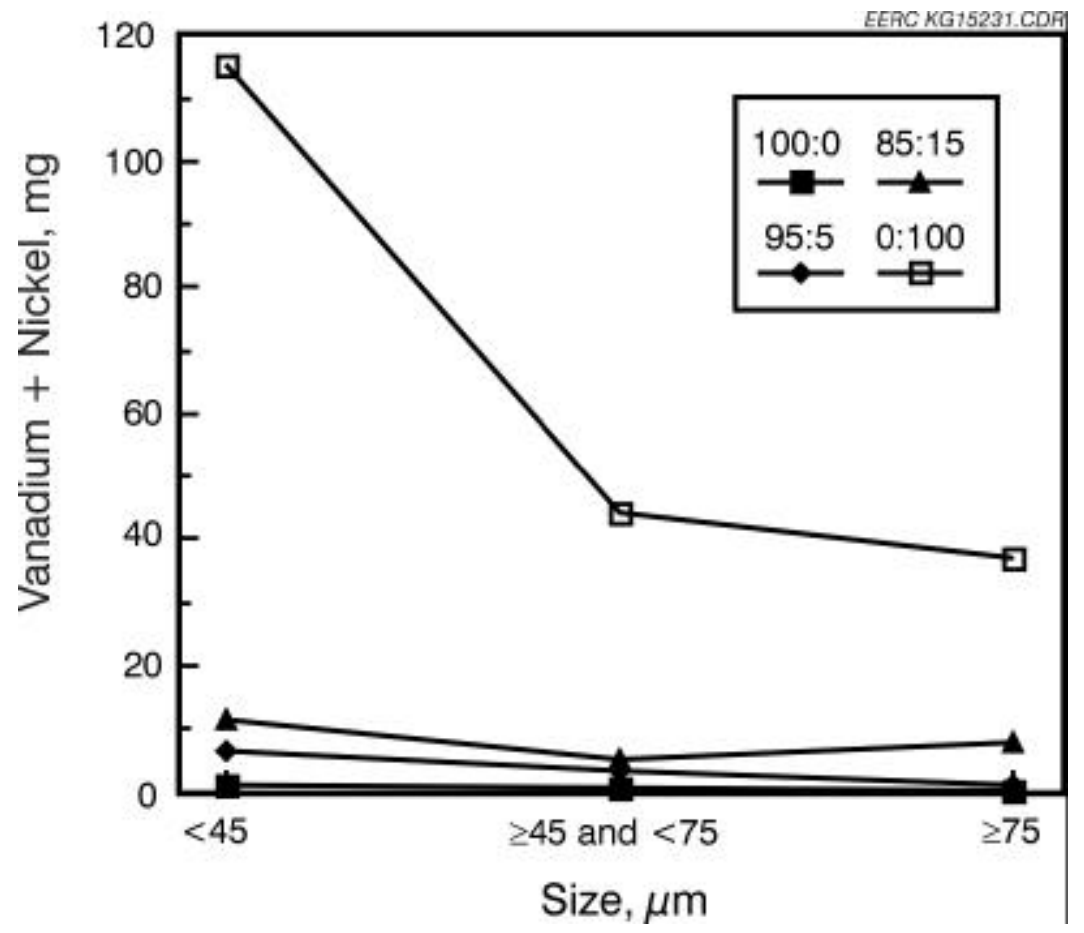

Figure 2-3 V and Ni contents for three size fractions of the fuels as a function of blend ratio (coal:coke on a weight basis).

fractions. The lack of a $\mathrm{V}$ and $\mathrm{Ni}$ enrichment in the finest size fractions of the coal-coke blends suggests that the softer $\mathrm{V}$ - and $\mathrm{Ni}$-depleted coal particles concentrated in the finer size fractions during pulverization, thus diluting the fine-particle $\mathrm{V}$ - and Ni-enrichment signature of the petroleum coke. 


\section{Chapter 3 Combustion Kinetics of PRB Coal- Petroleum Coke Blends}

\section{Introduction}

The relatively low combustion reactivity of petroleum coke poses several technical challenges to the burning of coal-petroleum coke blends in boilers. In addition to a decrease in boiler efficiency associated with the incomplete combustion of petroleum coke, unburned carbon particles can promote boiler tube fouling, erosion, and corrosion as well as stack plume opacity. In this investigation, a PRB subbituminous coal and a petroleum shot coke were used for evaluating the effects of blending on fuel reactivity.

\section{Experimental}

A PRB coal and petroleum coke were pulverized separately to a nominal utility grind ( $90 \%$ of the particles $<75 \mu \mathrm{m})$. A mixture of $80 \mathrm{wt} \% \mathrm{PRB}$ coal and $20 \mathrm{wt} \%$ petroleum coke was blended by pulverizing the parent fuels as described in Section 2.2. Particle-size distributions of the pulverized fuels were determined using a Malvern laser diffraction particle sizer. Proximate, ultimate, and bulk density analyses were also performed on the fuels.

The coal, petroleum coke, and a coal-coke (80:20) blend were burned in an atmospheric droptube furnace (ADTF), described in detail in Appendix B, at various temperatures and residence times to calculate carbon conversion rates. A short-time-residence probe was used to quench and collect the ash at desired residence times. Tests were performed on the 80:20 blend at $800^{\circ}, 900^{\circ}$, $1000^{\circ}$, and $1100^{\circ} \mathrm{C}$ with particle residence times ranging from 0.2 to $1.2 \mathrm{~s}$. The temperatures and residence times were selected to enable combustion measurements of the less reactive petroleum coke while avoiding excessively fast burnout of the more reactive coal. Combustion tests for the coal and coke were performed at $800^{\circ}, 900^{\circ}$, and $1000^{\circ} \mathrm{C}$, with particle residence times ranging from 0.06 to $3.0 \mathrm{~s}$. Oxygen concentration was maintained at $21 \mathrm{~mol} \%$ during all the tests. Gas analyzers were used to monitor $\mathrm{O}_{2}$ and determine $\mathrm{CO}$ and $\mathrm{CO}_{2}$ concentrations.

Carbon conversion was calculated from the $\mathrm{CO}$ and $\mathrm{CO}_{2}$ gas analysis results using Equations 1-4:

$$
\begin{gathered}
\text { moles } \mathrm{CO}_{2}=(\text { total gas flow rate }) \times\left(\mathrm{CO}_{2} \mathrm{~mol} \% / 100\right) \times(\mathrm{P} / 760 \mathrm{~mm} \mathrm{Hg}) /(\mathrm{R} \times \mathrm{T}) \\
\text { moles } \mathrm{CO}=(\text { total gas flow rate }) \times(\mathrm{CO} \text { mol \%/100) } \times(\mathrm{P} / 760 \mathrm{~mm} \mathrm{Hg}) /(\mathrm{R} \times \mathrm{T}) \\
\text { molar } \mathrm{C} \text { feed rate }=(\mathrm{C} \mathrm{wt} \% / 100) \times(\text { coal feed rate }) \times(1 \text { mole } \mathrm{C} / 12 \mathrm{~g} \mathrm{C}) \\
\text { carbon conversion } \%=\left(\left[\text { moles } \mathrm{CO}_{2}+\text { moles } \mathrm{CO}\right] /[\text { molar } \mathrm{C} \text { feed rate }]\right) \times
\end{gathered}
$$

[Eq. 3-4] where $\mathrm{P}$ is the barometric pressure $(\mathrm{mm} \mathrm{Hg}), \mathrm{R}$ is the univesal gas constant $(0.082 \mathrm{~L} \mathrm{~atm} / \mathrm{K} \mathrm{mol})$, and $\mathrm{T}$ is the gas temperature in Kelvin. Carbon conversion was also calculated gravimetrically using the following equation: 


$$
\mathrm{C} \text { conversion } \%=\left[1-\frac{\mathrm{g} \text { char collected }-\mathrm{g} \text { ash fed }}{\mathrm{g} \text { coal fed }-\mathrm{g} \text { ash fed }-\mathrm{g} \text { water fed }}\right] \times 100
$$

\section{Results and Discussion}

\section{Carbon Conversion}

Proximate and ultimate analysis results for the PRB coal, petroleum coke, and 80:20 blend are presented in Table 3-1. As expected, the petroleum coke is significantly enriched in carbon and sulfur, but depleted in moisture, volatile matter, ash, hydrogen, and oxygen relative to the PRB coal. Bulk densities of the PRB coal, petroleum coke, and 80:20 blend are very similar at 1.43, 1.44 , and $1.43 \mathrm{~g} / \mathrm{cm}^{3}$, respectively. Mean particle sizes of the pulverized PRB coal, petroleum coke, and 80:20 blend are 25.2, 18.2, and $23.8 \mu \mathrm{m}$, respectively. These density and particle-size values were used to calculate residence times in the ADTF.

Table 3-1 Proximate and Ultimate Analysis Results for the PRB Coal and Petroleum Coke Fuels (wt\% as-determined unless otherwise noted)

\begin{tabular}{|l|l|l|l|}
\hline Parameter & PRB Coal & Petroleum Coke & $\mathbf{8 0 : 2 0}$ Blend \\
\hline Moisture & 16.0 & 0.31 & 12.8 \\
\hline Volatile Matter & 41.1 & 9.67 & 34.8 \\
\hline Fixed Carbon & 37.5 & 89.6 & 47.9 \\
\hline Ash & 5.42 & 0.42 & 4.42 \\
\hline Calorific Value, Btu/lb & 10537 & 15410 & 11512 \\
\hline Hydrogen & 6.05 & 3.66 & 5.57 \\
\hline Carbon & 58.8 & 89.8 & 65.0 \\
\hline Nitrogen & 0.84 & 1.54 & 0.98 \\
\hline Sulfur & 0.50 & 6.00 & 1.60 \\
\hline Oxygen & 28.4 & $<0.1$ & 22.4 \\
\hline
\end{tabular}

Tables 3-2a-c compare carbon conversion results calculated from $\mathrm{CO}$ and $\mathrm{CO}_{2}$ concentrations (Equations 3-1-4) and gravimetrically (Equation 3-5). The gravimetrically determined carbon conversion values are more precise. However, carbon conversion values determined in this manner are generally biased high relative to the gas analysis method, as indicated in Tables 3$2 \mathrm{a}-\mathrm{c}$, because it is assumed that all of the ash and unburned coke is collected and weighed. In practice, some of the unburned carbon may not reach or remain on the filter for weighing, thus indicating higher conversion values than actually obtained.

The carbon conversion curve for the 80:20 blend exhibits asymptotic behavior, as shown in Figure 3-1, at approximately $80 \%$ burnout, suggesting that the coal burned before significant petroleum coke combustion occurred. Tests were performed using the parent fuels to investigate 
Table 3-2a Carbon Conversion Results for the PRB Coal

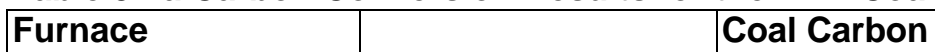

\begin{tabular}{l|l|l} 
Temperature, ${ }^{\circ} \mathbf{C}$ & Residence Time, $\mathbf{s}$ & Conversion, \%
\end{tabular}

\begin{tabular}{|l|c|l|}
\hline 1000 & 0.05 & 64.4 \\
\hline 1000 & 0.10 & 79.3 \\
\hline
\end{tabular}

\begin{tabular}{|l|l|l|}
\hline 1000 & 0.10 & 79.3 \\
\hline 1000 & 0.20 & 94.2 \\
\hline 1000 & 0.30 & 100.0 \\
\hline 1000 & 0.40 & 100.0 \\
\hline 1000 & 0.50 & 100.0 \\
\hline 1000 & 0.60 & 100.0 \\
\hline
\end{tabular}

\begin{tabular}{|l|l|l|}
\hline 1000 & 0.70 & 100.0 \\
\hline 1000 & 0.80 & 100.0 \\
\hline 1000 & 0.90 & 100.0 \\
\hline 1000 & 1.00 & 100.0 \\
\hline
\end{tabular}

\begin{tabular}{|l|l|l|}
\hline 1000 & 1.00 & 100.0 \\
\hline 1000 & 1.50 & 100.0 \\
\hline 1000 & 1.70 & 100.0 \\
\hline 1000 & 1.80 & 100.0 \\
\hline
\end{tabular}

\begin{tabular}{|l|l|l|}
\hline 1000 & 1.70 & 100.0 \\
\hline 1000 & 1.90 & 100.0 \\
\hline
\end{tabular}

\begin{tabular}{|l|l|l|}
\hline 900 & 0.05 & 38.8 \\
\hline 900 & 0.10 & 51.8 \\
\hline 900 & 0.20 & 69.1 \\
\hline 900 & 0.30 & 81.9 \\
\hline
\end{tabular}

\begin{tabular}{|l|l|l|}
\hline 900 & 0.30 & 81.9 \\
\hline 900 & 0.40 & 92.4 \\
\hline 900 & 0.50 & 100.0 \\
\hline 900 & 0.60 & 100.0 \\
\hline 900 & 0.70 & 100.0 \\
\hline 900 & 0.80 & 100.0 \\
\hline 900 & 0.90 & 100.0 \\
\hline 900 & 1.00 & 100.0 \\
\hline 900 & 1.50 & 100.0 \\
\hline 900 & 2.00 & 100.0 \\
\hline 900 & 2.40 & 100.0 \\
\hline 900 & 2.50 & 100.0 \\
\hline 800 & 0.05 & 6.0 \\
\hline 800 & 0.10 & 12.0 \\
\hline 800 & 0.20 & 24.0 \\
\hline 800 & 0.30 & 35.9 \\
\hline 800 & 0.40 & 47.9 \\
\hline 800 & 0.50 & 59.9 \\
\hline 800 & 0.60 & 71.9 \\
\hline 800 & 0.70 & 83.9 \\
\hline 800 & 0.80 & 95.8 \\
\hline 800 & 0.90 & 100.0 \\
\hline 800 & 1.00 & 100.0 \\
\hline 800 & 1.50 & 100.0 \\
\hline 800 & 2.00 & 100.0 \\
\hline 800 & 3.00 & 100.0 \\
\hline 800 & 3.50 & 100.0 \\
\hline 800 & 3.70 & 100.0 \\
\hline & & \\
\hline 000 & & \\
\hline 000 & &
\end{tabular}


Table 3-2b Carbon Conversion Results for the Petroleum Coke

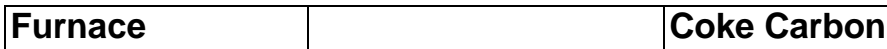

Temperature, ${ }^{\circ} \mathbf{C}$ Residence Time, s $\quad$ Conversion, \%

\begin{tabular}{|l|l|l|}
\hline 1000 & 0.05 & 0.0 \\
\hline 1000 & 0.10 & 0.0 \\
\hline 1000 & 0.20 & 0.0 \\
\hline 1000 & 0.30 & 0.0 \\
\hline 1000 & 0.40 & 9.8 \\
\hline 1000 & 0.50 & 23.1 \\
\hline 1000 & 0.60 & 34.0 \\
\hline 1000 & 0.70 & 43.2 \\
\hline 1000 & 0.80 & 51.2 \\
\hline 1000 & 0.90 & 58.3 \\
\hline 1000 & 1.00 & 64.6 \\
\hline 1000 & 1.50 & 88.8 \\
\hline 1000 & 1.70 & 96.3 \\
\hline 1000 & 1.80 & 99.7 \\
\hline 1000 & 1.90 & 103.0 \\
\hline 900 & 0.05 & 0.0 \\
\hline 900 & 0.10 & 0.0 \\
\hline 900 & 0.20 & 0.0 \\
\hline 900 & 0.30 & 0.0 \\
\hline 900 & 0.40 & 0.0 \\
\hline 900 & 0.50 & 0.0 \\
\hline 900 & 0.60 & 0.0 \\
\hline 900 & 0.70 & 0.0 \\
\hline 900 & 0.80 & 4.4 \\
\hline 900 & 0.90 & 14.3 \\
\hline 900 & 1.00 & 23.2 \\
\hline 900 & 1.50 & 57.4 \\
\hline 900 & 2.00 & 81.7 \\
\hline 900 & 2.40 & 97.1 \\
\hline 900 & 2.50 & 100.5 \\
\hline 800 & 0.05 & 0.0 \\
\hline 800 & 0.10 & 0.0 \\
\hline 800 & 0.20 & 0.0 \\
\hline 800 & 0.30 & 0.0 \\
\hline 800 & 0.40 & 0.0 \\
\hline 800 & 0.50 & 0.0 \\
\hline 800 & 0.60 & 0.0 \\
\hline 800 & 0.70 & 0.0 \\
\hline 800 & 0.80 & 0.0 \\
\hline 800 & 0.90 & 0.0 \\
\hline 800 & 1.00 & 0.0 \\
\hline 800 & 1.50 & 32.7 \\
\hline 800 & 3.00 & 91.6 \\
\hline 800 & & \\
\hline 800 & 3.50 & \\
\hline & & \\
\hline 800 & & \\
\hline & & \\
\hline
\end{tabular}




Table 3-2c Carbon Conversion Results for the 80:20 PRB
Coal-Petroleum Coke Blend
\begin{tabular}{|l|l|l|l|}
\hline $\begin{array}{l}\text { Furnace } \\
\text { Temperature, }{ }^{\circ} \text { C }\end{array}$ & $\begin{array}{l}\text { Residence } \\
\text { Time, s }\end{array}$ & $\begin{array}{l}\text { Gas Carbon } \\
\text { Conversion, \% }\end{array}$ & Fuel Burned, \% \\
\hline 1100 & 0.2 & 74.1 & 85.7 \\
\hline 1100 & 0.4 & 84.9 & 92.0 \\
\hline 1100 & 0.6 & 90.6 & 96.9 \\
\hline 1100 & 0.8 & 91.9 & 99.3 \\
\hline 1000 & 0.2 & 69.5 & 79.8 \\
\hline 1000 & 0.4 & 81.1 & 88.0 \\
\hline 1000 & 0.6 & 86.8 & 92.7 \\
\hline 1000 & 0.8 & 90.7 & 94.9 \\
\hline 900 & 0.2 & 20.7 & 37.4 \\
\hline 900 & 0.2 & 32.2 & 46.1 \\
\hline 900 & 0.4 & 67.6 & - \\
\hline 900 & 0.4 & 63.7 & 81.7 \\
\hline 900 & 0.4 & 71.5 & 80.6 \\
\hline 900 & 0.6 & 79.0 & 86.5 \\
\hline 900 & 0.6 & 87.1 & 88.6 \\
\hline 900 & 0.6 & 83.6 & 87.4 \\
\hline 900 & 0.8 & 84.2 & 89.0 \\
\hline 900 & 0.8 & 83.2 & 90.4 \\
\hline 900 & 1.0 & 88.0 & 93.0 \\
\hline 800 & 0.2 & 13.2 & 30.0 \\
\hline 800 & 0.2 & 8.9 & 30.1 \\
\hline 800 & 0.4 & 15.8 & 33.9 \\
\hline 800 & 0.4 & 24.8 & 39.3 \\
\hline 800 & 0.6 & 25.0 & 42.6 \\
\hline 800 & 0.6 & 35.8 & 47.6 \\
\hline 800 & 0.8 & 71.3 & 82.5 \\
\hline 800 & 0.8 & 82.6 & 89.3 \\
\hline 800 & 1.0 & 85.3 & 88.1 \\
\hline 800 & 1.2 & & \\
\hline & & & \\
\hline
\end{tabular}

this two-stage combustion hypothesis. Best-fit curves to the experimental conversion results for the parent fuels are presented in Figures 3-2 and 3-3. The carbon conversion curves from Figures 3-2 and 3-3 were weighted appropriately to calculate conversion results for the 80:20 blend. As shown in Figures 3-4a-c, the calculated results compare favorably to the empirical conversion results for the $80: 20$ blend at $800^{\circ}, 900^{\circ}$, and $1000^{\circ} \mathrm{C}$. This agreement in calculated and empirical conversion values corroborates the hypothesis that coal and petroleum coke burned separately. Unburned petroleum coke particles, shown in Figures 3-5-7, were identified easily using electron probe microanalysis (EPMA) on the basis of the presence of relatively high $\mathrm{V}$ and $\mathrm{Ni}$ contents.

Best-fit curves and regression equations for the 80:20 blend are presented in Figure 3-8 and Table 3-2c, respectively. As indicated in Figure 3-8, only the results corresponding to $\geq 80 \%$ of the fuel burned in Figure 3-1 were considered in the regression analysis. Therefore, results of the regression analysis primarily apply to petroleum coke combustion because of the two-stage combustion process. 


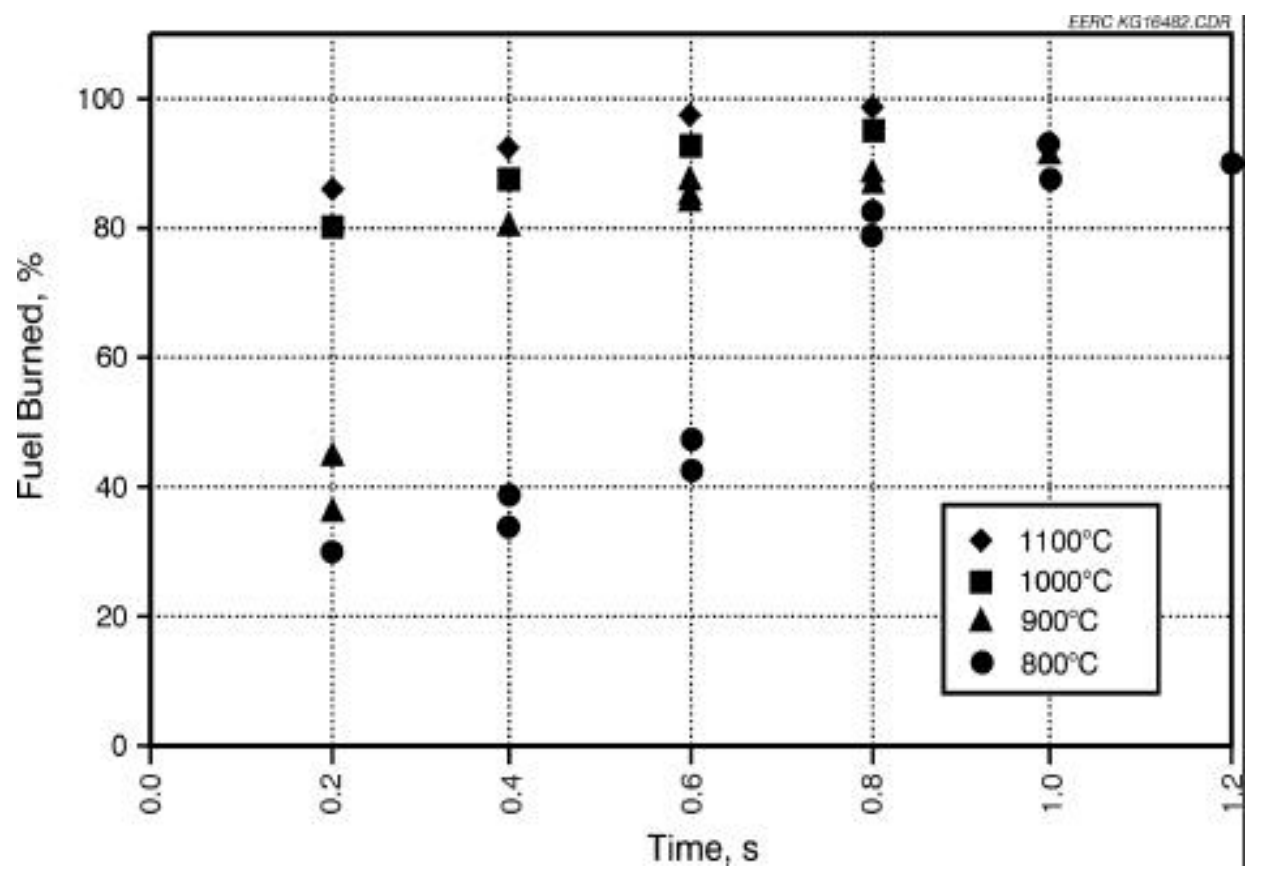

Figure 3-1 Carbon conversion as a function of residence time and temperature for the 80:20 PRB coal-petroleum coke blend.

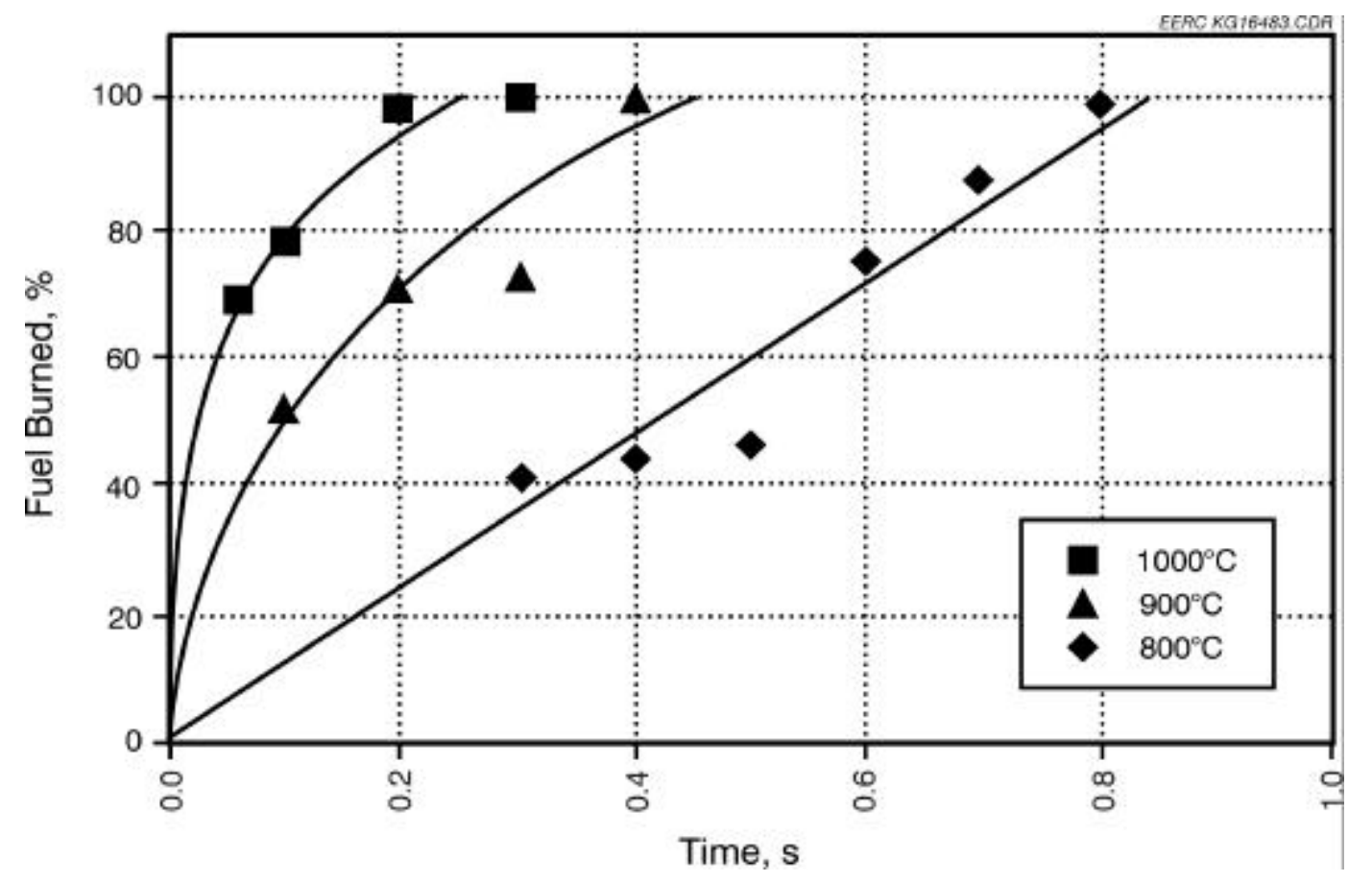

Figure 3-2 Carbon conversion as a function of residence time and temperature for the PRB coal. 


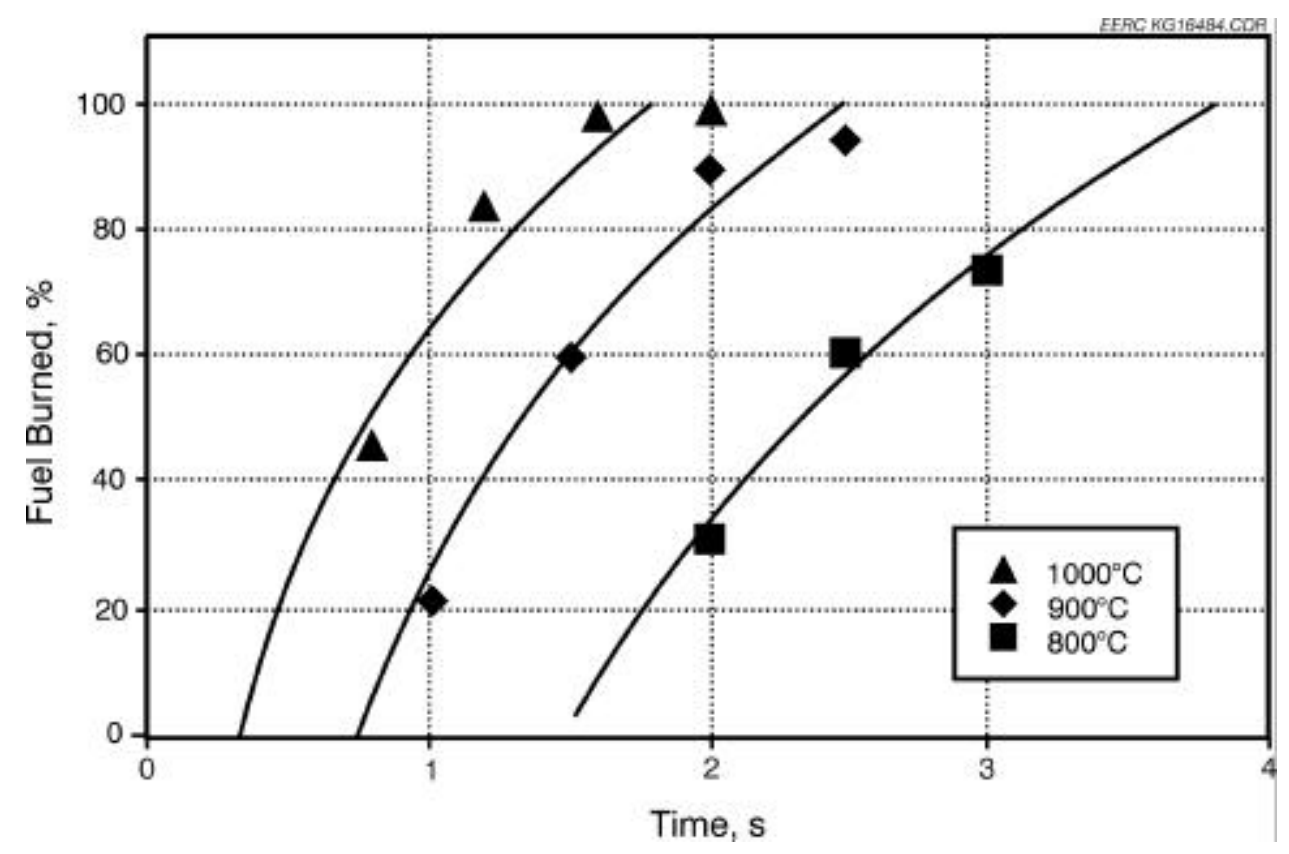

Figure 3-3 Carbon conversion as a function of residence time and temperature for the petroleum coke.

\section{Kinetic Calculations and Modeling}

Kinetic values were determined from the gravimetrically determined carbon loss data in Tables 3-2a-c using the formulation of Field $(5,6)$ as modified by Nsakala et al. (7). The calculations are based on surface area, employing a shrinking core model. Volatile evolution was not modeled because data for these materials were unavailable and the devolatilization rate is expected to be short compared to the char-burning rate.

From the formulation of Nsakala et al. (7), the rate of carbon removal per unit surface area, $q$, in $\mathrm{g} \mathrm{cm}^{-2} \mathrm{sec}^{-1}$ is given in integrated form by:

$$
\mathrm{q}=3\left(1-\mathrm{U}^{1 / 3}\right) /\left(\mathrm{S}_{\mathrm{o}} \mathrm{t}\right)
$$

where $\mathrm{U}$ is the fraction of unburned material, $\mathrm{t}$ is the residence time in seconds, $\mathrm{S}_{\mathrm{o}}$ is the initial surface area in $\mathrm{cm}^{2} / \mathrm{g}$, and

$$
S_{o}=6 /(X \rho)
$$

where $\mathrm{X}$ is the original particle diameter in centimeters and $\rho$ is the particle density in $\mathrm{g} / \mathrm{cm}^{3}$.

The overall reaction rate coefficient $\mathrm{K}$ is defined as

$$
\mathrm{K}=\mathrm{q} / \mathrm{P}_{\mathrm{g}}
$$


a.

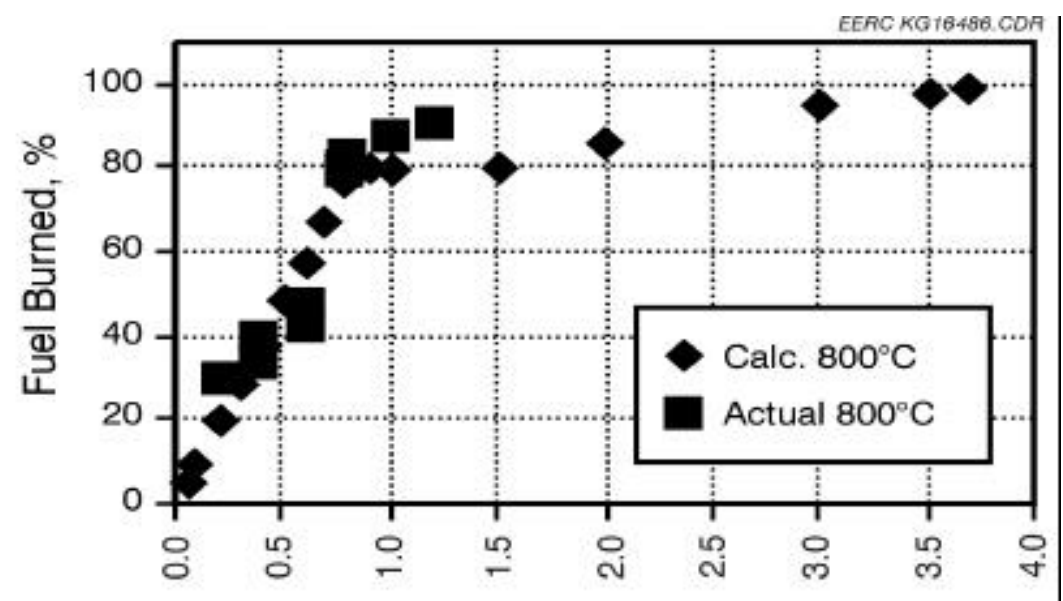

Time, s

b.
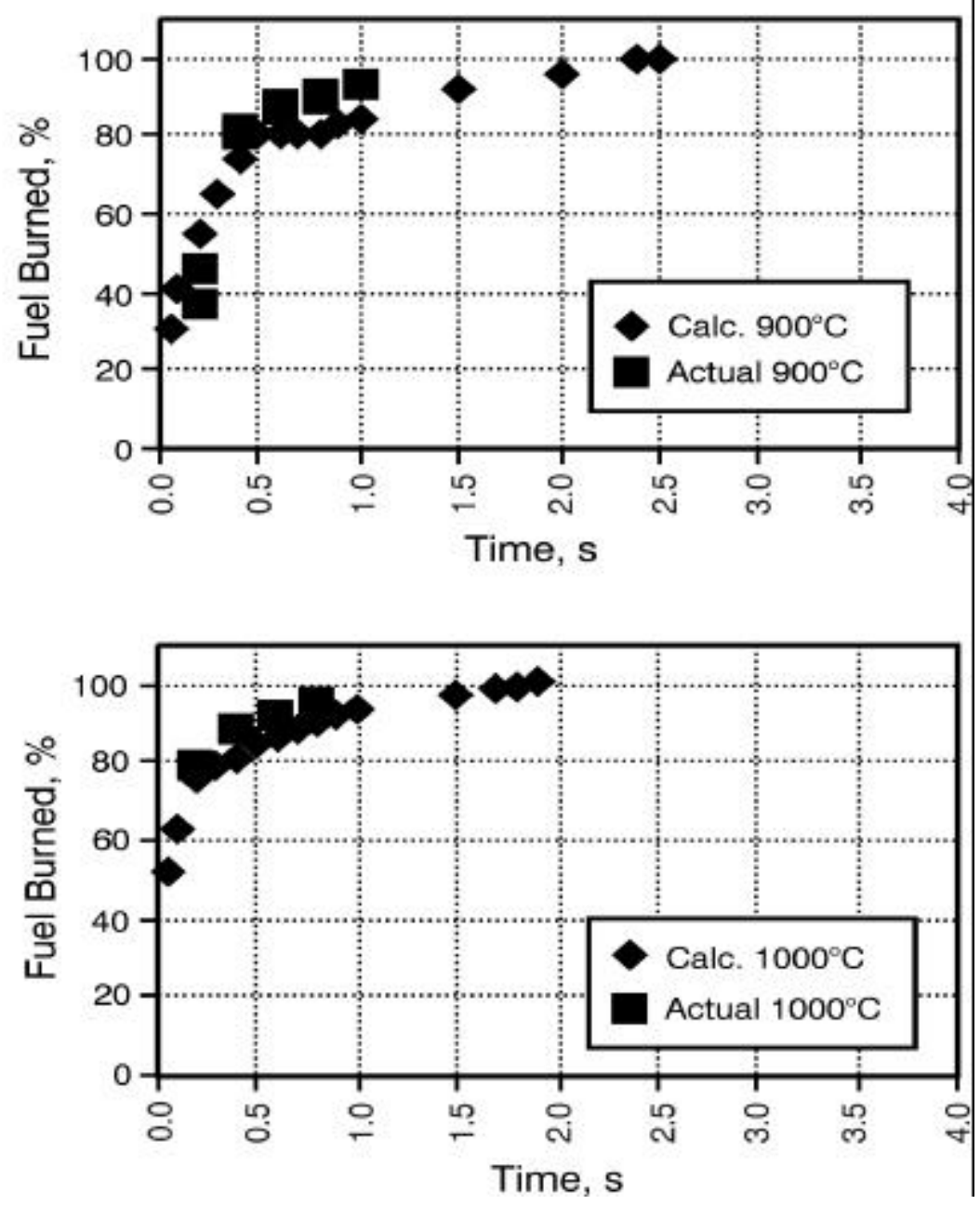

Figure 3-4 (a) Comparison of calculated and empirical carbon conversion results at $800^{\circ} \mathrm{C}$; (b) comparison of calculated and empirical carbon conversion results at $900^{\circ} \mathrm{C}$; (c) comparison of calculated and empirical carbon conversion results at $1000^{\circ} \mathrm{C}$. 


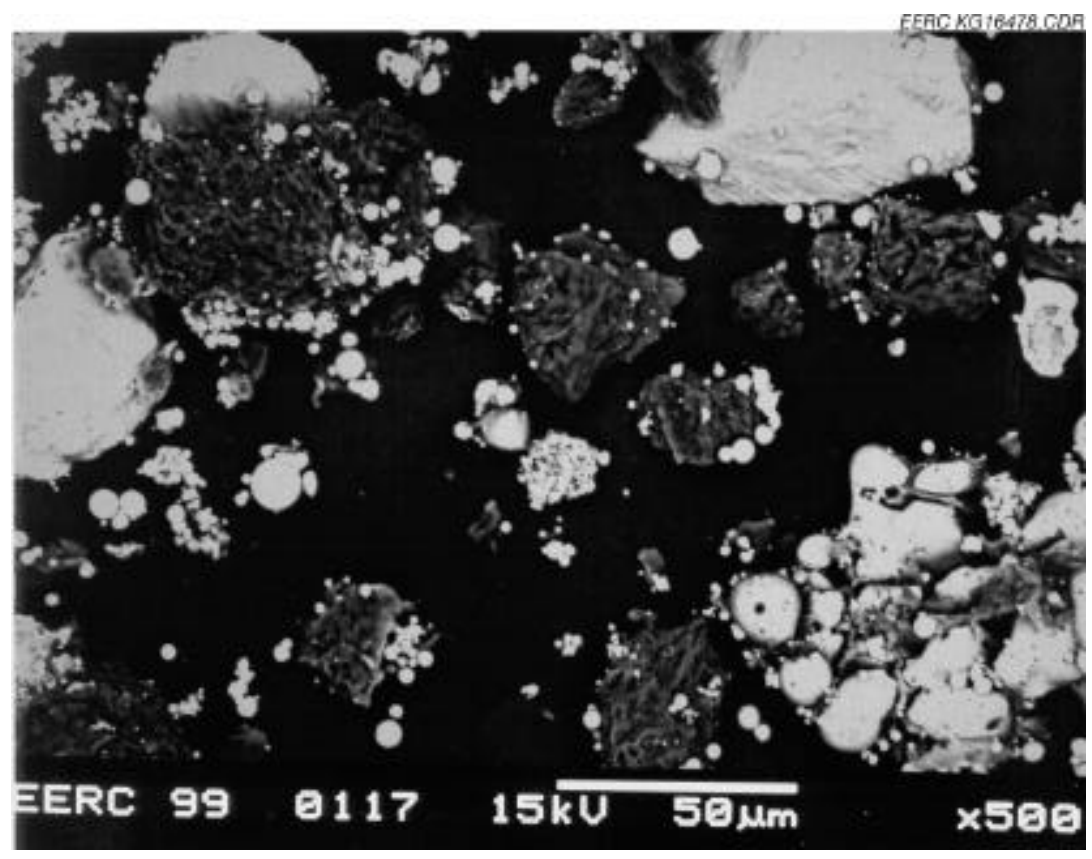

Figure 3-5 Backscattered electron image of coal ash and unburned petroleum coke particles produced from an 80:20 coal-coke blend at $1000^{\circ} \mathrm{C}$ for $0.4 \mathrm{~s}$.

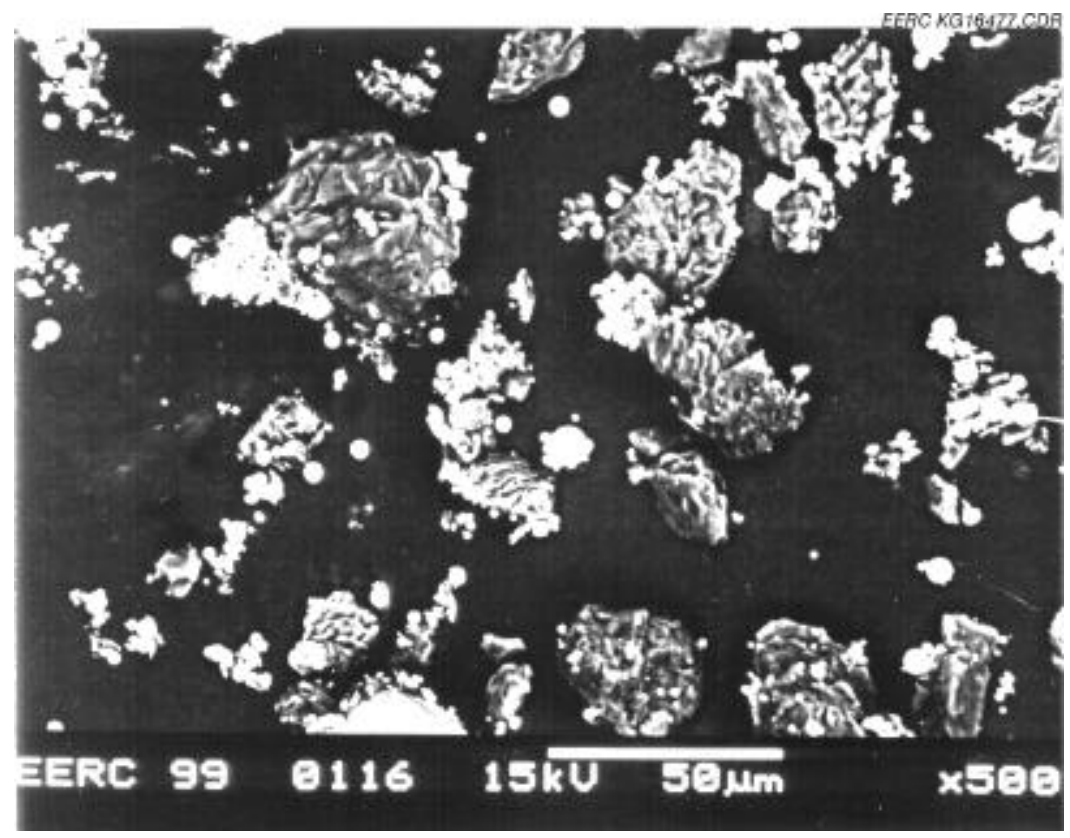

Figure 3-6 Backscattered electron image of coal ash and unburned petroleum coke particles produced from an $80: 20 \mathrm{coal}-$ coke blend at $900^{\circ} \mathrm{C}$ for $0.6 \mathrm{~s}$. 


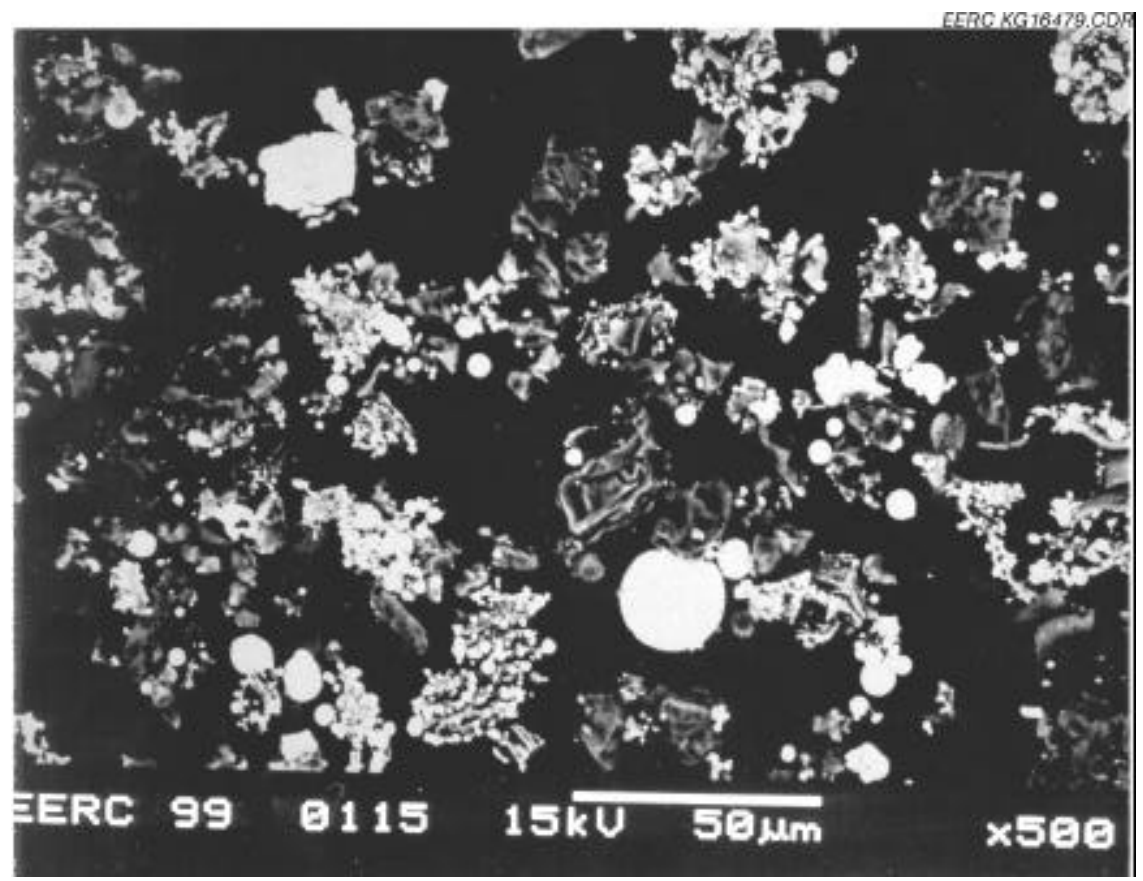

Figure 3-7 Backscattered electron image of coal ash and unburned petroleum coke particles produced from an $80: 20 \mathrm{coal}-$ coke blend at $800^{\circ} \mathrm{C}$ for $0.8 \mathrm{~s}$.

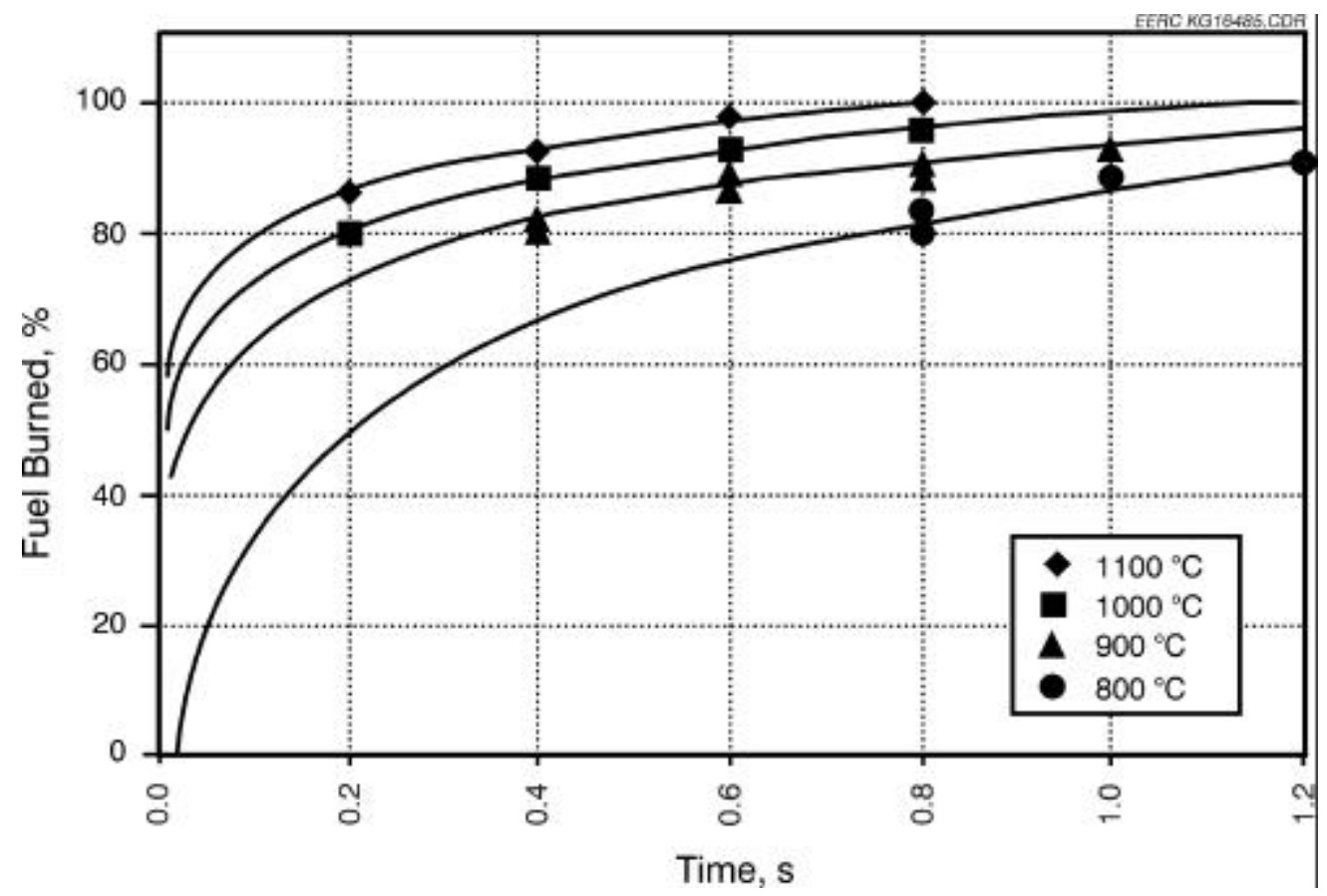

Figure 3-8 Best-fit curves for the 80:20 PRB coal-petroleum coke blend carbon conversion results. 
where $\mathrm{P}_{\mathrm{g}}$ is the partial pressure of oxygen in the gas in atm.

The overall reaction rate coefficient, $\mathrm{K}$, depends on the rate of oxygen diffusion to the particle surface and on the rate of reaction of oxygen at the surface:

$$
1 / \mathrm{K}=1 / \mathrm{K}_{\mathrm{diff}}+1 / \mathrm{K}_{\mathrm{s}}
$$

where $\mathrm{K}_{\text {diff }}$ is the diffusional reaction rate coefficient and $\mathrm{K}_{\mathrm{s}}$ is the surface reaction rate coefficient. Units on $\mathrm{K}_{\text {diff }}$ and $\mathrm{K}_{\mathrm{s}}$ are $\mathrm{g} /\left(\mathrm{cm}^{2}\right.$-s-atm).

The diffusional reaction rate coefficient, $\mathrm{K}_{\text {diff }}$, in $\mathrm{g} /\left(\mathrm{cm}^{2}\right.$-s-atm) is given by:

$$
\mathrm{K}_{\text {diff }}=(2 \times \mathrm{AW} \text { carbon }) \phi \mathrm{D} /(\mathrm{X} \mathrm{R} \mathrm{T})
$$

where AW is the atomic weight of carbon $(12 \mathrm{~g} / \mathrm{mole}) ; \phi$ is the molar ratio of product gases to reactant gases (equivalent to 2 for the reaction $\mathrm{O}_{2}+2 \mathrm{C} \rightarrow 2 \mathrm{CO}$ ); $\mathrm{D}$ is the binary diffusion coefficient of oxygen in nitrogen in $\mathrm{cm}^{2} / \mathrm{s} ; \mathrm{X}$ is the average particle diameter in $\mathrm{cm}$ at time $\mathrm{t}$; $\mathrm{R}$ is the ideal gas constant, $82.06 \mathrm{~cm}^{3}$ atm $/ \mathrm{mole} \mathrm{K}$; and $\mathrm{T}_{\mathrm{m}}$ is the temperature of the boundary layer in $K$ (equivalent to $T_{g}$ when calculation was based on gas temperature and $\left[T_{g}+T_{\text {particle }}\right] / 2$ when calculation was based on calculated particle temperature).

The surface reaction rate constant, $\mathrm{K}_{\mathrm{s}}$, is traditionally used to determine the apparent activation energy, $\mathrm{E}_{\mathrm{a}}$, and the frequency factor, $\mathrm{A}$, from the relationship:

$$
\mathrm{K}_{\mathrm{s}}=\mathrm{A} \exp \left(-\mathrm{E}_{\mathrm{a}} / \mathrm{RT}_{\mathrm{g}}\right)
$$

The particle surface temperature, $\mathrm{T}_{\text {particle }}$, is calculated from a heat balance on the particle, assuming steady-state burning conditions and $\mathrm{CO}$ as the primary product of the combustion:

$$
\mathrm{H}_{\mathrm{g}}=\mathrm{H}_{\mathrm{c}}+\mathrm{H}_{\mathrm{r}}
$$

where $\mathrm{H}_{\mathrm{g}}$ is the rate of heat generation per unit area in cal/ $\left(\mathrm{cm}^{2}-\mathrm{s}\right) ; \mathrm{H}_{\mathrm{c}}$ is the rate of heat transfer by conduction in $\mathrm{cal} /\left(\mathrm{cm}^{2} \mathrm{~s}\right)$; and $\mathrm{H}_{\mathrm{r}}$ is the rate of heat transfer by radiation in $\mathrm{cal} /\left(\mathrm{cm}^{2}-\mathrm{s}\right)$.

The rate of heat generation, $\mathrm{H}_{\mathrm{g}}$, is given by

$$
\mathrm{H}_{\mathrm{g}}=\mathrm{q} \Delta \mathrm{H}
$$

where $\Delta \mathrm{H}$ is the enthalpy of the reaction $\mathrm{C}+1 / 2 \mathrm{O}_{2} \rightarrow \mathrm{CO}$.

The rate of heat transfer by conduction is given by

$$
\mathrm{H}_{\mathrm{c}}=2 \lambda\left(\mathrm{T}_{\text {particle }}-\mathrm{T}_{\mathrm{g}}\right) / \mathrm{X}
$$


where $\lambda$ is the thermal conductivity of the gas in $\mathrm{cal} /(\mathrm{cm}-\mathrm{s} \mathrm{K})$ and $\mathrm{X}$ is the particle diameter in $\mathrm{cm}$ at residence time $\mathrm{t}$.

The rate of heat transfer by radiation is given by

$$
\mathrm{H}_{\mathrm{r}}=\epsilon \sigma\left(\mathrm{T}_{\text {particle }}^{4}-\mathrm{T}_{\text {wall }}^{4}\right)
$$

where $\epsilon$ is the emissivity of particle and wall, taken as 0.8; $\sigma$ is the Stefan-Boltzmann constant, $1.36 \times 10^{-12} \mathrm{cal} / \mathrm{cm}-\mathrm{s} \mathrm{K}$; and $\mathrm{T}_{\text {wall }}$ is the furnace wall temperature in $\mathrm{K}$. For these calculations, $\mathrm{T}_{\mathrm{wall}}=\mathrm{T}_{\mathrm{g}}$.

A BASIC program was used to calculate the values of $\mathrm{q}, \mathrm{T}_{\text {particle }}, \mathrm{K}, \mathrm{K}_{\mathrm{diff}}$, and $\mathrm{K}_{\mathrm{s}}$. The heat capacity, thermal conductivity, and diffusion values compiled by Mitchell (8) were used in the calculations. Calculated $\mathrm{q}, \mathrm{K}, \mathrm{K}_{\mathrm{diff}}, \mathrm{K}_{\mathrm{s}}$, and $\ln \left(\mathrm{K}_{\mathrm{s}}\right)$ values for the three fuels are presented in Tables 3-a-c.

Arrhenius plots for the fuels are presented in Figures 3-9a-c. Carbon conversion values derived from the best-fit curves in Figures 3-2, 3-3, and 3-8 were used to construct these plots. Activation energy $\left(E_{a}\right)$ and preexponential term $(A)$ values are presented in Table 3-4. Line slopes in the Arrhenius plots, Figures 3-9a-c, are linear over the range of residence times considered. The range of temperatures and residence times bracket the time-temperature regime where the coal and coke were burning, while avoiding complete burnout at short residence time. $E_{a}$ values of the coke are consistently higher than those of the coal, indicating a lower coke reactivity. $\mathrm{E}_{\mathrm{a}}$ values of the blend are consistently low, an artifact of the best-fit curves in the Arrhenius plots (Figures 3-9a-c).

In summary, the petroleum coke tested is significantly less reactive than the PRB coal. Approximately $10 \%$ burnout of the coke occurs at $0.4 \mathrm{~s}$, and complete burnout does not occur until $1.8 \mathrm{~s}$ at $1000^{\circ} \mathrm{C}$, while the PRB coal of similar particle size is completely consumed in $0.3 \mathrm{~s}$ at $1000^{\circ} \mathrm{C}$. The parent coal and coke fuels in the blend burn independently. Thus, as demonstrated in Table 3-5, the combustion kinetics of a given coal-coke blend in the ADTF can be predicted from those of the parent fuels. 
Table 3-3a Calculated Kinetic Parameters for the PRB Coal

\begin{tabular}{|c|c|c|c|c|c|c|c|c|c|c|c|c|}
\hline Test ID & \begin{tabular}{|l} 
Fuel \\
Type \\
\end{tabular} & Time, s & \begin{tabular}{|l} 
Temperature, \\
${ }^{\circ} \mathbf{C}$
\end{tabular} & $1 / T, K$ & \begin{tabular}{|l} 
Fuel \\
Burned, \% \\
\end{tabular} & \begin{tabular}{|l|} 
Particle \\
Temperature, \\
${ }^{\circ} \mathrm{C}$
\end{tabular} & $\begin{array}{l}\text { Dia. }(\mu \mathrm{m}), \\
\text { final } x \text { bar }\end{array}$ & $q$ & $\mathbf{K}$ & $K_{\text {diff }}$ & $K_{s}$ & $\ln K_{s}$ \\
\hline 572 & Coal & 0.8 & 1000 & $7.86 \mathrm{E}-04$ & 100.0 & 1001 & 0.5 & 0.00220 & 0.01093 & 20.49666 & 0.01094 & -4.51571 \\
\hline 573 & Coal & 0.6 & 1000 & $7.86 \mathrm{E}-04$ & 100.0 & 1001 & 0.5 & 0.00294 & 0.01457 & 20.49666 & 0.01458 & -4.22785 \\
\hline 574 & Coal & 0.4 & 1000 & $7.86 \mathrm{E}-04$ & 100.0 & 1002 & 0.5 & 0.00441 & 0.02186 & 20.49666 & 0.02188 & -3.82203 \\
\hline 577 & Coal & 0.3 & 1000 & $7.86 \mathrm{E}-04$ & 100.0 & 1002 & 0.5 & 0.00588 & 0.02915 & 20.49666 & 0.02919 & -3.53399 \\
\hline 575 & Coal & 0.2 & 1000 & $7.86 \mathrm{E}-04$ & 98.5 & 1023 & 6.3 & 0.00677 & 0.03359 & 1.77957 & 0.03424 & -3.37446 \\
\hline 576 & Coal & 0.1 & 1000 & $7.86 \mathrm{E}-04$ & 77.8 & 1056 & 15.3 & 0.00710 & 0.03522 & 0.72918 & 0.03701 & -3.29657 \\
\hline 589 & Coal & 0.06 & 1000 & $7.86 \mathrm{E}-04$ & 68.3 & 1083 & 17.2 & 0.00955 & 0.04672 & 0.63890 & 0.05040 & -2.98774 \\
\hline 578 & Coal & 0.8 & 900 & $8.53 \mathrm{E}-04$ & 100.0 & 901 & 0.5 & 0.00220 & 0.01101 & 19.54207 & 0.01101 & -4.50856 \\
\hline 579 & Coal & 0.6 & 900 & $8.53 \mathrm{E}-04$ & 100.0 & 901 & 0.5 & 0.00294 & 0.01468 & 19.54207 & 0.01469 & -4.22069 \\
\hline 580 & Coal & 0.4 & 900 & $8.53 \mathrm{E}-04$ & 100.0 & 902 & 0.5 & 0.00441 & 0.02193 & 19.46275 & 0.02195 & -3.81891 \\
\hline 588 & Coal & 0.3 & 900 & $8.53 \mathrm{E}-04$ & 72.8 & 920 & 16.3 & 0.00211 & 0.01034 & 0.63655 & 0.01051 & -4.55519 \\
\hline 581 & Coal & 0.2 & 900 & $8.53 \mathrm{E}-04$ & 70.5 & 928 & 16.8 & 0.00301 & 0.01499 & 0.63024 & 0.01535 & -4.17651 \\
\hline 582 & Coal & 0.1 & 900 & $8.53 \mathrm{E}-04$ & 52.5 & 943 & 19.7 & 0.00396 & 0.01932 & 0.52684 & 0.02005 & -3.90945 \\
\hline 584 & Coal & 0.8 & 800 & 9.32E-04 & 98.8 & 807 & 5.8 & 0.00174 & 0.00846 & 1.69096 & 0.00851 & -4.76697 \\
\hline 590 & Coal & 0.7 & 800 & 9.32E-04 & 87.6 & 810 & 12.6 & 0.00129 & 0.00632 & 0.77966 & 0.00637 & -5.05655 \\
\hline 583 & Coal & 0.6 & 800 & 9.32E-04 & 74.3 & 811 & 16.0 & 0.00109 & 0.00533 & 0.60906 & 0.00538 & -5.22508 \\
\hline 586 & Coal & 0.5 & 800 & 9.32E-04 & 46.4 & 809 & 20.5 & 0.00068 & 0.00330 & 0.47664 & 0.00332 & -5.70747 \\
\hline 585 & Coal & 0.4 & 800 & 9.32E-04 & 44.5 & 810 & 20.7 & 0.00080 & 0.00392 & 0.47119 & 0.00395 & -5.53423 \\
\hline 587 & Coal & 0.3 & 800 & $9.32 \mathrm{E}-04$ & 41.4 & 813 & 21.1 & 0.00098 & 0.00479 & 0.46435 & 0.00484 & -5.32997 \\
\hline
\end{tabular}


Table 3-3b Calculated Kinetic Parameters for the Petroleum Coke

\begin{tabular}{|c|c|c|c|c|c|c|c|c|c|c|c|c|}
\hline Test ID & $\begin{array}{l}\text { Fuel } \\
\text { Type }\end{array}$ & Time, s & $\begin{array}{l}\text { Temperature, } \\
{ }^{\circ} \mathrm{C}\end{array}$ & $1 / T, K$ & \begin{tabular}{|l|} 
Fuel \\
Burned, \\
$\%$
\end{tabular} & $\begin{array}{l}\text { Particle } \\
\text { Temperature, } \\
{ }^{\circ} \mathrm{C}\end{array}$ & $\begin{array}{l}\text { Dia. }(\mu \mathrm{m}) \text {, } \\
\text { final } x \text { bar }\end{array}$ & $q$ & K & $\mathrm{K}_{\text {diff }}$ & $\mathrm{K}_{\mathbf{s}}$ & $\ln K_{s}$ \\
\hline 609 & Coke & 2.0 & 1000 & 7.86E-04 & 98.8 & 1002 & 4.1 & 0.00051 & 0.00249 & 2.65620 & 0.00249 & -5.99588 \\
\hline 610 & Coke & 1.6 & 1000 & 7.86E-04 & 97.5 & 1002 & 5.3 & 0.00058 & 0.00285 & 2.07645 & 0.00286 & -5.85818 \\
\hline 611 & Coke & 1.2 & 1000 & 7.86E-04 & 83.5 & 1003 & 10.0 & 0.00049 & 0.00242 & 1.10143 & 0.00243 & -6.02182 \\
\hline 612 & Coke & 0.8 & 1000 & 7.86E-04 & 45.6 & 1003 & 14.9 & 0.00030 & 0.00148 & 0.74078 & 0.00148 & -6.51481 \\
\hline 608 & Coke & 2.5 & 900 & $8.53 \mathrm{E}-04$ & 93.7 & 902 & 7.2 & 0.00032 & 0.00155 & 1.43794 & 0.00155 & -6.46824 \\
\hline 605 & Coke & 2.0 & 900 & $8.53 \mathrm{E}-04$ & 89.7 & 902 & 8.5 & 0.00035 & 0.00171 & 1.22046 & 0.00171 & -6.37018 \\
\hline 606 & Coke & 1.5 & 900 & 8.53E-04 & 59.3 & 902 & 13.5 & 0.00023 & 0.00111 & 0.77216 & 0.00111 & -6.80177 \\
\hline 607 & Coke & 1.0 & 900 & 8.53E-04 & 20.2 & 901 & 16.9 & 0.00010 & 0.00047 & 0.61726 & 0.00047 & -7.66774 \\
\hline 604 & Coke & 3.0 & 800 & 9.32E-04 & 73.1 & 802 & 11.7 & 0.00015 & 0.00076 & 0.83573 & 0.00076 & -7.17949 \\
\hline 603 & Coke & 2.5 & 800 & $9.32 \mathrm{E}-04$ & 60.3 & 802 & 13.4 & 0.00014 & 0.00068 & 0.73358 & 0.00068 & -7.28927 \\
\hline 602 & Coke & 2.0 & 800 & $9.32 \mathrm{E}-04$ & 30.8 & 801 & 16.1 & 0.00008 & 0.00037 & 0.60982 & 0.00037 & -7.89495 \\
\hline
\end{tabular}


Table 3-3c Calculated Kinetic Parameters for the 80:20 PRB Coal-Petroleum Coke Blend

\begin{tabular}{|c|c|c|c|c|c|c|c|c|c|c|c|c|}
\hline $\begin{array}{l}\text { Test } \\
\text { ID }\end{array}$ & $\begin{array}{l}\text { Fuel } \\
\text { Type }\end{array}$ & Time, s & $\begin{array}{l}\text { Temperature, } \\
{ }^{\circ} \mathrm{C}\end{array}$ & $1 / T, K$ & $\begin{array}{l}\text { Fuel } \\
\text { Burned, } \\
\% \\
\end{array}$ & $\begin{array}{l}\text { Particle } \\
\text { Temperature, } \\
{ }^{\circ} \mathrm{C}\end{array}$ & $\begin{array}{l}\text { Dia. ( } \mu \mathrm{m}) \text {, } \\
\text { final } x \text { bar }\end{array}$ & $\mathbf{q}$ & K & $\mathbf{K}_{\text {diff }}$ & $K_{s}$ & $\ln K_{s}$ \\
\hline 546 & $80 / 20$ & 0.8 & 1100 & 7.28E-04 & 99.3 & 1104 & 4.5 & 0.00172 & 0.00840 & 2.53486 & 0.00842 & -4.77679 \\
\hline 547 & $80 / 20$ & 0.6 & 1100 & $7.28 \mathrm{E}-04$ & 96.9 & 1108 & 7.4 & 0.00195 & 0.00950 & 1.54287 & 0.00956 & -4.65016 \\
\hline 548 & $80 / 20$ & 0.4 & 1100 & $7.28 \mathrm{E}-04$ & 92.0 & 1113 & 10.3 & 0.00242 & 0.01179 & 1.11811 & 0.01191 & -4.43011 \\
\hline 549 & $80 / 20$ & 0.2 & 1100 & $7.28 \mathrm{E}-04$ & 85.7 & 1125 & 12.4 & 0.00406 & 0.01978 & 0.92262 & 0.02022 & -3.90130 \\
\hline 550 & $80 / 20$ & 0.8 & 1000 & $7.86 \mathrm{E}-04$ & 94.9 & 1007 & 8.8 & 0.00134 & 0.00656 & 1.24331 & 0.00659 & -5.02220 \\
\hline 551 & $80 / 20$ & 0.6 & 1000 & $7.86 \mathrm{E}-04$ & 92.7 & 1009 & 10.0 & 0.00165 & 0.00807 & 1.09999 & 0.00813 & -4.81226 \\
\hline 552 & $80 / 20$ & 0.4 & 1000 & 7.86E-04 & 88.0 & 1014 & 11.7 & 0.00215 & 0.01055 & 0.93339 & 0.01067 & -4.54052 \\
\hline 553 & $80 / 20$ & 0.2 & 1000 & $7.86 \mathrm{E}-04$ & 79.8 & 1026 & 14.0 & 0.00352 & 0.01722 & 0.78543 & 0.01761 & -4.03949 \\
\hline 599 & $80 / 20$ & 1.0 & 900 & $8.53 \mathrm{E}-04$ & 93.0 & 906 & 9.8 & 0.00100 & 0.00491 & 1.06024 & 0.00493 & -5.31208 \\
\hline 554 & $80 / 20$ & 0.8 & 900 & $8.53 \mathrm{E}-04$ & 89.0 & 908 & 11.4 & 0.00111 & 0.00545 & 0.91419 & 0.00548 & -5.20670 \\
\hline 564 & $80 / 20$ & 0.8 & 900 & $8.53 \mathrm{E}-04$ & 90.4 & 908 & 10.9 & 0.00115 & 0.00566 & 0.95442 & 0.00569 & -5.16912 \\
\hline 555 & $80 / 20$ & 0.6 & 900 & $8.53 \mathrm{E}-04$ & 86.5 & 910 & 12.2 & 0.00138 & 0.00678 & 0.85220 & 0.00683 & -4.98611 \\
\hline 557 & $80 / 20$ & 0.6 & 900 & 8.53E-04 & 88.6 & 910 & 11.5 & 0.00146 & 0.00734 & 0.92318 & 0.00740 & -4.90637 \\
\hline 565 & $80 / 20$ & 0.6 & 900 & $8.53 \mathrm{E}-04$ & 87.4 & 910 & 11.9 & 0.00142 & 0.00694 & 0.87172 & 0.00699 & -4.96273 \\
\hline 556 & $80 / 20$ & 0.4 & 900 & $8.53 \mathrm{E}-04$ & 0.0 & 901 & 23.8 & 0.00000 & 0.00000 & 0.43750 & 0.00000 & -1.00000 \\
\hline 558 & $80 / 20$ & 0.4 & 900 & $8.53 \mathrm{E}-04$ & 81.7 & 914 & 13.5 & 0.00184 & 0.00923 & 0.78767 & 0.00934 & -4.67334 \\
\hline 566 & $80 / 20$ & 0.4 & 900 & $8.53 \mathrm{E}-04$ & 80.6 & 914 & 13.8 & 0.00179 & 0.00879 & 0.75464 & 0.00889 & -4.72273 \\
\hline 559 & $80 / 20$ & 0.2 & 900 & $8.53 \mathrm{E}-04$ & 37.4 & 914 & 20.4 & 0.00123 & 0.00617 & 0.52255 & 0.00624 & -5.07697 \\
\hline 567 & $80 / 20$ & 0.2 & 900 & 8.53E-04 & 46.1 & 917 & 19.4 & 0.00158 & 0.00776 & 0.53633 & 0.00787 & -4.84466 \\
\hline 601 & $80 / 20$ & 1.2 & 800 & 9.32E-04 & 89.8 & 806 & 11.1 & 0.00075 & 0.00371 & 0.88082 & 0.00372 & -5.59368 \\
\hline 600 & $80 / 20$ & 1.0 & 800 & $9.32 \mathrm{E}-04$ & 88.1 & 807 & 11.7 & 0.00086 & 0.00424 & 0.83737 & 0.00427 & -5.45722 \\
\hline 560 & $80 / 20$ & 0.8 & 800 & 9.32E-04 & 82.6 & 808 & 13.3 & 0.00094 & 0.00472 & 0.75551 & 0.00475 & -5.34945 \\
\hline 568 & $80 / 20$ & 0.8 & 800 & 9.32E-04 & 79.3 & 808 & 14.1 & 0.00087 & 0.00426 & 0.69576 & 0.00429 & -5.45249 \\
\hline 561 & $80 / 20$ & 0.6 & 800 & $9.32 \mathrm{E}-04$ & 42.6 & 806 & 19.8 & 0.00048 & 0.00241 & 0.50806 & 0.00242 & -6.02269 \\
\hline 569 & $80 / 20$ & 0.6 & 800 & 9.32E-04 & 47.6 & 807 & 19.2 & 0.00055 & 0.00270 & 0.51096 & 0.00271 & -5.90978 \\
\hline 562 & $80 / 20$ & 0.4 & 800 & 9.32E-04 & 33.9 & 807 & 20.7 & 0.00055 & 0.00275 & 0.48456 & 0.00277 & -5.88865 \\
\hline 570 & $80 / 20$ & 0.4 & 800 & 9.32E-04 & 39.3 & 808 & 20.1 & 0.00065 & 0.00320 & 0.48657 & 0.00323 & -5.73678 \\
\hline 563 & $80 / 20$ & 0.2 & 800 & $9.32 \mathrm{E}-04$ & 30.0 & 812 & 21.1 & 0.00095 & 0.00480 & 0.47551 & 0.00485 & -5.32902 \\
\hline 571 & $80 / 20$ & 0.2 & 800 & $9.32 \mathrm{E}-04$ & 30.09 & 813 & 21.1 & 0.000957 & 0.004697 & 0.464109 & 0.004745 & -5.35063 \\
\hline
\end{tabular}



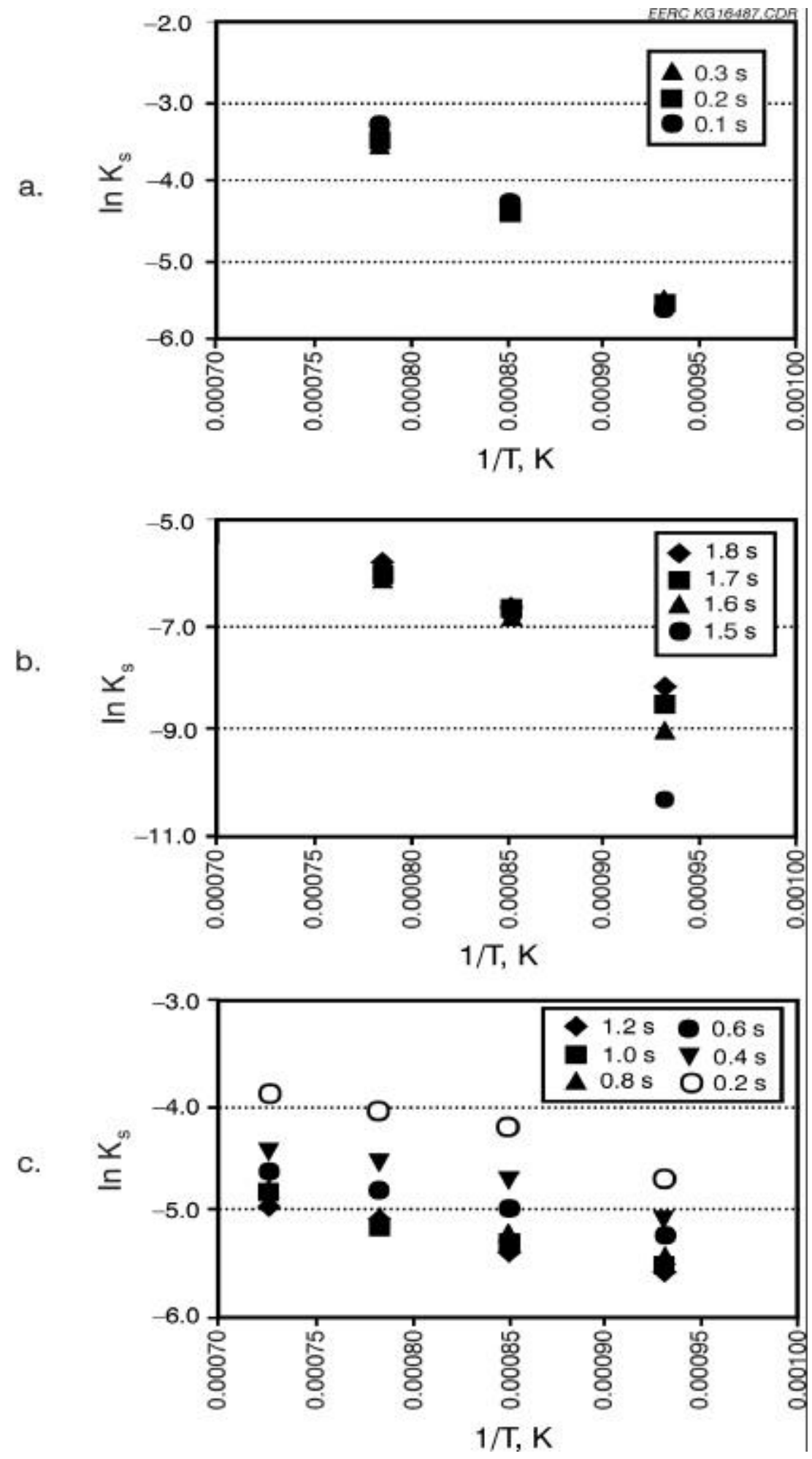

Figure 3-9 (a) Arrhenius plots of global PRB coal reaction rates at various residence times versus the inverse of temperature; (b) Arrhenius plots of global petroleum coke reaction rates at various residence times versus the inverse of temperature; (c) Arrhenius plots of global 80:20 PRB coal- 
petroleum coke reaction rates at various residence times versus the inverse of temperature.

Table 3-4 Values from Regression Analysis

\begin{tabular}{|l|l|l|l|l|l|l|l|l|}
\hline Fuel & Temperature, ${ }^{\circ} \mathbf{C}$ & $\begin{array}{l}\text { Residence } \\
\text { Time, s }\end{array}$ & $\mathbf{n}$ & $\mathbf{r}^{\mathbf{2}}$ & $\mathbf{m}$ & $\mathbf{b}$ & $\begin{array}{l}\mathbf{E}_{\mathbf{a}}, \\
\text { cal/mole }\end{array}$ & $\mathbf{A}, \mathbf{L} / \mathbf{s}$ atm \\
\hline Coal & $800,900,1000$ & 0.8 & 3 & 0.791 & -2784 & -2.269 & 5530 & 0.103 \\
\hline Coal & $800,900,1000$ & 0.6 & 3 & 0.791 & -7250 & 1.632 & 14,410 & 5.116 \\
\hline Coal & $800,900,1000$ & 0.4 & 3 & 0.897 & -11133 & 5.091 & 22,120 & 162.5 \\
\hline Coal & $800,900,1000$ & 0.3 & 3 & 0.998 & -13358 & 6.981 & 26,540 & 1076 \\
\hline Coal & $800,900,1000$ & 0.2 & 3 & 0.997 & -13452 & 7.020 & 26,730 & 1119 \\
\hline Coal & $800,900,1000$ & 0.1 & 3 & 1.000 & -15890 & 9.231 & 31,580 & 10,210 \\
\hline Coke & $800,900,1000$ & 1.8 & 3 & 0.990 & -16478 & 7.235 & 32,750 & 1390 \\
\hline Coke & $800,900,1000$ & 1.7 & 3 & 0.968 & -17219 & 7.689 & 34,220 & 2190 \\
\hline Coke & $800,900,1000$ & 1.6 & 3 & 0.947 & -20140 & 9.984 & 40,020 & 21680 \\
\hline Coke & $800,900,1000$ & 1.5 & 3 & 0.908 & -28924 & 17.04 & 57,480 & $25,053,150$ \\
\hline $80: 20$ & $800,900,1000,1100$ & 1.2 & 4 & 0.963 & -3117 & -2.692 & 6193 & 0.068 \\
\hline $80: 20$ & $800,900,1000,1100$ & 1.0 & 4 & 0.970 & -3357 & -2.413 & 6672 & 0.090 \\
\hline $80: 20$ & $800,900,1000,1100$ & 0.8 & 4 & 0.990 & -3083 & -2.540 & 6127 & 0.079 \\
\hline $80: 20$ & $800,900,1000,1100$ & 0.6 & 4 & 0.992 & -2884 & -2.552 & 5731 & 0.078 \\
\hline $80: 20$ & $800,900,1000,1100$ & 0.4 & 4 & 0.969 & -3112 & -2.108 & 6184 & 0.121 \\
\hline $80: 20$ & $800,900,1000,1100$ & 0.2 & 4 & 0.927 & -3910 & -0.984 & 7769 & 0.374 \\
\hline
\end{tabular}

Table 3-5 Comparison of Empirical and Predicted Carbon Conversions for the 80:20 Blend

\begin{tabular}{|l|l|l|l|}
\hline Temperature, ${ }^{\circ} \mathbf{C}$ & Time, s & Empirical C Conversion, \% & Predicted C Conversion, \% \\
\hline 1000 & 0.2 & 79.81 & 79.85 \\
\hline 1000 & 0.4 & 87.97 & 87.22 \\
\hline 1000 & 0.6 & 92.65 & 90.07 \\
\hline 1000 & 0.8 & 94.91 & 92.46 \\
\hline 900 & 0.2 & 46.07 & 52.20 \\
\hline 900 & 0.4 & 81.71 & 82.68 \\
\hline 900 & 0.6 & 86.47 & 85.39 \\
\hline 900 & 0.8 & 89.04 & 86.95 \\
\hline 800 & 0.2 & 30.01 & 19.48 \\
\hline 800 & 0.4 & 39.33 & 38.89 \\
\hline 800 & 0.6 & 47.61 & 58.19 \\
\hline 800 & 0.8 & 79.25 & 77.15 \\
\hline
\end{tabular}




\section{Chapter 4 Effect of PRB Coal-Petroleum Coke Blending on Fouling and Slagging Severity}

\section{Introduction}

The general increase in ash $\mathrm{S}, \mathrm{Ni}$, and $\mathrm{V}$ contents associated with the blending of petroleum coke with coal may significantly affect ash fouling and slagging characteristics (3). The effects of petroleum shot coke blending on initial slagging temperature, slag and fouling deposit strengths, and fouling deposit growth rate were investigated experimentally using a drop-tube furnace similar to the ADTF. This testing approach has been used previously in evaluating differences in the slagging and fouling characteristics of various PRB subbituminous coals (9).

\section{Experimental}

Pulverized samples of a PRB coal and coal-petroleum shot coke blends of 90:10 and 80:20 (on a weight basis) were used to investigate the effect of coke blending on fouling and slagging. The fuels and resulting combustion byproducts were chemically analyzed for major and minor element composition using wavelength-dispersive $\mathrm{X}$-ray fluorescence (WDXRF) spectrometry (ASTM Method D 4326). Ni and V concentrations were determined using microwave digestion (ASTM Method D 3683) and ICP-AES (EPA Method 6010). Mineralogical composition of the PRB coal was determined using computer-controlled scanning electron microscopy (CCSEM) as described by Galbreath et al. (10). CCSEM analysis of the petroleum shot coke sample was not feasible because of the low ash content and organically bound nature of the inorganic components.

An optical access drop-tube furnace (ODTF), described in Appendix C, was used for evaluating the effects of blending petroleum coke with PRB coal on fouling and slagging severity. A cylindrical deposition probe with a controlled surface temperature was inserted into the furnace deposition zone to determine deposit growth rates and initial slagging temperatures. The deposition probe simulates an actual boiler tube. An insulating refractory constrictor was used to accelerate the gas flow before it impinges on the deposit probe. An expendable sample coupon was attached to the probe and maintained at temperatures corresponding to a boiler heat-transfer surface $\left(540^{\circ}\right.$ and $350^{\circ} \mathrm{C}$ for fouling and slagging conditions, respectively).

Initial slagging temperatures were determined by slowly increasing the furnace temperature and closely monitoring deposit temperature with an optical pyrometer until the onset of deposit melting was observed using a long-range microscope. Deposit crushing strengths were determined using a miniature horizontal translator and pressure transducer. The translator has a range of travel of $25 \mathrm{~mm}$, a resolution of $0.1 \mu \mathrm{m}$, and a maximum translational speed of 15 $\mathrm{mm} / \mathrm{min}$. The pressure transducer is a diaphragm strain gauge design with one active sensing face. The pressure range is $0-17,250 \mathrm{kPa}(0-2500 \mathrm{psi}$.) The transducer is mounted in a slot on top of an aluminum block and attached to the horizontal translator. A rod inserted in the side of the block meets the sensing face of the transducer and transmits the force exerted on the deposit as the translator moves. The mineralogical, morphological (i.e., porosity), and chemical 
characteristics of the ash fouling and slag deposits produced in the ODTF were analyzed using $\mathrm{x}$ ray diffraction (XRD), scanning electron microscopy (SEM), EPMA, and digital image analysis techniques.

\section{Results and Discussion}

As shown in Table 4-1, the petroleum shot coke is depleted in moisture, volatile matter, ash, hydrogen, and oxygen but enriched in fixed carbon, calorific value, carbon, nitrogen, and sulfur relative to the PRB coal. These enrichment/depletion relationships are consistent with other comparisons of coal and petroleum coke compositions (3). The predominant minerals in the PRB coal, as indicated in Table 4-2, are quartz $\left(\mathrm{SiO}_{2}\right)$, kaolinite $\left(\mathrm{Al}_{2} \mathrm{Si}_{2} \mathrm{O}_{5}[\mathrm{OH}]_{4}\right)$, illite $\left(\mathrm{K}[\mathrm{Al}, \mathrm{Si}]_{4} \mathrm{O}_{10}[\mathrm{OH}]_{2} \cdot \mathrm{H}_{2} \mathrm{O}\right)$, mixed clays $\left([\mathrm{Na}, \mathrm{K}, \mathrm{Ca}, \mathrm{Mg}, \mathrm{Fe}]_{\mathrm{x}}[\mathrm{Al}, \mathrm{Si}]_{\mathrm{x}}\left[\mathrm{OH}, \mathrm{H}_{2} \mathrm{O}\right]\right)$, pyrite $\left(\mathrm{FeS}_{2}\right)$, gypsum $\left(\mathrm{CaSO}_{4} \cdot 2 \mathrm{H}_{2} \mathrm{O}\right)$, and a calcium aluminophosphate mineral, which has been tentatively identified as crandallite $\left(\mathrm{CaAl}_{3}\left[\mathrm{PO}_{4}\right]_{2}[\mathrm{OH}]_{5} \cdot \mathrm{H}_{2} \mathrm{O}\right)$. Hematite $\left(\mathrm{Fe}_{2} \mathrm{O}_{3}\right)$, rutile $\left(\mathrm{TiO}_{2}\right)$, and calcite $\left(\mathrm{CaCO}_{3}\right)$ are present in PRB coal as accessory (i.e., $\left.<1 \mathrm{wt} \%\right)$ minerals.

Table 4-1 Proximate and Ultimate Analysis Results of the PRB Coal and
Petroleum Coke Fuels (wt\% as-received unless otherwise noted)
\begin{tabular}{|l|l|l|}
\hline Parameter & PRB Coal & Petroleum Coke \\
\hline Moisture & 27.1 & 3.40 \\
\hline Volatile Matter & 35.6 & 9.37 \\
\hline Fixed Carbon & 32.6 & 86.8 \\
\hline Ash & 4.70 & 0.41 \\
\hline Calorific Value, Btu/lb & 9135 & 14,935 \\
\hline Hydrogen & 6.72 & 3.89 \\
\hline Carbon & 51.0 & 87.0 \\
\hline Nitrogen & 0.73 & 1.49 \\
\hline Sulfur & 0.43 & 5.82 \\
\hline Oxygen & 36.4 & 1.37 \\
\hline
\end{tabular}

Table 4-2 PRB Coal Mineralogical Composition

\begin{tabular}{|l|c|}
\hline Mineral & wt\% \\
\hline Quartz & 36.3 \\
\hline Kaolinite & 25.3 \\
\hline Illite & 1.3 \\
\hline Mixed Clays & 11.0 \\
\hline Pyrite & 11.6 \\
\hline Crandallite & 12.5 \\
\hline Hematite & 0.4 \\
\hline Rutile & 0.3 \\
\hline Gypsum & 1.0 \\
\hline Calcite & 0.3 \\
\hline
\end{tabular}

Table 4-3 Chemical Compositions of PRB Coal-Petroleum Shot Coke Blends (wt\% on an ash basis)

\begin{tabular}{|l|l|l|l|l|}
\hline Blend Ratio (coal:coke): & \multicolumn{100}{|c|}{$\mathbf{1 0 0}$} & $\mathbf{9 0 : 1 0}$ & $\mathbf{8 0 : 2 0}$ & $\mathbf{0 : 1 0 0}$ \\
\hline $\mathrm{SiO}_{2}$ & 23.3 & 23.6 & 23.2 & 14.7 \\
\hline
\end{tabular}




\begin{tabular}{|l|l|l|l|l|}
\hline $\mathrm{Al}_{2} \mathrm{O}_{3}$ & 13.3 & 12.2 & 12.7 & 4.05 \\
\hline $\mathrm{Fe}_{2} \mathrm{O}_{3}$ & 4.60 & 3.99 & 4.27 & 4.70 \\
\hline $\mathrm{MnO}$ & $\mathrm{NA}^{1}$ & NA & NA & 0.06 \\
\hline $\mathrm{TiO} \mathrm{O}_{2}$ & 1.40 & 1.17 & 1.26 & 0.93 \\
\hline $\mathrm{CaO}$ & 25.2 & 21.6 & 22.4 & 8.53 \\
\hline $\mathrm{MgO}$ & 7.62 & 4.79 & 4.92 & 1.29 \\
\hline $\mathrm{Na}_{2} \mathrm{O}$ & 0.35 & 0.84 & 0.89 & 1.03 \\
\hline $\mathrm{K}_{2} \mathrm{O}$ & $<0.1$ & 0.37 & 0.28 & 0.46 \\
\hline $\mathrm{SO}$ & 22.4 & 23.0 & 24.5 & 33.0 \\
\hline $\mathrm{NiO}$ & NA & 0.11 & 0.23 & 9.73 \\
\hline $\mathrm{V}_{2} \mathrm{O}_{5}$ & NA & 0.29 & 0.62 & 31.8 \\
\hline
\end{tabular}

${ }^{1}$ Not analyzed.

Table 4-4 Deposit Initial Slagging Temperatures

\begin{tabular}{|l|l|l|l|}
\hline PRB Coal:Petroleum Coke & $100: 0$ & $90: 10$ & $80: 20$ \\
\hline Initial Slagging Temperature, ${ }^{\circ} \mathrm{C}$ & 1180 & 1175 & 1170 \\
\hline
\end{tabular}

The chemical analyses in Table 4-3 indicate that relative to the PRB coal combustion ash, the coal-petroleum shot coke blend ashes are significantly enriched in $\mathrm{Na}_{2} \mathrm{O}, \mathrm{K}_{2} \mathrm{O}, \mathrm{SO}_{3}, \mathrm{NiO}$, and $\mathrm{V}_{2} \mathrm{O}_{5}$ but depleted in $\mathrm{Al}_{2} \mathrm{O}_{3}, \mathrm{CaO}$, and $\mathrm{MgO}$.

Initial slagging temperatures for the PRB coal-petroleum shot coke blends, presented in Table 4-4, indicate that petroleum coke blending with PRB coal slightly lowers initial slagging temperatures. Consequently, the degree of slagging is probably directly related to the proportion of petroleum coke for a given temperature.

Deposits from burning PRB coal-petroleum shot coke blends (coke blends of 0\%, 10\%, and 20\% on a weight basis) in the ODTF were produced under high-temperature fouling (HTF) and slagging conditions. After the deposits were allowed to cool, the base, middle, and top portions of each deposit were tested for crushing strength. The average crushing strengths for the slag and HTF deposits, presented in Figures 4-1 and 4-2, respectively, suggest that petroleum coke blending with PRB coal promotes slag deposit strength but inhibits HTF deposit strength.

As shown in Figure 4-3, petroleum coke blending with PRB coal impedes the growth rate of fouling deposits. The decrease in fouling deposit growth rate is attributable to the reduction in ash content associated with petroleum coke blending.

The main (upper) and base (lower) portions of deposits produced in the ODTF were separated and analyzed using XRD, SEM, EPMA, and digital image analysis techniques. Main deposit portions produced from the PRB coal and $80 \mathrm{wt} \%$ PRB coal- $20 \mathrm{wt} \%$ petroleum coke blend were also analyzed using the EPMA point count method described by Galbreath et al. (11). All of the 


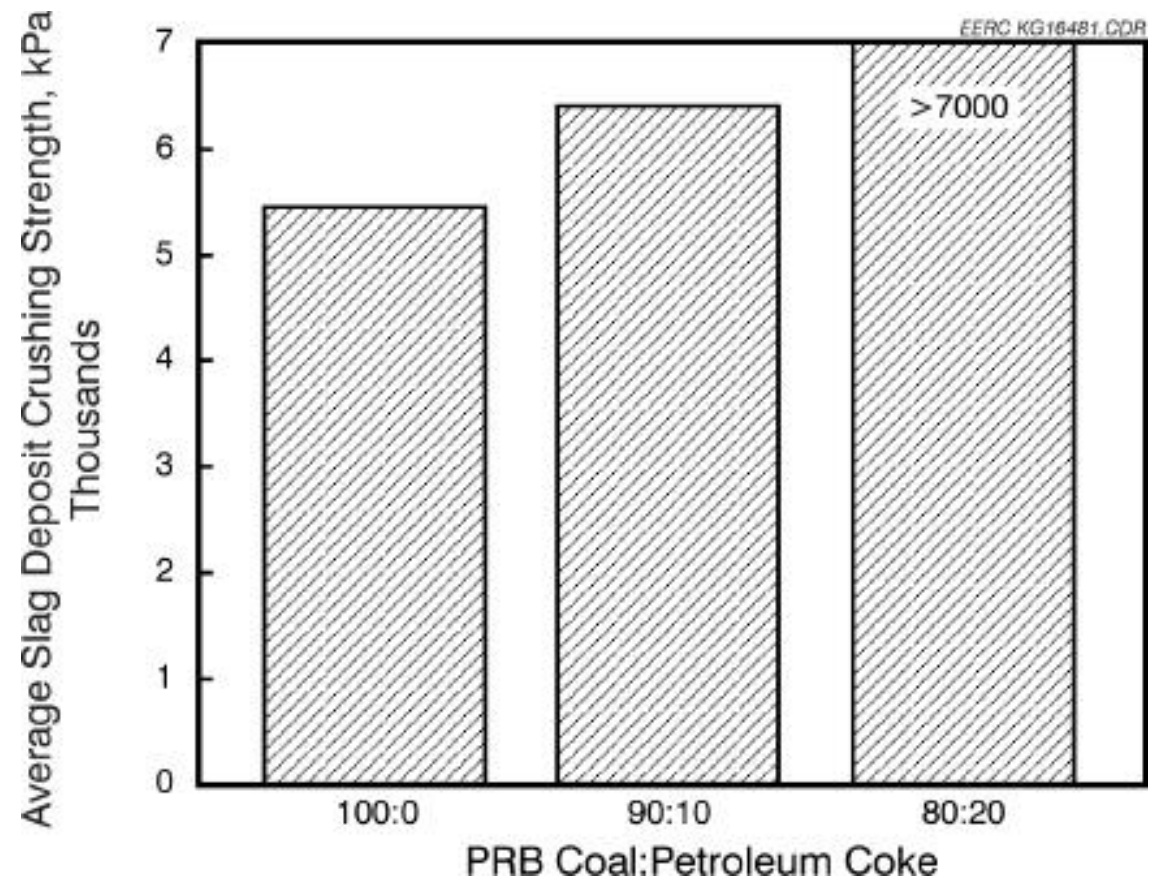

Figure 4-1 Bar plot of average crushing strengths for deposits produced in the ODTF by burning three PRB coal-petroleum shot coke blends (100:0, 90:10, and 80:20) under slagging conditions.

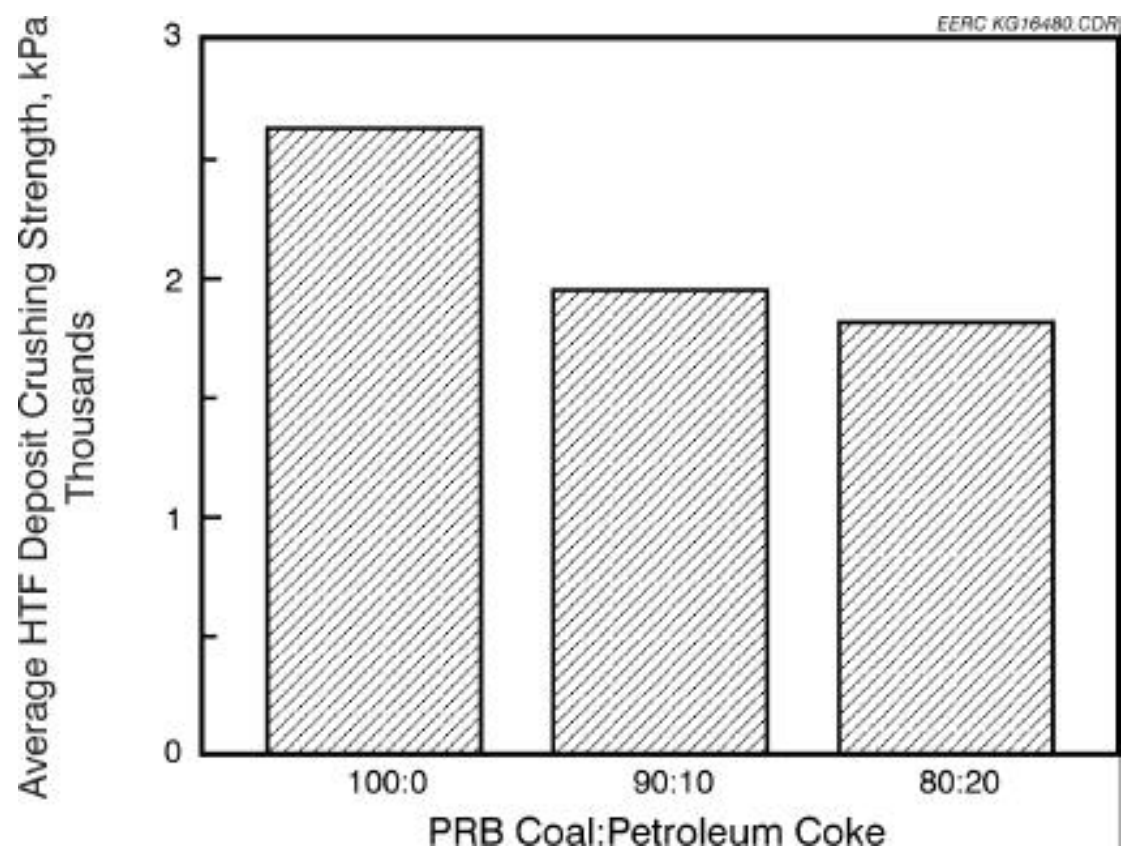

Figure 4-2 Bar plot of average crushing strengths for deposits produced in the ODTF by burning three PRB coal-petroleum shot coke blends (100:0, 90:10, and 80:20) under high-temperature fouling conditions. 


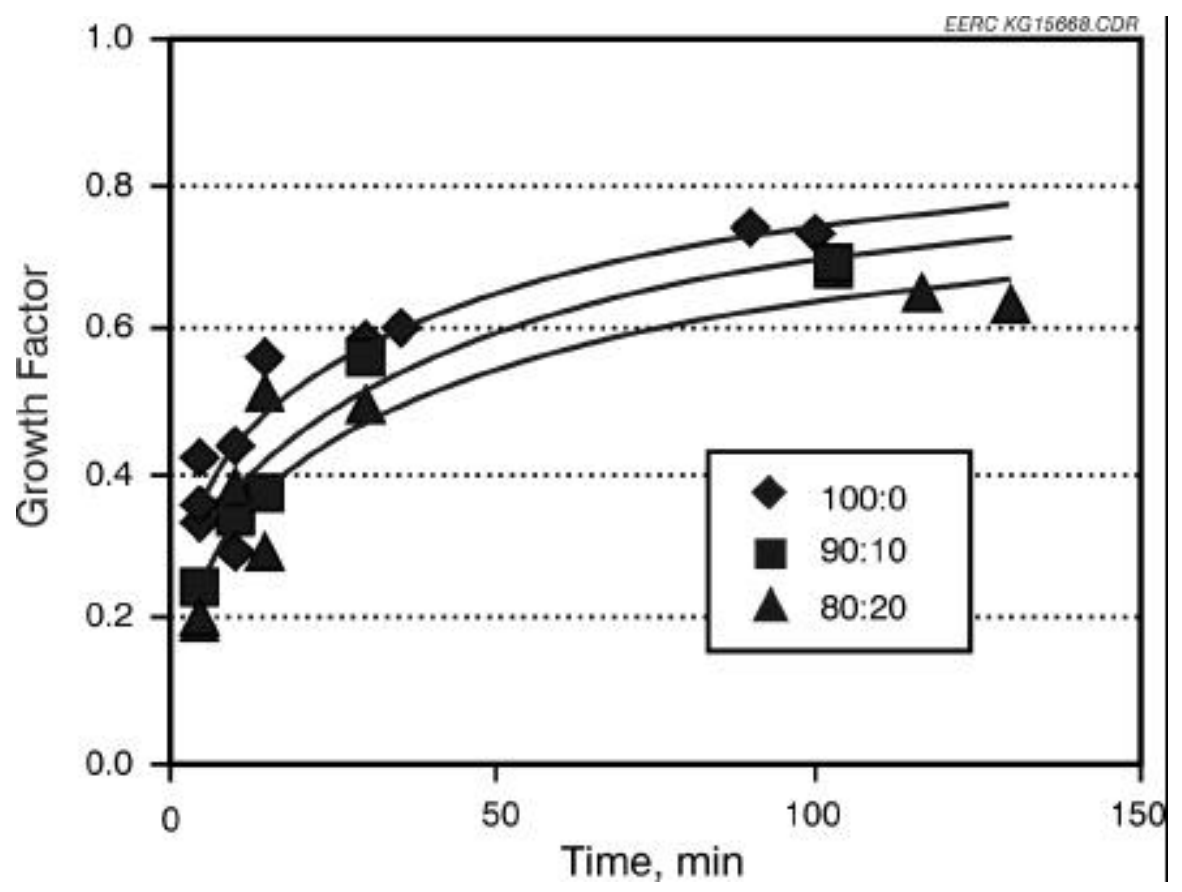

Figure 4-3 Growth factors versus time for deposits produced in the ODTF by burning PRB coalpetroleum shot coke blends under high-temperature fouling conditions. Best-fit lines for the three coal-coke blends (100:0, 90:10, and 80:20) tested are indicated.

deposits are largely amorphous, containing an aluminosilicate glass component. Small crystals, however, with chemical compositions consistent with the minerals melilite, clinopyroxene, plagioclase, and quartz were identified using SEM and EPMA. The identities of these minerals were confirmed with XRD. In addition, several other mineral species were identified using XRD, as indicated in Table 4-5. XRD analysis results for the slag and fouling deposits are presented in Tables 4-6 and 4-7, respectively.

Table 4-5 Deposit Mineral Species

\begin{tabular}{|l|l|}
\hline Mineral & Chemical Formula \\
\hline Melilite & $(\mathrm{Ca}, \mathrm{Na})_{2}(\mathrm{Al}, \mathrm{Mg}, \mathrm{Fe})\left(\mathrm{Si}, \mathrm{Al}_{2}\right)_{2} \mathrm{O}_{7}$ \\
\hline Quartz & $\mathrm{SiO}_{2}$ \\
\hline Clinopyroxene & $\mathrm{Ca}(\mathrm{Mg}, \mathrm{Fe}, \mathrm{Al})(\mathrm{Si}, \mathrm{Al})_{2} \mathrm{O}_{6}$ \\
\hline Gypsum & $\mathrm{CaSO}_{4} \cdot 2 \mathrm{H}_{2} \mathrm{O}$ \\
\hline Hematite & $\mathrm{Fe}_{2} \mathrm{O}_{3}$ \\
\hline Merwinite & $\mathrm{Ca}_{3}(\mathrm{Mg}, \mathrm{Fe}) \mathrm{Si}_{2} \mathrm{O}_{8}$ \\
\hline Mullite & $\mathrm{Al}_{6} \mathrm{Si}_{2} \mathrm{O}_{13}$ \\
\hline Plagioclase & $\left(\mathrm{Ca}, \mathrm{Na}_{2} \mathrm{~K}\right)\left(\mathrm{Al}, \mathrm{Si}_{4}\right)_{8} \mathrm{O}_{8}$ \\
\hline Anhydrite & $\mathrm{CaSO} O_{4}$ \\
\hline Periclase & $\mathrm{MgO}$ \\
\hline Lime & $\mathrm{CaO}$ \\
\hline
\end{tabular}


Table 4-6 Crystalline Components of Slag Deposits

\begin{tabular}{|l|l|l|l|l|l|l|}
\hline \multicolumn{7}{|l|}{ PRB Coal:Petroleum Shot Coke } \\
\hline & $\mathbf{1 0 0 : 0}$ & $\mathbf{9 0 : 1 0}$ & $\mathbf{8 0 : 2 0}$ \\
\hline Mineral & Main & Base & Main & Base & Main & Base \\
\hline Melilite & $\mathrm{m}^{1}$ & & $\mathrm{~m}$ & $\mathrm{~m}$ & $\mathrm{~m}$ & $\mathrm{~m}$ \\
\hline Quartz & $\mathrm{M}^{\mathbf{2}}$ & $\mathrm{M}$ & $\mathrm{M}$ & $\mathrm{M}$ & $\mathrm{M}$ & $\mathrm{M}$ \\
\hline Clinopyroxene & $\mathrm{m}$ & & $\mathrm{m}$ & & $\mathrm{m}$ & \\
\hline Gypsum & & & $\mathrm{m}$ & & & \\
\hline Hematite & $\mathrm{m}$ & $\mathrm{m}$ & $\mathrm{m}$ & $\mathrm{m}$ & $\mathrm{m}$ & $\mathrm{m}$ \\
\hline Merwinite & $\mathrm{m}$ & & $\mathrm{m}$ & $\mathrm{m}$ & $\mathrm{m}$ & \\
\hline Mullite & & & & $\mathrm{m}$ & & \\
\hline Plagioclase & $\mathrm{m}$ & & $\mathrm{m}$ & & $\mathrm{m}$ & \\
\hline Anhydrite & $\mathrm{m}$ & $\mathrm{m}$ & $\mathrm{m}$ & $\mathrm{M}$ & $\mathrm{m}$ & $\mathrm{M}$ \\
\hline Periclase & & $\mathrm{m}$ & & $\mathrm{m}$ & $\mathrm{m}$ & $\mathrm{m}$ \\
\hline Lime & & $\mathrm{m}$ & & $\mathrm{m}$ & & $\mathrm{m}$ \\
\hline
\end{tabular}

1 Minor component.

2 Major component.

Table 4-7 Crystalline Components of High-Temperature Fouling Deposits

\begin{tabular}{|c|c|c|c|c|c|c|}
\hline \multirow[b]{3}{*}{ Mineral } & \multicolumn{6}{|c|}{ PRB Coal:Petroleum Shot Coke } \\
\hline & \multicolumn{2}{|l|}{ 100:0 } & \multicolumn{2}{|c|}{$90: 10$} & \multicolumn{2}{|l|}{$80: 20$} \\
\hline & Main & Base & Main & Base & Main & Base \\
\hline Melilite & $M^{1}$ & $\mathrm{~m}$ & $\mathrm{M}$ & $\mathrm{m}$ & M & \\
\hline Quartz & $\mathrm{m}^{2}$ & $\mathrm{M}$ & $\mathrm{m}$ & $\mathrm{M}$ & $\mathrm{m}$ & M \\
\hline Clinopyroxene & $\mathrm{m}$ & $\mathrm{m}$ & $\mathrm{m}$ & & $\mathrm{m}$ & \\
\hline Gypsum & $\mathrm{m}$ & & $\mathrm{m}$ & & $\mathrm{m}$ & \\
\hline Hematite & $\mathrm{m}$ & $\mathrm{m}$ & $\mathrm{m}$ & $\mathrm{m}$ & $\mathrm{m}$ & $\mathrm{m}$ \\
\hline Merwinite & $\mathrm{m}$ & $\mathrm{m}$ & $\mathrm{m}$ & $\mathrm{m}$ & $\mathrm{m}$ & $\mathrm{m}$ \\
\hline Mullite & & & & & & $\mathrm{m}$ \\
\hline Plagioclase & $\mathrm{m}$ & & & & & \\
\hline Anhydrite & $\mathrm{m}$ & $\mathrm{m}$ & $\mathrm{m}$ & $\mathrm{m}$ & $\mathrm{m}$ & $\mathrm{m}$ \\
\hline Periclase & $\mathrm{m}$ & $\mathrm{m}$ & $\mathrm{m}$ & $\mathrm{m}$ & $\mathrm{m}$ & $\mathrm{m}$ \\
\hline Lime & & $\mathrm{m}$ & & $\mathrm{m}$ & & $\mathrm{m}$ \\
\hline
\end{tabular}

\footnotetext{
${ }^{1}$ Major component.
}

2 Minor component.

The main slag deposit portions are characterized by a complex mineral assemblage with quartz as a major component and melilite + clinopyroxene + hematite + merwinite + plagioclase + anhydrite \pm gypsum \pm periclase as minor components. Relative to the main slag deposits, the base slag deposits generally lack the silicate minerals clinopyroxene, merwinite, and plagioclase, but contain periclase and lime. Apparently the lower-temperature conditions in the base deposit 
inhibit reactions between periclase and lime with the aluminosilicate-rich glass component. The mineral assemblage for the main slag deposits was relatively unaffected by the blending of petroleum coke; however, the deposit base portions are enriched in anhydrite as a result of adding petroleum coke.

The main HTF portions are also characterized by a complex mineral assemblage with melilite as a major component and quartz + clinopyroxene + gypsum + hematite + merwinite + anhydrite + periclase \pm plagioclase as minor components. The base fouling deposits generally lack clinopyroxene and gypsum, but contain much higher abundances of quartz and lime relative to the main fouling deposits.

As indicated in Tables 4-6 and 4-7, quartz is relatively abundant in the deposits. Quartz grains in the slag and fouling deposits are relatively large and generally subrounded as shown in Figure 4-4. These morphological characteristics indicate that the quartz in coal remained relatively inert during the combustion and subsequent deposit formation processes. Quartz grains morphologies of other silicate minerals in the deposits, shown in Figure 4-5, suggest that they formed during the solidification of a melt.

A total of 250 randomly selected locations on the PRB coal and 80\% PRB coal-20\% petroleum coke deposit samples were chemically analyzed using EPMA. The average bulk compositions of the deposits were calculated (on an $\mathrm{SO}_{3}$-free basis) on the basis of the 250 chemical microanalyses performed on each deposit. These deposit compositions were used to calculate enrichment-depletion factors (i.e., ratios of elemental oxide concentrations in the deposits to

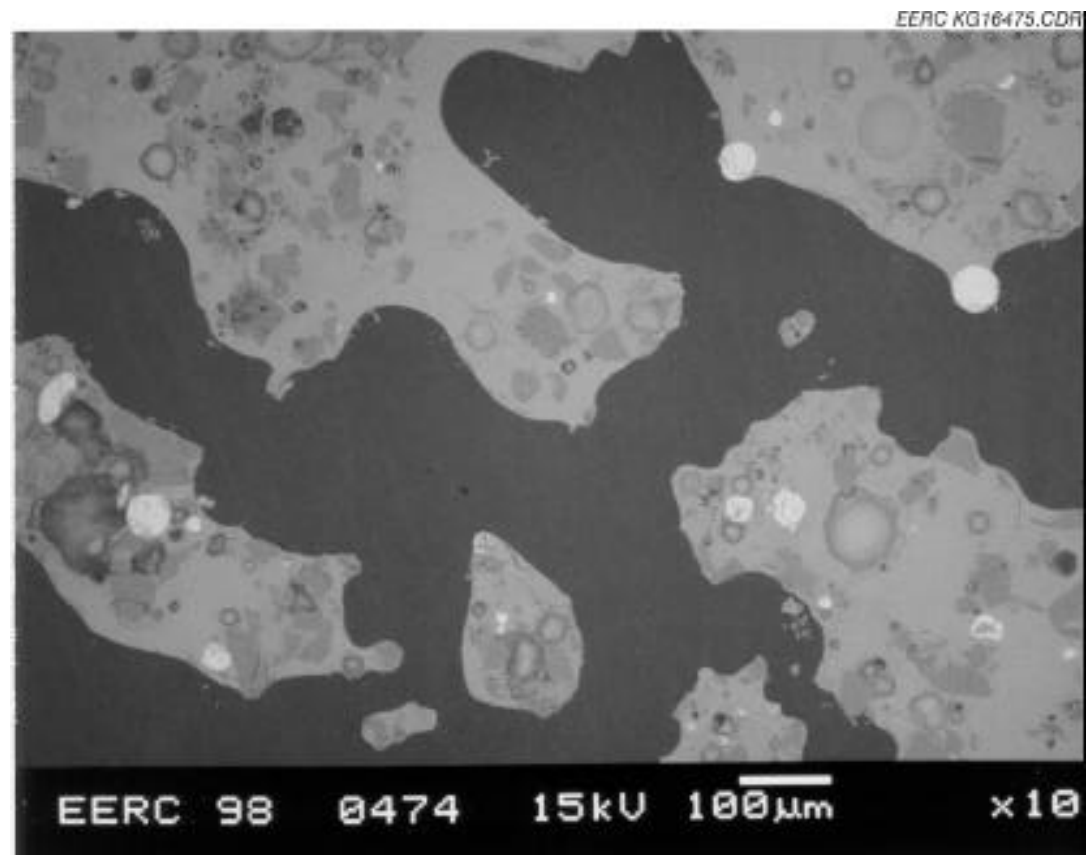

Figure 4-4 Backscattered electron image of a fouling deposit produced from a 90\% PRB coal-10\% petroleum coke blend. 


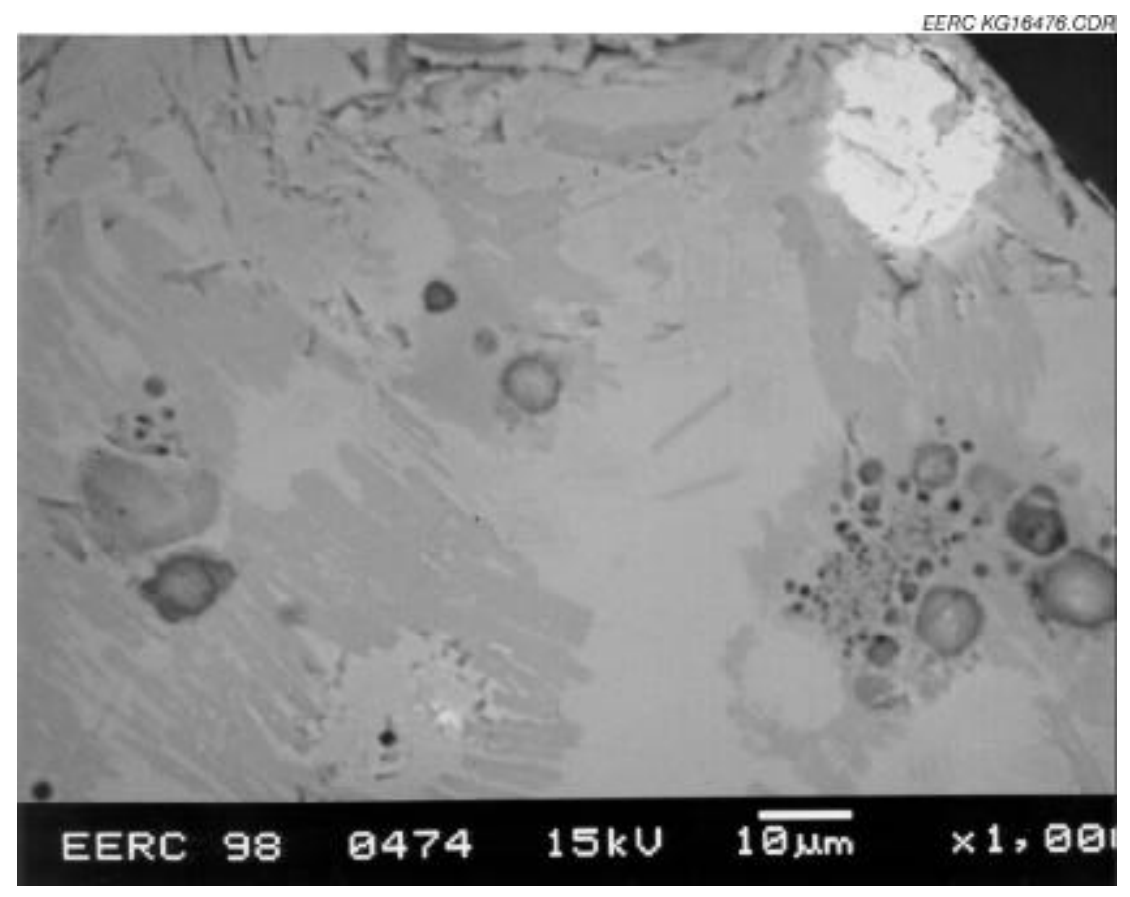

Figure 4-5 Backscattered electron image of mineral crystals in a fouling deposit produced from a $90 \%$ PRB coal-10\% petroleum coke blend.

concentrations in their corresponding coal ashes [Table 4-3]). Enrichment-depletion factors are presented in Table 4-8 for the dominant elemental oxides that compose the fuel ashes and deposits. Factors for minor and trace element oxides, $\mathrm{Na}_{2} \mathrm{O}, \mathrm{K}_{2} \mathrm{O}, \mathrm{V}_{2} \mathrm{O}_{5}$, and $\mathrm{NiO}$, were not are probably deposited through inertial impaction because of their relatively large size. Crystal calculated because of the inaccuracy and imprecision of EPMA for elements at low concentrations $(<1 \mathrm{wt} \%)$. Factors of greater than 1.2 or less than 0.8 are considered significant enrichments and depletions, respectively, based on the dispersion introduced in the values by sampling and analytical uncertainties. Elemental oxides that are insignificantly enriched or depleted presumably participate equally in the deposit formation process. These factors indicate that the coal slag deposit is enriched in $\mathrm{SiO}_{2}$ and $\mathrm{Fe}_{2} \mathrm{O}_{3}$ but depleted in $\mathrm{CaO}$ and $\mathrm{MgO}$ relative to its corresponding ash precursor (Table 4-3). The $80 \%$ PRB coal-20\% petroleum coke slag deposit is enriched in $\mathrm{SiO}_{2}$ but depleted in $\mathrm{TiO}_{2}, \mathrm{CaO}$, and $\mathrm{MgO}$ relative to its corresponding ash precursor. The addition of petroleum coke appears to have inhibited the participation of $\mathrm{Fe}_{2} \mathrm{O}_{3}$ in the slagging process. The coal fouling deposit is enriched in $\mathrm{Fe}_{2} \mathrm{O}_{3}$ relative to its ash precursor. The other elemental oxides are insignificantly enriched or depleted, suggesting that they participate equally in the high-temperature fouling process. The fouling deposit produced from an $80 \%$ PRB coal-20\% petroleum coke blend is enriched in $\mathrm{Fe}_{2} \mathrm{O}_{3}, \mathrm{TiO}_{2}$, and $\mathrm{MgO}$ but depleted in $\mathrm{SiO}_{2}$ relative to its corresponding ash precursor. Apparently, the addition of petroleum coke promoted the participation of $\mathrm{TiO}_{2}$ and $\mathrm{MgO}$ in the ash fouling process but inhibited $\mathrm{SiO}_{2}$ participation.

Deposit porosities, defined here as the percentage of voids in a cross-sectioned deposit, are given in Tables 4-9 and 4-10 for the slag and fouling deposits (base and main portions). Deposit porosities decrease significantly from the base to the upper main deposit portions. Porosity 
Table 4-8 Enrichment-Depletion Factors for Selected Slag and High-Temperature Fouling Deposits Produced in the ODTF

\begin{tabular}{|l|l|l|l|l|}
\hline & \multicolumn{2}{|l|}{ Slag Deposits } & High-Temperature & Fouling Deposits \\
\hline PRB Coal:Pet. Coke & $\mathbf{1 0 0 : 0}$ & $\mathbf{8 0 : 2 0}$ & $\mathbf{1 0 0 : 0}$ & $\mathbf{8 0 : 2 0}$ \\
\hline $\mathrm{SiO}_{2}$ & 1.3 & 1.7 & 1.0 & 0.7 \\
\hline $\mathrm{Al}_{2} \mathrm{O}_{3}$ & 1.1 & 1.1 & 1.1 & 1.0 \\
\hline $\mathrm{Fe}_{2} \mathrm{O}_{3}$ & 1.7 & 0.9 & 1.5 & 2.8 \\
\hline $\mathrm{TiO}_{2}$ & 1.0 & 0.3 & 1.0 & 1.7 \\
\hline $\mathrm{CaO}$ & 0.6 & 0.4 & 0.9 & 0.8 \\
\hline $\mathrm{MgO}$ & 0.7 & 0.3 & 1.0 & 1.8 \\
\hline
\end{tabular}

Table 4-9 Porosity of Slag Deposits

\begin{tabular}{|l|l|l|}
\hline \multicolumn{3}{|l|}{ Porosity, \% } \\
\hline PRB Coal:Pet. Coke & Main & Base \\
\hline $100: 0$ & 51.7 & 84.5 \\
\hline $90: 10$ & 56.1 & 85.6 \\
\hline $80: 20$ & 62.3 & 84.3 \\
\hline
\end{tabular}

Table 4-10 Average Porosity of High-Temperature Fouling Deposits

\begin{tabular}{|l|l|l|}
\hline & \multicolumn{2}{|l|}{ Average Porosity, \% } \\
\hline PRB Coal:Pet. Coke & Main & Base \\
\hline $100: 0$ & 63.4 & 76.5 \\
\hline $90: 10$ & 61.5 & 70.1 \\
\hline $80: 20$ & 69.1 & 70.5 \\
\hline
\end{tabular}

reduction is the result of an increase in sintering and partial melting associated with increasing temperature as the growing deposit becomes insulated from the cooled probe substrate. As shown in Figure 4-6, the main deposit surface is enriched in glass as a result of the temperature gradient within the deposit. Slag deposit base porosities are very similar. However, porosity progressively increases for the main slag deposits with increasing blend levels of petroleum coke. The increase in porosity corresponds to an increase in crushing strength (Figure 4-1).

In summary, results from this investigation of a PRB coal and petroleum shot coke suggest that increasing blend levels of petroleum coke promote slag deposition and strength but inhibit ash fouling deposition and strength. Petroleum coke blending also promotes ash sulfation and the formation of an anhydrite-rich base layer on tube surfaces. 


\section{Blaok Thunder \#681 $.5 \mathrm{~mm}$

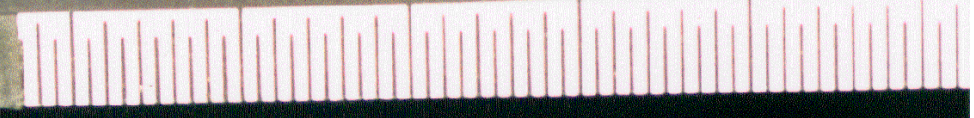

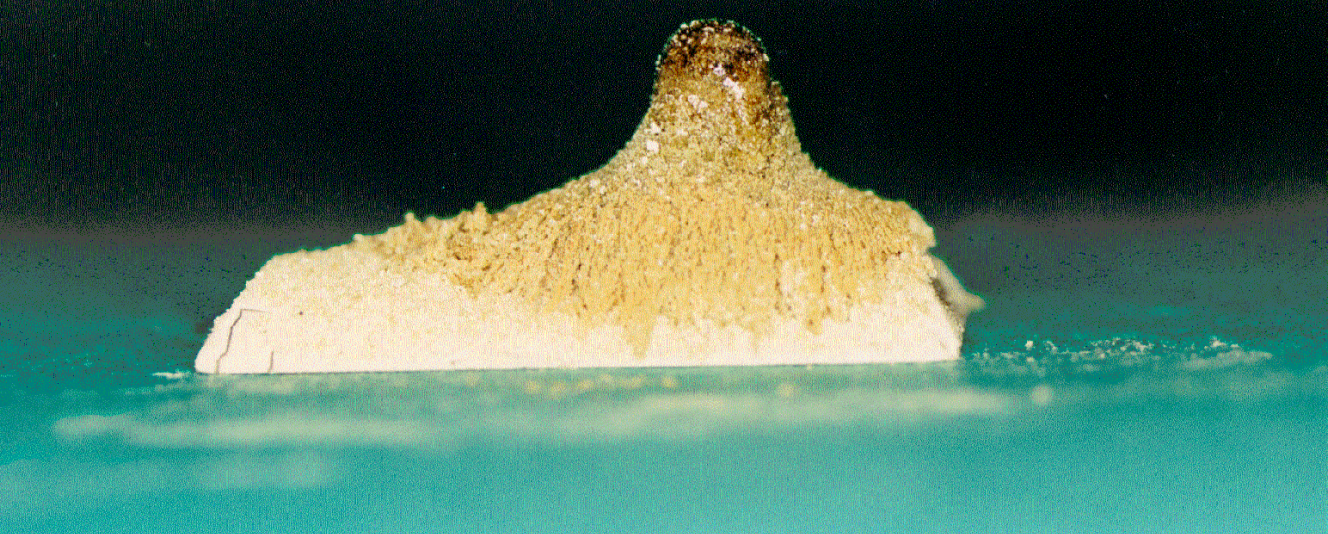

Figure 4-6 Photograph of a slag deposit produced from the $80 \%$ PRB coal-20\% petroleum coke blend. 


\section{Chapter 5 Effect of PRB Coal-Petroleum Coke Blending on ESP Fly Ash Collection Performance}

\section{Introduction}

A PRB subbituminous coal and a petroleum shot coke were received from NSP for evaluating the utility of petroleum coke blending as a strategy for improving ESP fly ash collection efficiency. The blending of petroleum coke with coal may enhance ESP fly ash collection efficiency. Petroleum cokes contain much higher concentrations of $\mathrm{V}$ relative to coals. Consequently, coke blending can significantly increase the $\mathrm{V}$ content of fly ash resulting from coal-coke combustion. Pentavalent vanadium $\left(\mathrm{V}^{5+}\right)$ is a known catalyst for transforming gaseous sulfur dioxide $\left(\mathrm{SO}_{2}[\mathrm{~g}]\right)$ to gaseous sulfur trioxide $\left(\mathrm{SO}_{3}[\mathrm{~g}]\right)(12) . \mathrm{SO}_{3}(\mathrm{~g})$ reacts with water vapor $\left(\mathrm{H}_{2} \mathrm{O}[\mathrm{g}]\right)$ in flue gas to form sulfuric acid $\left(\mathrm{H}_{2} \mathrm{SO}_{4}[\mathrm{~g}]\right)$. At temperatures below the sulfuric acid dew point, $\mathrm{H}_{2} \mathrm{SO}_{4}(\mathrm{l})$ condenses on ash particle surfaces. The presence of $\mathrm{SO}_{3}(\mathrm{~g})$ and $\mathrm{H}_{2} \mathrm{SO}_{4}(\mathrm{~g}, \mathrm{l})$ strongly affects fly ash resistivity and, thus, ESP performance.

\section{Experimental}

The PRB coal and two coal:coke blends of 95:5 and 85:15 were burned in a 42-MJ/hr 40,000-Btu/hr) downfired combustion system shown in Figure 5-1 and described in Appendix D. Flue gas $\mathrm{SO}_{2}$ and $\mathrm{SO}_{3}$ concentrations were measured using an on-line analyzer and a controlled condensation method, respectively, to evaluate $\mathrm{V}^{+5}$ catalytic activity. The controlled

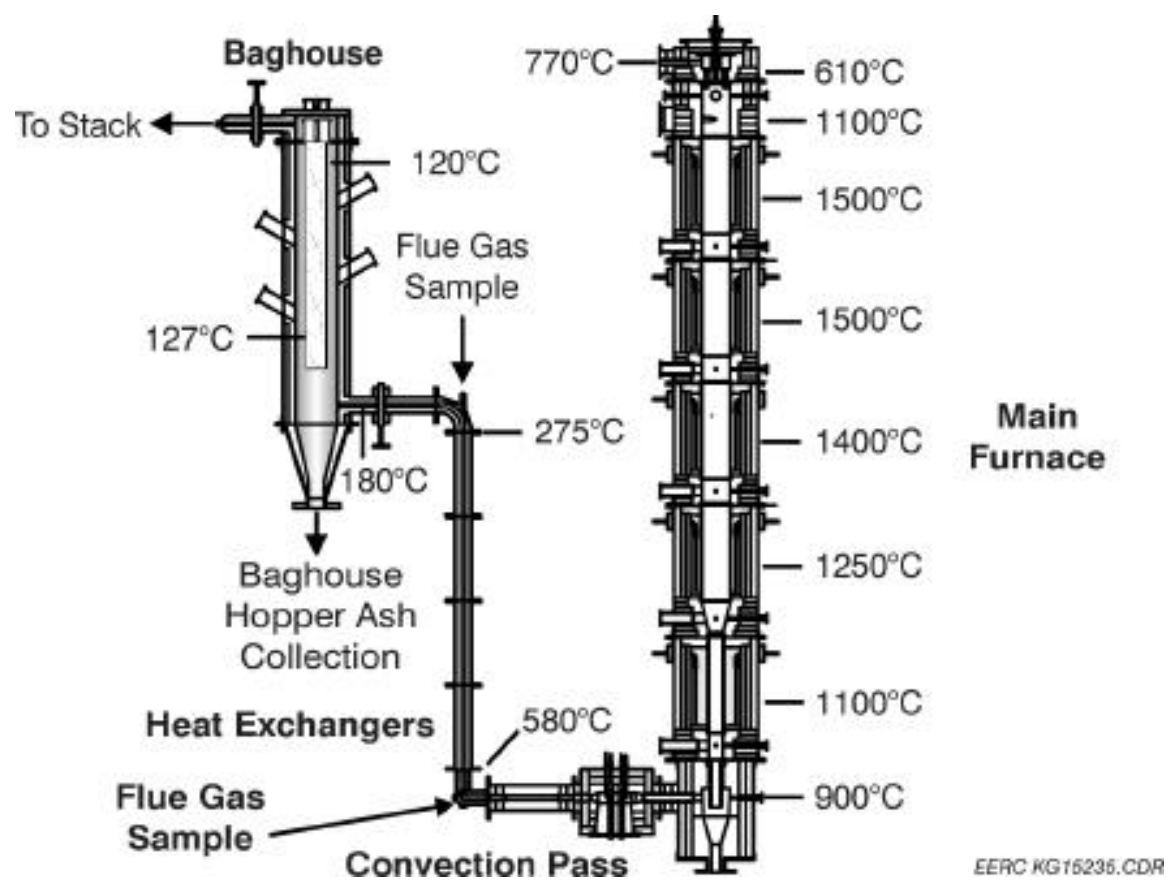

Figure 5-1 Schematic of the 40,000-Btu/hr combustor showing $\mathrm{SO}_{3}(\mathrm{~g})$ sampling locations and temperatures. 
condensation method is described by DeVito and Smith (13). In addition, EPA Method 8 was used during testing of the 85:15 blend to compare $\mathrm{SO}_{3}(\mathrm{~g})$ analysis results with the controlled condensation method. $\mathrm{SO}_{3}(\mathrm{~g})$ samples were collected from two different locations in the combustor, as indicated in Figure 5-1, corresponding to temperatures of approximately $275^{\circ}$ and $580^{\circ} \mathrm{C}$. Fly ash samples were collected from the baghouse after each test and analyzed for major and minor element composition using WDXRF spectrometry (ASTM Method D 4326). Ni and V concentrations of the baghouse ashes were determined using microwave digestion (ASTM Method D 3683) and ICP-AES (EPA Method 6010). The valance state of V in a baghouse ash was determined using x-ray absorption fine-structure (XAFS) spectroscopy at beam line IV-3 of the Stanford Synchrotron Radiation Laboratory, Stanford University, California. Details of the XAFS spectroscopy procedures have been presented by Huggins and Huffman (14) and Galbreath et al. $(15,16)$.

\section{Results and Discussion}

Proximate and ultimate analyses of the PRB coal and petroleum coke fuels, presented in Table 5-1, compare favorably, with relative percent differences of generally $<10$, to yearly average values for moisture, ash, calorific value, and sulfur provided by NSP (4). The flue gas compositions resulting from burning the PRB coal and two coal-coke blends in the 40,000$\mathrm{Btu} / \mathrm{hr}$ combustion system are presented in Table 5-2. Mass balance calculations, based on the fuel compositions in Table 5-1 and fuel feed rates, were used to estimate the inorganic sulfate $\left(\mathrm{SO}_{4}\right)$ composition of the flue gas. As expected, the primary effect of petroleum coke blending on flue gas composition is a significant increase in sulfur concentration. Sulfur speciation analyses indicate that although $\mathrm{SO}_{2}(\mathrm{~g})$ concentrations increase significantly with increasing coke blending, the $\mathrm{SO}_{3}(\mathrm{~g})$ remains undetectable. Mass balance calculations indicate that increasing coke blending promotes the conversion of fuel sulfur to inorganic $\mathrm{SO}_{4}$ compounds in the fly ash. Chemical analyses of fly ashes collected in the baghouse, presented in Table 5-3, confirm the direct relationship between coke blending and sulfation of the fly ash. In addition to sulfur, the $\mathrm{V}$ concentrations of the ashes increase significantly with increasing coke blending, suggesting that $\mathrm{V}^{+5}$ catalysis of $\mathrm{SO}_{2}(\mathrm{~g})$ oxidation is responsible for the increase in fly ash sulfation. Indeed, a comparison of the x-ray absorption near edge structure (XANES) spectrum for the ash produced from the 85:15 coal-coke blend, Figure5-2, with the XANES spectra for various V compounds in Figure 5-3, indicates clearly that the $\mathrm{V}$ is in a pentvalent oxidation state $\left(\mathrm{V}^{+5}\right)$. Both the position and height of the pre-edge peak are compatible with $\mathrm{V}^{+5}$ surrounded by oxygen anions. However, inspection reveals that the XANES spectrum of the ash is not identical to that of $\mathrm{V}_{2} \mathrm{O}_{5}$ : it has less structure, and the pre-edge peak in the ash spectrum is much sharper than that of the oxide. It appears to be more similar to pre-edges exhibited by $\mathrm{CrVO}_{4}$ and other metal vanadate compounds, in which $\mathrm{V}^{+5}$ is present in a tetrahedral coordina-tion environment by oxygen anions (17).

The decrease in fuel combustion reactivity with increasing blend proportions of petroleum shot coke is reflected in the carbon contents of the resulting combustion ashes in Table 5-3. The presence of carbon in the ash can have a negative effect on ash salability to the cement industry. 
Table 5-1 Proximate and Ultimate Analysis Results of the PRB Coal and Petroleum Coke Fuels (wt\% as-received unless otherwise noted)

\begin{tabular}{|l|l|l|}
\hline Parameter & PRB Coal & Petroleum Coke \\
\hline Moisture & 26.6 & 6.00 \\
\hline Volatile Matter & 34.4 & 8.60 \\
\hline Fixed Carbon & 34.9 & 84.8 \\
\hline Ash & 4.14 & 0.60 \\
\hline Calorific Value, Btu/lb & 9355 & 14,280 \\
\hline Hydrogen & 6.85 & 4.00 \\
\hline Carbon & 51.8 & 83.3 \\
\hline Nitrogen & 0.64 & 1.49 \\
\hline Sulfur & 0.26 & 6.14 \\
\hline Oxygen & 36.3 & 4.44 \\
\hline
\end{tabular}

Table 5-2 Flue Gas Compositions, Mean Values of Five Analyses with $95 \%$ Confidence Limits ( $\pm 2 \sigma$ )

\begin{tabular}{|c|c|c|c|}
\hline Blend Ratio (coal:coke): & 100:0 & $95: 5$ & $85: 15$ \\
\hline $\mathrm{CO}_{2}, \mathrm{~mol} \%$ & $14.8 \pm 0.2$ & $15.4 \pm 0.2$ & $15.4 \pm 0.2$ \\
\hline $\mathrm{CO}, \mathrm{ppmv}$ & $<3$ & $<3$ & $<3$ \\
\hline Excess $\mathrm{O}_{2}, \mathrm{~mol} \%$ & $4.2 \pm 0.2$ & $4.0 \pm 0.2$ & $4.0 \pm 0.2$ \\
\hline $\mathrm{NO}_{\mathrm{x}}, \mathrm{ppmv}$ & $1185 \pm 15$ & $1080 \pm 70$ & $1090 \pm 70$ \\
\hline $\mathrm{SO}_{2}, \mathrm{ppmv}$ & $251 \pm 5$ & $451 \pm 6$ & $790 \pm 30$ \\
\hline $\mathrm{SO}_{3}, \mathrm{ppmv}$ & $<0.5$ & $<0.4$ & $<0.5$ \\
\hline Inorganic $\mathrm{SO}_{4}, \mathrm{ppmv}^{1}$ & $<5$ & 54 & 180 \\
\hline
\end{tabular}

${ }^{1}$ Estimated on the basis of the mass balance calculations.

Table 5-3 Chemical Compositions of the Baghouse Ashes (wt\%)

\begin{tabular}{|l|l|l|l|}
\hline Blend Ratio (coal:coke): & $\mathbf{1 0 0 : 0}$ & $\mathbf{9 5 : 5}$ & $\mathbf{8 5 : 1 5}$ \\
\hline $\mathrm{SiO}_{2}$ & 27.8 & 28.4 & 25.4 \\
\hline $\mathrm{Al}_{2} \mathrm{O}_{3}$ & 20.1 & 20.0 & 18.7 \\
\hline $\mathrm{Fe}_{2} \mathrm{O}_{3}$ & 7.2 & 6.8 & 6.9 \\
\hline $\mathrm{TiO}_{2}$ & 1.6 & 1.6 & 1.6 \\
\hline $\mathrm{P}_{2} \mathrm{O}_{5}$ & 1.6 & 1.5 & 1.5 \\
\hline $\mathrm{CaO}$ & 29.1 & 27.9 & 28.6 \\
\hline $\mathrm{MgO}$ & 6.7 & 6.5 & 6.4 \\
\hline $\mathrm{Na}_{2} \mathrm{O}$ & 1.5 & 1.5 & 1.5 \\
\hline $\mathrm{K}_{2} \mathrm{O}$ & 0.3 & 0.3 & 0.3 \\
\hline $\mathrm{SO}$ & 2.9 & 4.1 & 7.4 \\
\hline $\mathrm{C}$ & 0.77 & 1.24 & 2.05 \\
\hline $\mathrm{Ni}$ & 0.012 & 0.036 & 0.090 \\
\hline $\mathrm{V}$ & 0.033 & 0.165 & 0.531 \\
\hline Total & 99.6 & 100.0 & 101.0 \\
\hline
\end{tabular}


In summary, essentially all of the sulfur in the PRB coal and coal-coke blends is released as $\mathrm{SO}_{2}(\mathrm{~g})$ during combustion. A fraction of the $\mathrm{SO}_{2}(\mathrm{~g})$, however, is probably oxidized downstream of the combustion zone to $\mathrm{SO}_{3}(\mathrm{~g})$, which reacts with water vapor to form $\mathrm{H}_{2} \mathrm{SO}_{4}(\mathrm{~g}, 1)$. Recent

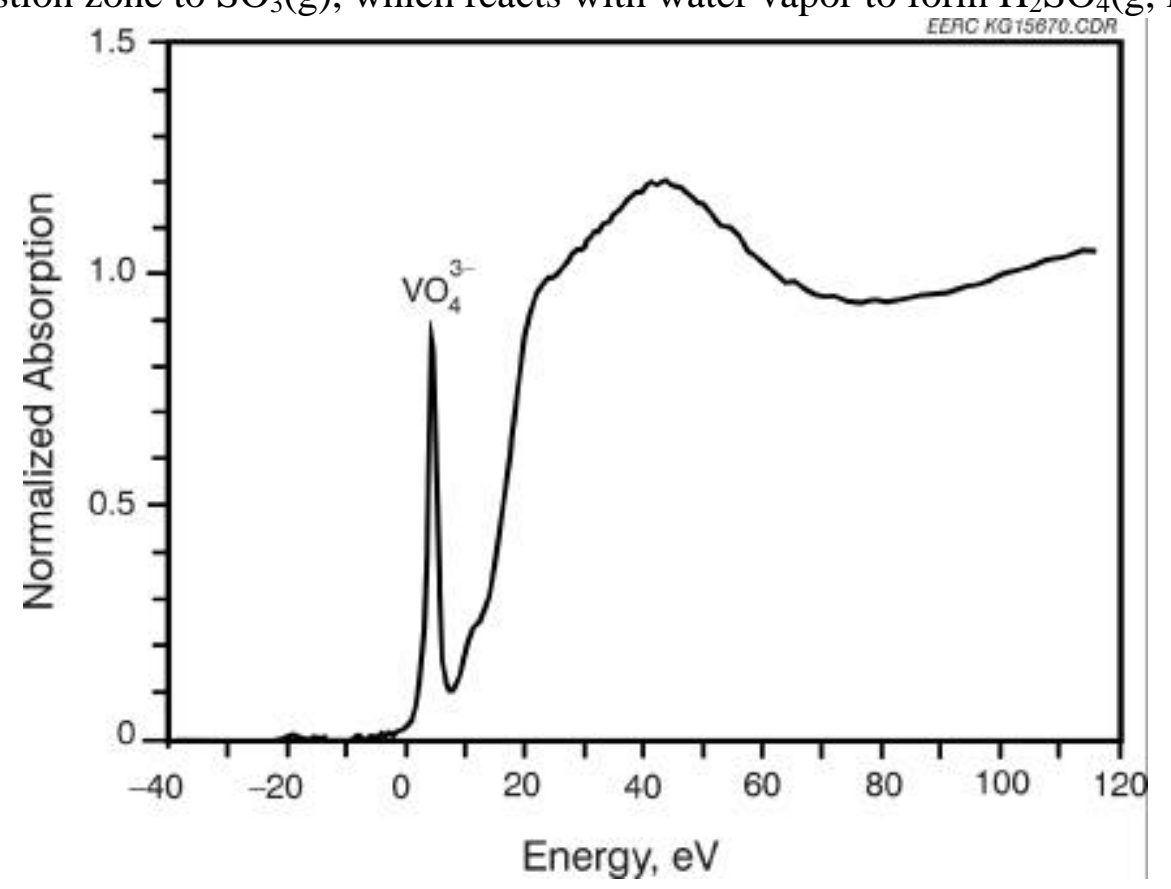

Figure 5-2 V K-edge XANES spectrum of the PRB coal-petroleum coke ash blend (85:15). 


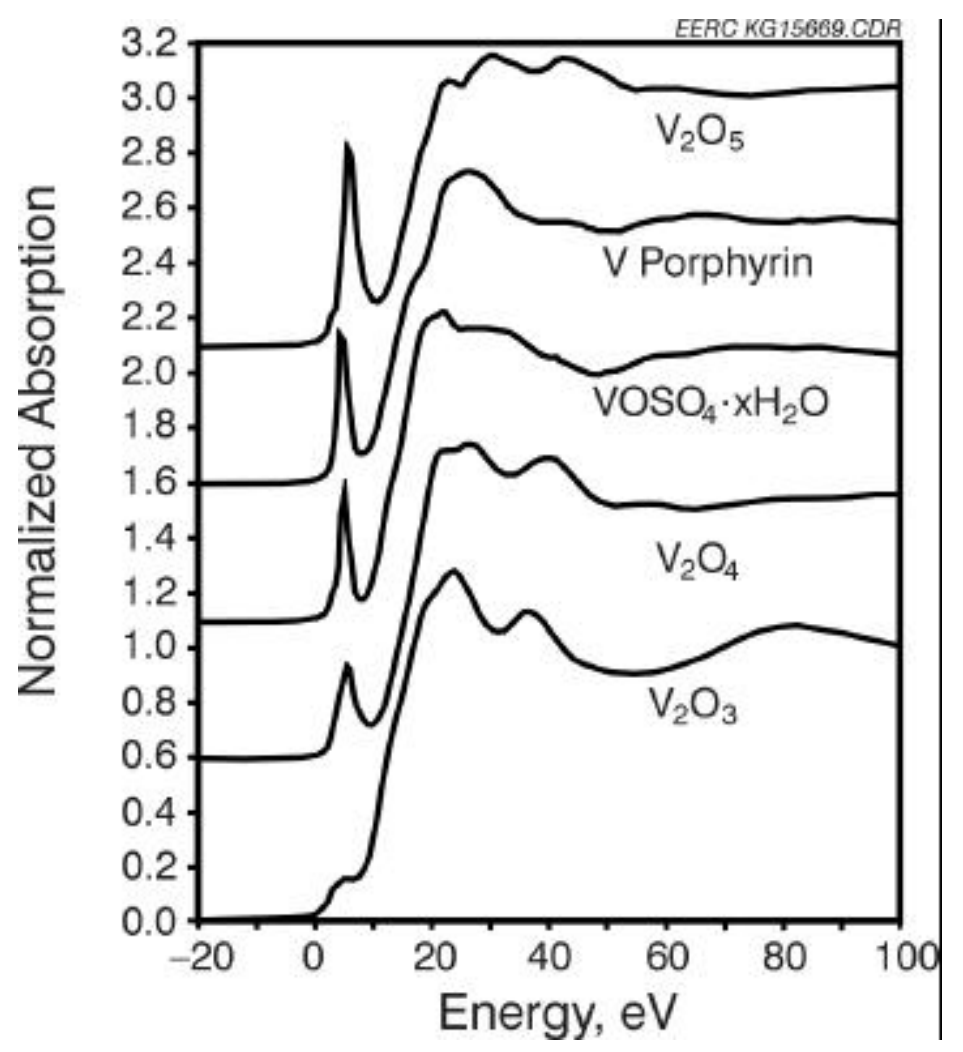

Figure 5-3 V K-edge XANES spectra of five V reference compounds.

experimental tests by Graham and Sarofim (18) indicate that submicrometer ash is important in controlling the fate of sulfur in combustion flue gas because it contains known catalytic species for $\mathrm{SO}_{2}(\mathrm{~g})$ oxidation, generally contributes $>90 \%$ of the total aerosol surface area, and is intimately mixed with the flue gas. Therefore, both the amount of sulfur released and the fraction of $\mathrm{SO}_{2}(\mathrm{~g})$ converted to $\mathrm{SO}_{3}(\mathrm{~g})$ and $\mathrm{H}_{2} \mathrm{SO}_{4}(\mathrm{~g}, \mathrm{l})$ depend strongly on the composition of the submicrometer ash. The submicrometer ash produced from burning subbituminous PRB coals is enriched in alkaline species such as lime $(\mathrm{CaO})$ that readily react with $\mathrm{SO}_{2}(\mathrm{~g}), \mathrm{SO}_{3}(\mathrm{~g})$, and $\mathrm{H}_{2} \mathrm{SO}_{4}(\mathrm{~g}, \mathrm{l})$ to form anhydrite $\left(\mathrm{CaSO}_{4}[\mathrm{~s}]\right)$, a dominant component of ash fouling deposits $(9,19$, 20). Therefore, petroleum coke blending with the PRB coal promotes ash sulfation (i.e., the formation of $\mathrm{CaSO}_{4}$ ) as well as the desired effect of improving ash resistivity characteristics. 


\section{Chapter 6 Vanadium Speciation in PRB Coal- Petroleum Coke Fly Ash}

\section{Introduction}

Determining the redox state of $\mathrm{V}$ is important because its toxicity varies with oxidation state. Vanadium has several roles in physiological systems. Vanadium is important in various enzyme systems and as a catalyst in numerous metabolic cycles, including oxidation of catecholamines such as adrenaline. Vanadium can exist in several oxidation states and, depending on $\mathrm{pH}$ and concentration, as numerous polyoxo anions in aqueous solution. There are two oxidation states, vanadium(IV) and vanadium(V), which are relatively stable under ambient conditions. The distribution of vanadium between these two common oxidation states is important because of the difference in toxicity, with vanadium(V) being more toxic than vanadium(IV). Because of the difference in toxicity between valence states, ascorbic acid has been found to be an effective antidote against lethal doses of vanadium in test animals because of its ability to reduce vanadium(V) to the less toxic vanadium (IV) (21).

Figure 6-1 is an Eh-pH diagram for a vanadium-water system, and the distribution of vanadium species as a function of $\mathrm{pH}$ and concentration is shown in Figure 6-2 (22). From these figures, it can be deduced that vanadium $(\mathrm{V})$ would be expected to be the primary form in groundwater in contact with atmospheric oxygen, with vanadium(IV) present in reducing systems.

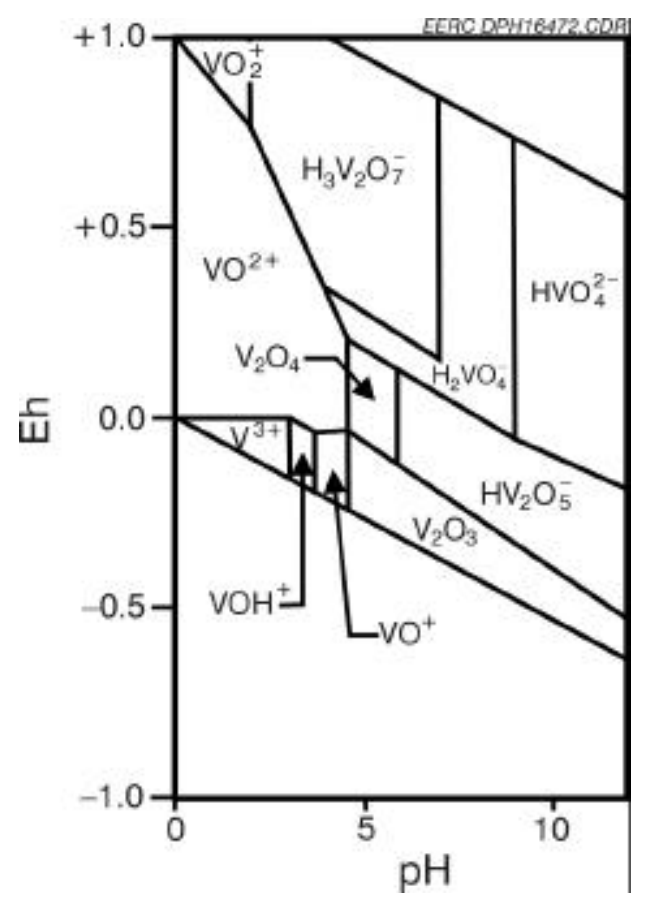

Figure 6-1 Eh-pH diagram of aqueous vanadium. 


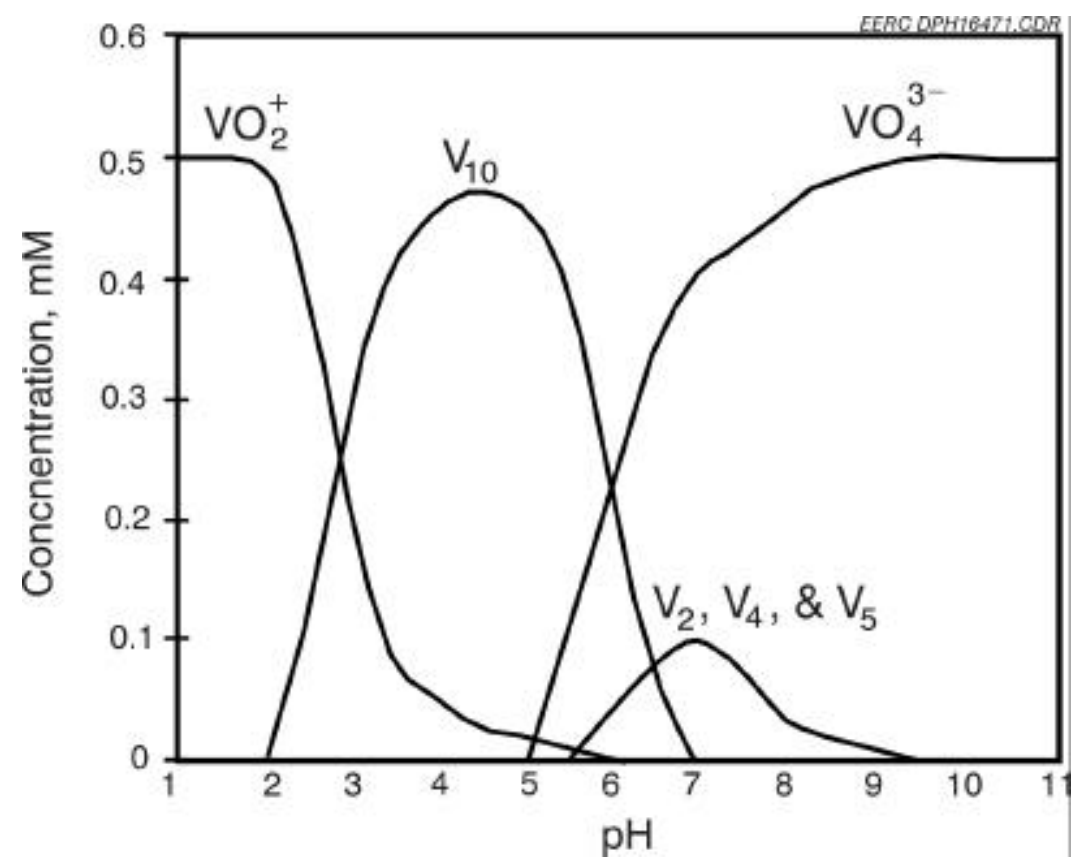

Figure 6-2 Distribution of vanadium species as a function of $\mathrm{pH}$ and concentration.

Since the toxicity of vanadium is tied to oxidation state, it is important that any analytical protocol for determining the redox state of available vanadium in coal ash, especially in fly ash where it will tend to concentrate, should mimic potential environmental scenarios for release. While inhalation or ingestion of fugitive dust are potential pathways, the more likely route would be through ingestion or contact with vanadium-containing leachate that has infiltrated into and presumably been diluted by groundwater. In the case of ingestion or inhalation, the ultimate redox state would be a function of the initial oxidation state and the physiological fluid likely to be involved in release (e.g., mucous, gastric acid). The rate of oxidation of vanadium(IV) to the more toxic pentavalent state is dependent on the acidity of the medium in which it is placed. At $\mathrm{pH}$ lower than 2.4, vanadium(IV) is stable in the presence of oxygen (23); thus in normal groundwater systems exposed to atmospheric oxygen, vanadium would be expected to be converted to the pentavalent state. In gastric fluid, ingested ash would be expected to release vanadium in the redox state or ratio of redox states in which it was deposited on the ash substrate.

\section{Experimental}

A bulk analysis of five ash samples was performed. The moisture, loss on ignition, vanadium, nickel, and molybdenum content was determined. Two samples were generated at the pilot-scale facilities at the EERC using blends of PRB coal and petroleum coke. Two samples were collected from full-scale power plants. One sample was generated using PRB coal in a pulverized coal-fired unit, and the other was a blend of PRB coal and petroleum coke fired in a cyclone unit. The pilot-scale and full-scale samples were from PRB coal and petroleum coke from the same sources. The ash samples were also evaluated for moisture, loss on ignition, major elemental composition, and other minor and trace constituents. 


\section{Results and Discussion}

The results of the analyses are noted in Tables 6-1 (results for samples from the pilot scale) and 6-2 (results for samples from full scale). Replicate results are noted where they were available.

Results for the pilot-scale samples cannot be directly compared with the results for the full-scale samples, but the concentrations of the trace elements most commonly associated with pet coke are similar. The concentrations of vanadium are not high enough to use these ash samples for vanadium recovery, so typical disposal management options will likely be used. These most likely will be disposal in a dedicated landfill or other surface impoundment, or utilization in appropriate applications that would be selected on the basis of other properties of the ash. The key issue relative to vanadium in ash in these management scenarios is the potential for adverse effects of vanadium from several potential ingestion pathways. From an experimental standpoint, the vanadium is most likely to find its way into the food chain through transport with groundwater. The issue concerning speciation of vanadium then becomes a question of the form in which vanadium is leached and transported rather than the issue of the redox state in the ash matrix.

Several experimental approaches for vanadium speciation were investigated for suitability in the characterization of combustion residues. These were colorimetric reactions for spectrophotometric determination, ion chromatography, and thin-layer chromatography (TLC). Separations of vanadium(IV) and vanadium(V) were easily attained using ion-exchange chromatography. Column ion-exchange chromatography was performed using a strongly acidic cation-exchange resin in the hydrogen form (Dowex-50W) and an iminodiacetic chelating resin (Chelex-100). Using appropriate eluents, the separation of the two prominent redox states of vanadium was easily achieved (23-26). Column chromatography of vanadium(IV) and

Table 6-1 Composition of Ash Samples Generated in EERC Conversion and Environmental Process Simulator Facility, wt.\%

\begin{tabular}{|l|l|l|l|}
\hline Blend Ratio (coal: coke) & \multicolumn{1}{|c|}{$\mathbf{1 0 0 : 0}$} & \multicolumn{1}{|c|}{$\mathbf{9 5 : 5}$} & \multicolumn{1}{|c|}{$\mathbf{8 5 : 1 5}$} \\
\hline $\mathrm{Ni}$ & 0.012 & $0.036 / 0.040$ & $0.090 / .092$ \\
\hline $\mathrm{V}$ & 0.033 & $0.165 / .170$ & $0.531 / .447$ \\
\hline $\mathrm{Mo}$ & & 0.01 & 0.12 \\
\hline Moisture & & 0.19 & 0.14 \\
\hline LOI & & 1.03 & 1.59 \\
\hline
\end{tabular}

Table 6-2 Composition of Full-Scale Ash Samples, wt\%

\begin{tabular}{|l|l|l|}
\hline Blend Ratio (coal: coke) & \multicolumn{1}{|c|}{$\mathbf{1 0 0 : 0}$} & \multicolumn{1}{c|}{$\mathbf{9 2 : 8}$} \\
\hline $\mathrm{Ni}$ & 0.005 & 0.086 \\
\hline $\mathrm{V}$ & 0.022 & 0.167 \\
\hline $\mathrm{Mo}$ & 0.00 & 0.01 \\
\hline
\end{tabular}




\begin{tabular}{|l|l|l|}
\hline Moisture & 0.07 & 0.52 \\
\hline LOI & 0.00 & 19.95 \\
\hline
\end{tabular}

vanadium(V) was carried out using a glass column with an inside diameter of $10 \mathrm{~mm}$ and a length of $100 \mathrm{~mm}$. A bed of ion-exchange resin approximately $20 \mathrm{~mm}$ in length was introduced as a slurry and backflushed to eliminate air and to maximize column efficiency by classification of resin particles with small particles at the top and larger particles at the bottom of the column. If necessary, resin was conditioned to the $\mathrm{H}^{+}$form using $1 \mathrm{~N}$ hydrochloric acid. Flow of eluent was maintained at a nominal flow rate of $1-2 \mathrm{~mL}$ per minute. An automated fraction collector was used to collect column effluent. An appropriate color indicator was added to each of the collection tubes to give a visual indication of vanadium being eluted. Chrome azurol S (CAS) was the indicator used in most of the experiments, giving a purple color with vanadium(IV) and an orange color with vanadium $(\mathrm{V})$. CAS gives a blue color with iron and could also be used as a visual indicator in experiments where iron was also to be separated. A clean separation between cationic and anionic vanadium species was easily achieved using the strongly acidic cationexchange resin (27), while more exacting manipulation of the $\mathrm{pH}$ of eluent was required with the iminodiacetic chelating resin (23-26). At this point, with a complete separation of redox species, any of a number of instrumental or colorimetric techniques could be applied for the actual determination.

Thin-layer chromatography proved to be more problematic, although workable. A silica thin layer was used with a formic acid-tributylamine-alcohol mobile phase (28). Chloroform extracts of 1-(2-pyridylazo)-2-naphthol (PAN), as well as aqueous solutions of vanadium, were chromatographed using the recommended reagent combination, which was tributylamine-formic acid-acetone (1:12:7). The chloroform extract of vanadium-PAN complexes was chosen because the extract of vanadium(IV) is yellow and the vanadium(V) complex is dark blue; thus a visual indication of the separation is apparent without the need for spraying the TLC plates with a visualization reagent. Additionally, the application of aqueous standards to silica layer plates that have been activated tends to deactivate the plates at the area of spotting and can result in tailing. Although severe tailing was observed, some separation could be achieved. An alternate and simpler solvent system consisting of heptane and butanol (1:1) proved to be a more efficient solvent for the chromatographic separation of the vanadium-PAN complex on a silica thin layer.

Several colorimetric and indicator reagents were evaluated, these are listed in Table 6-3. Although not all of these reagents give distinct color changes with both vanadium(IV) and vanadium $(\mathrm{V})$, they have been used in one form or another for the quantitation of vanadium and other metals. Numerous spectrophotometric methods are summarized in a review document (21). The reagents listed in Table 6-3 were screened for suitability using acidic aqueous solutions.

Table 6-4 shows the various color developments obtained in aqueous solutions using only colorimetric reagent and the appropriate vanadium species. Concentration of the vanadium was approximately $50 \mathrm{ppm}$. Colorimetric reagents were prepared in ethanol at a nominal concentration of .025 M. Although there are interferences, especially with iron, many of the reagents can still be made applicable by masking the iron interference using 1,2cyclohexylenedinitrilo- tetraacetic acid (CDTA). Although no specific experiments were used for 
quantitation, several of the colorimetric reagents were used as a developer in the TLC method and as an indicator to indicate the elution of the redox species of vanadium in an automated fraction collector used in the ion-exchange experiments.

\begin{tabular}{|c|c|}
\hline 1 & 3,4-Dihydroxycinnamic acid (DHCA) \\
\hline 2 & Xylenol orange $(\mathrm{XO})$ \\
\hline 3 & 1-(2-Pyridylazo)-2-naphthol (PAN) \\
\hline 4 & Pyrocatechol violet (PV) \\
\hline 5 & 4-(2-Thiazoylazo)-resorcinol (TAR) \\
\hline 6 & Tannic acid (TA) \\
\hline 7 & Chrome azurol S (CAS) \\
\hline 8 & 4-Benzoyl-3-methyl-1-phenyl-2-pyrazolyn-5-one (BAPP) \\
\hline 9 & N-Benzoyl-N-phenyl-hydroxylamine (BPHA) \\
\hline 10 & 1-Pyrrolidinecarbodithioic acid, ammonium salt (PYCDT) \\
\hline
\end{tabular}

Table 6-4 Color Development Using Colorimetric Indicators

\begin{tabular}{|l|c|c|}
\hline Reagent & V(IV) & $\mathbf{V}(\mathbf{V})$ \\
\hline DHCA & Clear & Yellow \\
\hline XO & Purple & Blue \\
\hline PAN & Yellow & Pink \\
\hline PV & Yellow & Clear \\
\hline TAR & Yellow & Red \\
\hline TA & Clear & Purple (fades quickly) \\
\hline CAS & Purple & Orange \\
\hline BAPP & Clear & Orange \\
\hline BPH & Light orange & Orange \\
\hline PYCDT & Yellow & Yellow \\
\hline
\end{tabular}

The information above shows that several reagents could be applied directly for estimating the redox state of vanadium directly, and as reported by Taylor 1994 (21), numerous indicator reagents that appear to give similar colors actually provide an adequate spectral shift between redox states of vanadium to allow for the direct spectrophotometric determination of vanadium species in aqueous solution. Additionally, iron, which is a common interferent and which is nearly always present as a major or minor component of coal fly ash, can often be masked using CDTA or could be removed using one of the separation techniques investigated. 


\section{Chapter 7 Conclusions}

A 2-year investigation of the effects of blending petroleum coke with PRB subbituminous coals on grindability, combustion reactivity, fouling/slagging, and ESP fly ash collection efficiency was completed. Observations and conclusions from this investigation include the following:

- Samples of a PRB coal, petroleum shot coke, and coal-coke blends of 95:5 and 85:15 (on a weight basis) were pulverized under identical conditions. Summations of the Ni and $\mathrm{V}$ contents for three size fractions $(<45 \mu \mathrm{m}, \geq 45 \mu \mathrm{m}$ but $<75 \mu \mathrm{m}$, and $\geq 75 \mu \mathrm{m})$ of the fuels indicate that the finest particle-size fraction of the petroleum coke is significantly enriched in $\mathrm{V}$ and Ni relative to its coarser size fractions. In contrast, V and $\mathrm{Ni}$ are uniformly distributed among the three particle-size fractions of the pulverized PRB coal. The finest particle-size fractions of the coal-coke blends are not enriched in $\mathrm{V}$ and $\mathrm{Ni}$ relative to their coarser size fractions, suggesting that the softer $\mathrm{Ni}$ - and V-depleted coal particles are preferentially fractioned into the finest size fractions during pulverization.

- Combustion kinetic testing of a PRB coal, petroleum coke, and an 80 wt\% PRB coal$20 \mathrm{wt} \%$ petroleum coke blend indicates that the parent fuels essentially burn independently of each other in a drop-tube furnace. Consequently, the combustion kinetics of a given coal-petroleum coke blend in a drop-tube furnace can be predicted from those of the parent fuels.

- Measurements of deposits (i.e., initial slagging temperatures, crushing strengths, and ash fouling deposition rates), produced from burning PRB coal-petroleum coke blends (coke blends of $0 \%, 10 \%$, and $20 \%$ on a weight basis) in a drop-tube furnace under slagging and high-temperature fouling conditions, indicate that petroleum coke blending with PRB coal impedes the rate of fouling deposit growth but promotes slagging and slag deposit strength. Although petroleum coke blending slows the rate of ash fouling deposition, it promotes ash sulfation and the formation of an anhydrite-rich base layer on tube surfaces.

- Combustion testing of a PRB coal and two coal-coke blends in a 42-MJ/hr (40,000-Btu/hr) downfired combustion system indicates that the primary effect of petroleum coke blending on flue gas composition is a significant increase in sulfur concentration. Sulfur speciation analyses indicate that although $\mathrm{SO}_{2}(\mathrm{~g})$ concentrations increase significantly with increasing coke blending, $\mathrm{SO}_{3}(\mathrm{~g})$ remains undetectable $(<0.5$ ppmv). Mass balance calculations and chemical analyses of fly ashes indicate that petroleum coke blending promotes the conversion of fuel sulfur to inorganic $\mathrm{SO}_{4}$ compounds in the fly ash as well as the desired effect of improving ash resistivity characteristics. An x-ray absorption fine structure spectroscopy analysis of an 85:15 (coal:coke) blend fly ash suggests that $\mathrm{V}^{+5}$ catalysis of $\mathrm{SO}_{2}(\mathrm{~g})$ oxidation is responsible for the increase in fly ash sulfation. 
- Experiments using color reagents and chromatographic techniques indicate that several relatively simple approaches may be applied to the determination of redox state of vanadium in acidic and neutral leachates of coal fly ash. Preliminary experiments indicate that a large fraction of vanadium leached from a fly ash sample obtained from the co-combustion of coal and petroleum coke $(85 \%-15 \%)$ was in the pentavalent state. More work is required to confirm this preliminary observation. 


\section{Chapter 8 References}

1. Rossi, R.A. Refinery Byproduct Emerges as a Viable Powerplant Fuel. Power Aug, 1993, pp 16-22.

2. Swain, E.J. U.S. Petroleum Coke Production Expected to Increase. Oil \& Gas Journal Nov 10, 1997, pp 79-82.

3. Bryers, R.W. Utilization of Petroleum Coke and Petroleum Coke/Coal Blends as a Means of Steam Raising. Fuel Processing Technology 1995, 44, 121-141.

4. Joe Brobjorg. Personal communication, Northern States Power Company, Nov 1998.

5. Field, M.A. Combust. Flame 1969, 13, 237-252.

6. Field, M.A. Combust. Flame 1970, 14, 237-252.

7. Nsakala, N.; Patel, R.L.; Lao, T.C. Combustion Characterization of Coals for Industrial Applications; final technical report for the period January 1, 1981, to May 29, 1985, DOE/PC/40267-5; 1985.

8. Mitchell, R.E. A Theoretical Model of Chemically Reacting Recirculating Flows; Sandia Laboratories Energy Report SAND-79-8236; 1980.

9. Zygarlicke, C.J.; Galbreath, K.C.; McCollor, D.P.; Toman, D.L. Development of Fireside Performance Indices; EPRI Report No. RP-357902; Nov 1995.

10. Galbreath, K.; Zygarlicke, C.; Casuccio, G.; Moore, T.; Gottlieb, P.; Agron-Olshina, N.; Huffman, G.; Shah, A.; Yang, N.; Vleeskens, J.; Hamburg, G. Collaborative Study of Quantitative Coal Mineral Analysis Using Computer-Controlled Scanning Electron Microscopy. Fuel 1996, 75 (4), 424-430.

11. Galbreath, K.C.; Brekke, D.W.; Folkedahl, B.C. Automated Analytical Scanning Electron Microscopy and Image Analysis Methods for Characterizing the Inorganic Phases in Coal and Coal Combustion Products. Prepr. Pap.-Am. Chem. Soc., Div. Fuel Chem. 1992, 37 (3), $1170-1176$.

12. Clark, R.J.H. Vanadium. In Comprehensive Inorganic Chemistry; Bailar, J.C., Jr., Emeléus, H.J., Nyholm, R., Trotman-Dickenson, A.F., Eds.; Pergamon Press Ltd.: Oxford England, Chapter 34, pp 491-551.

13. DeVito, M.S.; Smith, D.L. Controlled Condensation Method: New Option for $\mathrm{SO}_{3} \mathrm{Sampling}$ Power Feb. 1991, pp 41-44. 
14. Huggins, F.E.; Huffman, G.P. In Mineral Spectroscopy: A Tribute to Roger G. Burns; Dyar, M.D., McCammon, C., Schaefer, M.W., Eds.; The Geochemical Society, Special Publication No. 5; 1996; pp. 133-151.

15. Galbreath, K.C.; Zygarlicke, C.J.; Toman, D.L.; Huggins, F.E.; Huffman, G.P. Nickel and Chromium Speciation of Residual Oil Combustion Ash. Combustion Science and Technology 1998, 134 (1-6), 243-262.

16. Galbreath, K.C.; Zygarlicke, C.J.; Huggins, F.E.; Huffman, G.P.; Wong, J. Chemical Speciation of Nickel in Residual Oil Ash. Energy \& Fuels 1998, 12 (4), 818-822.

17. Wong, J.; Lytle, F.W.; Messmer, R.P.; Maylotte, D.H. Phys. Rev. B 1984, 30, 5596-5610.

18. Graham, K.A.; Sarofim, A.F. Inorganic Aerosols and Their Role in Catalyzing Sulfuric Acid Production in Furnaces. J. Air \& Waste Manage. Assoc. 1998, 48, 106-112.

19. Galbreath, K.C.; Zygarlicke, C.J.; McCollor, D.P.; Toman, D.L. Development of a StackPlume Opacity Index for Subbituminous Coal-Fired Utility Boilers. In Proceedings of the 12th Annual International Pittsburgh Coal Conference, Sept. 11-15, 1995; Shiao-Hung Chiang, Ed.; pp 19-26.

20. Davies, N.H.; Hayhurst, A.N. On the Formation of Liquid Melts of CaS and $\mathrm{CaSO}_{4}$ and Their Importance in the Absorption of $\mathrm{SO}_{2}$ by $\mathrm{CaO}$. Combustion and Flame 1996, 106, 359-362.

21. Taylor, M.J.C.; Van Staden, J.F. Spectrophotometric Determination of Vanadium(IV) and Vanadium(V) in Each Other's Presence. Analyst 1994 119, 1263-1276.

22. Lu, Xiaoqiao; Johnson, W.D.; Hook, J. Reaction of Vanadate with Aquatic Humic Substances: An ESR and 51V NMR Study. Environmental Science and Technology, 1998, $32,2257-2263$.

23. Soldi, T.; Pesavento, M.; Alberti, G. Separation of Vanadium(V) and -(IV) by Sorption on an Iminodiacetic Chelating Resin. Analytica Chimica Acta 1996, 323, 27-37.

24. Hartenstein, S.D.; Ruzicka, J.; Christian, G.D.; Sensitivity Enhancements for Flow Injection Analysis-Inductively Coupled Plasma Atomic Emission Spectrometry Using an On-Line Preconcentrating Ion-Exchange Column. Analytical Chemistry, 1985, 57, 21-25.

25. Riley, J.P.; Taylor, D. Chelating Resins for the Concentration of Trace Elements from Sea Water and Their Analytical Use in Conjunction with Atomic Absorption Spectrophotometry. Analytica Chimica Acta 1968, 40, 479-485.

26. Shah, N.; Desai, M.N.; Menon, S.K.; Agrawal, Y.K.; Ion Exchange Separation and Spectrophotometric Determination of Vanadium in Environmental Samples. Talanta 1991, 38 (6), 649-652. 
27. Komarova, T.V.; Obrezkov, O.N.; Shpigun, O.A.; Ion Chromatographic Behaviour of Anionic EDTA Complexes of Vanadium(IV) and Vanadium(V). Analytica Chimica Acta 1991, 254, 61-63.

28. Ajmal, M.; Mohammad, A.; Fatima, N; Ahmad, J. TLC Separation of V(V) from Numerous Metal Ions with Formic Acid-Tributylamine-Alcohol/Ketone Solvent Systems. Journal of Planar Chromatography 1988, 1, 239-245. 


\section{APPENDIX A}

\section{SURVEY QUESTIONNAIRE}




\section{SURVEY QUESTIONNAIRE}

Potential Research Topics for Investigation

\begin{tabular}{|l|l|}
\hline Research Topic & $\begin{array}{l}\text { Relative Ranking }(1-10, \text { where } 1=\text { most } \\
\text { concern and } 10=\text { least concern })\end{array}$ \\
\hline Fuel handling and consistency of blend & \\
\hline Coal mill performance & \\
\hline $\begin{array}{l}\text { Furnace operation } \\
\text { - Flame stability } \\
\text { - Flagging } \\
\text { - Couling }\end{array}$ & \\
\hline $\begin{array}{l}\text { Petroleum coke characterization (chemical } \\
\text { and mineralogical composition) }\end{array}$ & \\
\hline Air preheater corrosion & \\
\hline Baghouse or ESP operation & \\
\hline FGD system performance $\left(\mathrm{SO}_{2}\right.$ emissions) & \\
\hline Emissions of SO & \\
\hline Trace metal emissions and $\mathrm{NO}_{\mathrm{X}}$ & \\
\hline Byproducts reuse and disposal & \\
\hline Other(s): & \\
\hline
\end{tabular}




\section{SURVEY QUESTIONNAIRE (Continued)}

Comments and suggestions regarding the project proposal (attach additional pages if necessary):

Is your organization willing to provide coal and/or petroleum coke samples for testing? Yes_, No

Are you willing to critically review draft project reports? Yes _ , No 
APPENDIX B

\section{DESCRIPTION OF THE ATMOSPHERIC DROP-TUBE FURNACE}




\section{DESCRIPTION OF THE ATMOSPHERIC DROP-TUBE FURNACE}

The atmospheric drop-tube furnace (ADTF) was used to investigate the combustion kinetics of a PRB coal-petroleum coke blend. A short-residence-time probe was used to collect ash samples at various residence times. The probe consists of a series of four concentric, water-cooled steel tubes. Quench gas is introduced through the outer shell at the top of the probe. The combustion products pass through the innermost shell, and the remaining shells carry the cooling water. The probe is covered with an alumina insulating cylinder $5 \mathrm{~cm}$ ( $2.0 \mathrm{in}$.) in outside diameter. The probe is inserted in the bottom of the furnace a set distance calculated from the desired residence time. The quench gas and the vacuum are turned on. The fuel is fed through the preheat injector, the combustion products are quenched upon entering the probe, and the residue char or ash is collected on a filter attached to the probe's innermost shell. 


\section{APPENDIX C}

\section{DESCRIPTION OF THE OPTICAL ACCESS DROP-TUBE FURNACE}




\section{DESCRIPTION OF THE OPTICAL ACCESS DROP-TUBE FURNACE}

The optical access drop-tube furnace (ODTF) is a laboratory-scale, entrained flow, vertical downfired tube furnace used to burn coal, coke, and other fuels to produce ash under closely controlled conditions. Combustion parameters-e.g., initial hot-zone temperature, residence time, and gas cooling rates-are closely controlled and monitored. The furnace is equipped with an optical section where a deposition probe can be inserted. This optical section allows visual monitoring of deposit formation and in situ strength adhesion measurements of a deposit collected on a probe. The optical access section allows in situ temperature measurements by optical pyrometry. Collection of entrained ash and process gas analyses can also be performed in conjunction with deposition tests.

The furnace system is housed in a laboratory that provides a clean environment for operation of the system. Furnaces are mounted on a common bar and can be reconfigured to accommodate specific applications. The furnace system is designed for gas flow rates of 5 standard liters per minute. Typical gas velocities are 2.5 to 3.5 meters per second for gas temperatures between $1200^{\circ}$ and $1500^{\circ} \mathrm{C}$. Flowmeters deliver air and/or nitrogen to the system to obtain oxygen concentrations ranging from 0 to 21 . Typically 1 liter per minute of air is used for primary gas, and 4 liters per minute of nitrogen is used for secondary gas to achieve excess air levels of 50\% using approximately 0.1 gram per minute of fuel. The unheated primary gas (used as the sample carrier gas) entrains the fuel from the sample feeder and carries it through the injector into the furnace. The preheated secondary gas is introduced into the furnace through a mullite flow straightener.

The furnace assembly consists of a $63.5 \mathrm{~mm}$ (2-1/2 in.)-inner-diameter (ID) alumina reaction tube heated externally by a series of tube furnaces as illustrated in Figure 1. These furnaces possess a total of five independently controlled, electrically heated zones. This provides maximum flexibility and precise control over combustion conditions. A preheat furnace heats the gas that will be used as secondary gas. A split-shell, two-zone furnace provides the heat for obtaining the desired reaction zone temperature. A bottom furnace is utilized to maintain the temperature of the collection zone located in the optical access section.

Fuel and primary air are introduced into the furnace system by means of a water-cooled injector. This system injects ambient-temperature primary air and fuel into the furnace at the center of the tube. Secondary gas is introduced into the furnace through the top of the alumina furnace tube and is preheated before passing through a mullite flow straightener located at the bottom of the injector. Thus the material to be combusted is introduced into the furnace with the primary air through the injector and combines with the preheated secondary gas. The fuel and gas travel down the furnace in a laminar flow regime and pass through an accelerator just above an optical access section where the deposition probe is located. The ash not adhering to the probe is carried with the combustion gases into a water-cooled particulate collection probe located below the optical access section, where they are quenched with nitrogen.

Downstream of the sampling probe and collection filter, the combustion gas is cooled and passes through a filter before entering an airtight diaphragm pump. The gas leaving the positivepressure side of the pump is passed through a flowmeter, which measures the volume of gas being pulled through the probe. After the flowmeter, part of the gas is directed through $\mathrm{NO}_{\mathrm{x}}$,

$\mathrm{C}-1$ 


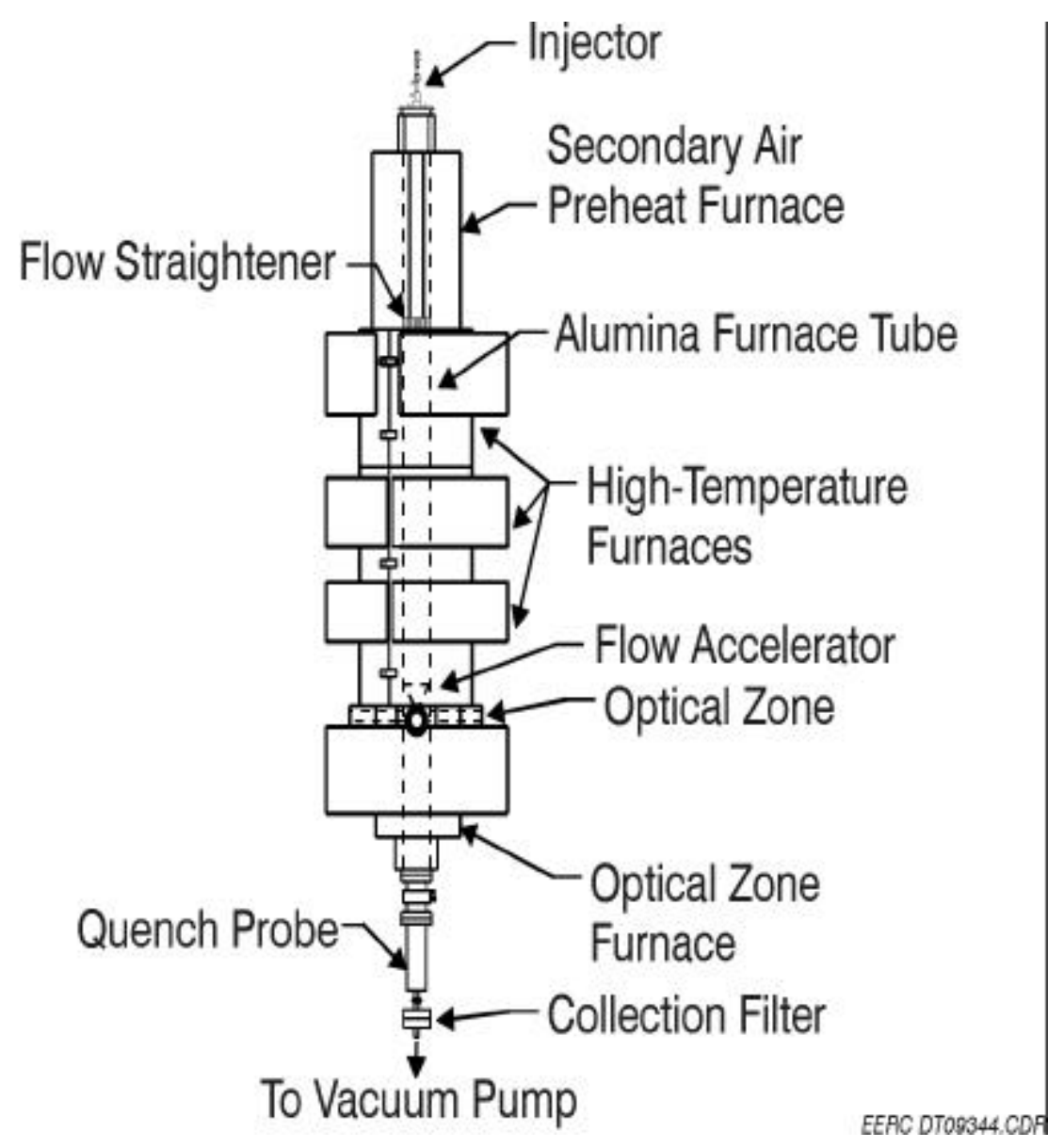

Figure C-1. Drop-tube furnace.

$\mathrm{CO}_{2}, \mathrm{CO}, \mathrm{SO}_{2}$, and $\mathrm{O}_{2}$ analyzers. The concentrations of these gases can then be read directly from the digital readouts of the analyzers or a chart recorder. The analyzers also send voltage signals to a computer, which records the gas concentrations. The computer allows real-time comparisons of gas concentrations with fuel feed rates.

The feed system is designed to feed particles of various sizes in the pulverized coal range at rates of 0.05 to 1.0 grams per minute and at primary carrier gas rates of approximately 1 liter per minute. The basic apparatus consists of a pressurized cylinder in which a container filled with fuel is placed. A rotating brush and stirrer attached to variable-speed motor feeds the fuel from the container into a funnel, where it is transported through the feed tubing into the furnace injector by the carrier gas. The fuel feeder is mounted on a top-loading balance, which monitors real-time coal feed rates. The balance is interfaced with RS232 to a computer, which records the feed rate.

The water/air-cooled ash deposition probe consists of a central water-cooled core surrounded by an air-cooled jacket. A central tube introduces a small stream of water, which is aspirated into the cooling air stream to enhance cooling effectiveness. 
Attached to the end of the probe is a removable, sacrificial steel coupon. The coupon is a tube $1.902 \mathrm{~cm}(0.75$ in.) $\mathrm{OD} \times 1.575 \mathrm{~cm}(0.62$ in.) $\mathrm{ID} \times 7.62 \mathrm{~cm}(3.0 \mathrm{in}$.$) long and can be easily$ fabricated from mild or stainless steel tubing with a minimum of machining. The coupon is press-fitted on the probe and held in place by two dovetail ridges on the probe located at the coupon ends. The dovetails keep the coupon tightly fitted to the probe to provide uniform heat transfer regardless of differential thermal expansion of the probe and coupon. The coupon is polished and oxidized prior to use. The coupon mounted on the probe can be maintained at a selected temperature between $350^{\circ}$ and $540^{\circ} \mathrm{C}$ to simulate a boiler heat-transfer surface by adjusting the air- and water-cooling flows. Coupon temperature is monitored by a Type $\mathrm{K}$ thermocouple in contact with the middle of the coupon, which provides feedback to regulate the probe-cooling air flow.

Various ceramic constrictors are used to accelerate the gas flow between 3 to 15 meters per second before it impinges on the coupon. These flow accelerators are made of Zircar AL-30 machined to fit the inside of the alumina reactor tube and coated with alumina cement. The accelerators are beveled at approximately 60 degrees to funnel the combustion gasses through various sized holes at the bottom to obtain the desired velocity impinging on the coupon. The coupon is placed $2.5 \mathrm{~cm}$ ( 1 in.) below the constrictor. 
APPENDIX D

\section{DESCRIPTION OF THE CONVERSION AND ENVIRONMENTAL PROCESS \\ SIMULATOR}




\section{DESCRIPTION OF THE CONVERSION AND ENVIRONMENTAL PROCESS SIMULATOR}

The conversion and environmental process simulator (CEPS), shown in Figure 1, is an extremely versatile system that can generate realistic combustion test results for a variety of fuels and combustion conditions. The intermediate size of the system and its relatively simple operation ensure adequate quantities of actual flue gas and ash for analysis in a relatively short period of time.

EERC engineers who designed the CEPS found that many similar intermediate-scale furnaces currently in operation have trouble attaining and maintaining high gas temperatures in the main combustion zones from the fuel alone. Acute control of gas temperatures and composition throughout the CEPS furnace is possible, independent of the heat capacity of the fuel, because of the external heating capacity of CEPS. Heating elements line the main furnace, convective pass section, and baghouse chambers. Temperatures of the flue gas (approximately 3-7 scfm) can attain a maximum of $1500^{\circ} \mathrm{C}\left(2732^{\circ} \mathrm{F}\right)$ in the radiant section and can be maintained at $500^{\circ}-$ $1200^{\circ} \mathrm{C}\left(932^{\circ}-2200^{\circ} \mathrm{F}\right)$ in the convective pass section and $120^{\circ}-250^{\circ} \mathrm{C}\left(248^{\circ}-482^{\circ} \mathrm{F}\right)$ in the baghouse, with the capability to go higher. The entire system is lined with either ceramic or refractory material, eliminating the possibility of reaction with and contamination of metal surfaces. Access ports located throughout the CEPS provide for sampling, observation, and optical diagnostics. A PC displays and records temperatures, gas flows, feed rates, and flue gas compositions. Flue gas $\left(\mathrm{O}_{2}, \mathrm{CO}_{2}, \mathrm{CO}, \mathrm{SO}_{2}\right.$, and $\left.\mathrm{NO}_{\mathrm{x}}\right)$ compositions are sampled from ports in the radiant section and after the collection device.

The CEPS is a down-fired design for nominally top firing $4.0 \mathrm{lb} / \mathrm{hr}(1.8 \mathrm{~kg} / \mathrm{hr})$ of pulverized coal or $1.5 \mathrm{lb} / \mathrm{hr}$ oil with a heat output of $\sim 42 \mathrm{MJ} / \mathrm{hr}(40,000 \mathrm{Btu} / \mathrm{hr})$. This modular system is capable of simulating conditions of both the radiant and convective sections of a full-scale utility boiler. The electrically heated 12-foot vertical radiant furnace portion has an inside diameter of 6 inches for the first 9 feet, with the final heated section diameter reduced to 3 inches. The radiant zone exit is through a horizontal 1.5-inch-inside-diameter ceramic tube. A portion of the particulate is removed before the flue gas goes to the convective pass section, which includes an optional ashfouling test section. From the convective section, the flue gas flows through several refractorylined heat exchangers, the particulate collection device, an air eductor, and a stack that exits through the roof of the building.

The combustion air is split into primary and secondary air. Fifteen to twenty-five percent of the air is introduced into the system as primary air and is used to carry the fuel into the CEPS. The secondary combustion air is preheated to a maximum of $800^{\circ} \mathrm{C}$ and can be introduced into the CEPS vertically or tangentially. Five electrically heated furnace sections comprise the main portion of the radiant furnace section and are constructed using a combination of ceramic tubes set into cast abrasion-resistant refractory. The refractory sections have access ports that are used for pressure and temperature measurements, injection of solids or gases, sampling of gaseous or particulate emissions, deposition observation, and optical analyses. The ceramic tubes are exposed to molybdenum disilicide heating elements, allowing operation to $1500^{\circ} \mathrm{C}$. Hightemperature fibrous insulating boards surround the high-temperature components housed inside the stainless steel shells. 
At the exit of the radiant section is a bottom (unheated) furnace section that is designed to remove and collect the larger ash particles before the flue gas enters the horizontally oriented convective pass. The convective pass is about 4 feet in length and constructed of a combination of ceramic tubing, refractory, and high-temperature fibrous insulating boards. There is the capability for studying deposition in the convective pass with two in-series highly instrumented air-cooled probes.

After the convective section, flue gas flows through a series of heat exchangers and then on to the particulate control device, which is either a baghouse, wet scrubber, or a cyclone. Flue gas temperatures are well-controlled going into the control device section for typical operation between $250^{\circ}$ and $350^{\circ} \mathrm{F}$, and flexibility has been built into the system to allow experimentation at even higher flue gas temperatures. Beyond the control device, the flue gas proceeds through an air eductor and up to a stack through the top of the roof of a new technology demonstration facility at the EERC. The system is designed so that the control devices can be interchanged without major system modifications. 


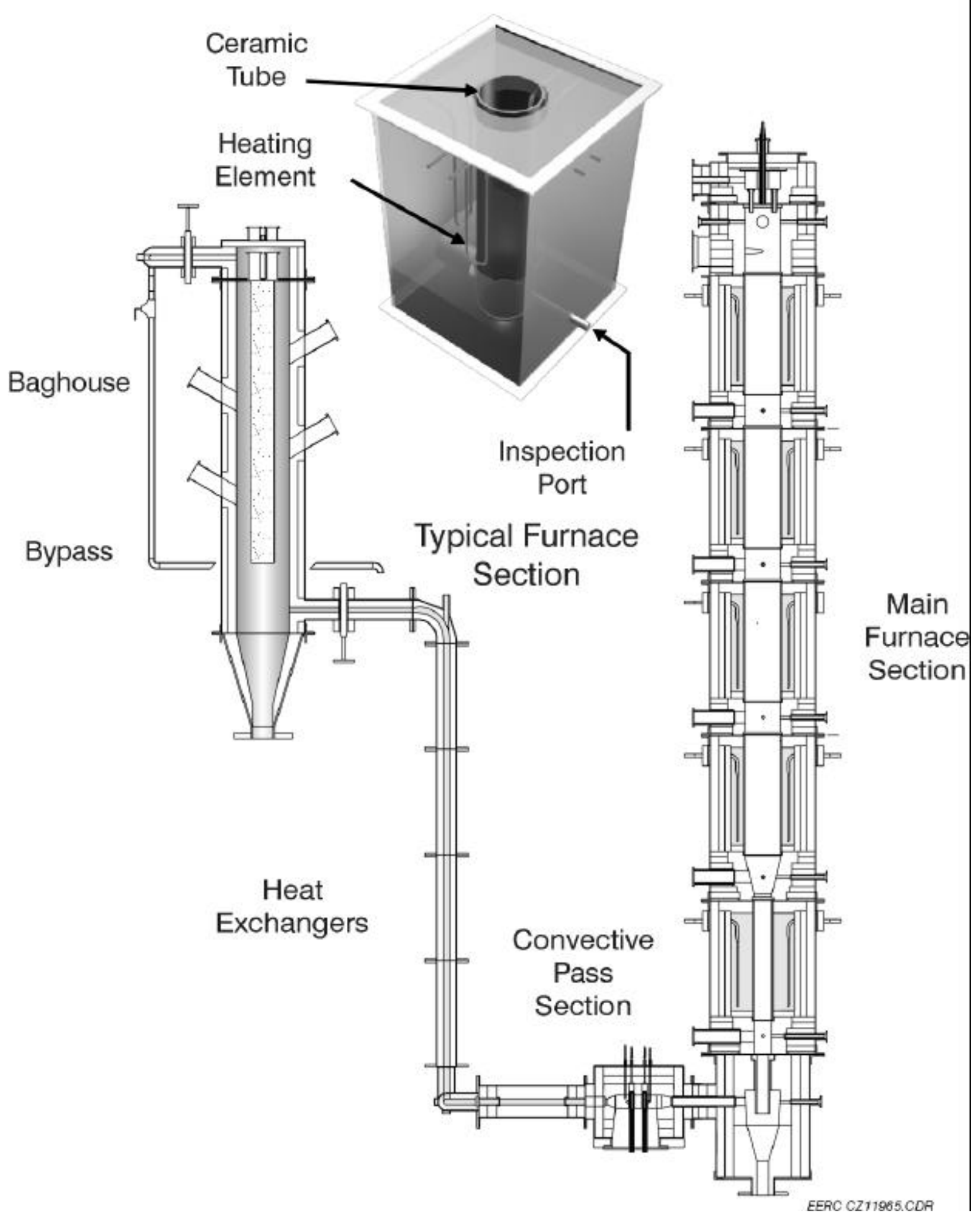

Figure D-1 Design sketch of the EERC conversion and environmental process simulator (CEPS) showing the main and convective pass section, heat exchangers, and baghouse. 